Guilherme Sobreira Spina

\title{
Níveis de citocinas proinflamatórias e seus antagonistas em pacientes com insuficiência aórtica crônica importante.
}

Tese apresentada à Faculdade de Medicina da Universidade de São Paulo para obtenção do título de Doutor em Ciências

Área de concentração : Cardiologia Orientador : Prof. Dr. Flávio Tarasoutchi

São Paulo 
A meus pais, José Miguel e Maria José e a meu irmão Leonardo pelo apoio e incentivo.

\begin{abstract}
A meu avô Manuel Sobreira (in memorian ) que com seu exemplo de amor pelos livros e conhecimento permitiu que os genes oriundos do Ceará, Minas, Calábria e Salerno encontrassem o ambiente ideal e resultassem no fenótipo que me permite hoje escrever esta tese.
\end{abstract}




\section{Agradecimentos}

Ao Prof. Dr. Flávio Tarasoutchi, amigo e exemplo de orientador no sendo estrito da palavra. Não se limita ao aspecto acadêmico e científico, servindo como exemplo de dedicação aos pacientes e à profissão. Tendo o privilégio de conhecê-lo desde a propedêutica no terceiro ano da Faculdade, seus ensinamentos desde então até a postura na vida profissional e acadêmica são de valor inestimável.

Ao Prof. Dr. Max Grinberg, pelo apoio, oportunidades e orientação. Professor e guardião da dimensão humana da Medicina. Nesta época em que se venera a tecnologia poderosa e a impessoalidade é reconfortante saber que ainda existam os incansáveis defensores da Soberana e da bioética.

Aos colegas da Unidade Clínica de Valvopatia, doutores Roney Orismar Sampaio, Eduardo Giusti Rossi, Luiz Francisco Cardoso, Solange Desireé Avakian, Walter Lunardi, Paulo de Lara Lavítola, Nelson Elias e Berta Napchan Borer pela amizade e contribuição para minha formação

Aos alunos de pós-graduação Marcelo Nigri, André Moreira Bento e Roberto Chaves Castro, colegas incansáveis de ambulatório, pela amizade e companheirismo.

Ao Prof. Dr. Francisco Laurindo, e à equipe do Laboratório de Biologia Vascular, em especial à Vanda Mitie Yoshida e Laura Inês Ventura Brandizzi pela ajuda e orientação na microaliquotagem e armazenagem das amostras deste trabalho.

À Dra Célia Maria Cassario Strunz, pela orientação nas coletas e nas técnicas de armazenagem e uso das instalações do Laboratório Clínico e a Regina Célia Matias de Oliveira e Izabete Mendes Nascimento pela dosagem de citocinas pelo método quimioluminescente. 
À Dra Luiza Guilherme, pela amizade, orientação e oportunidades de pesquisa em doença reumática. Espero que esta tese seja o começo de grandes colaborações, ajudando este clínico a ir da beira do leito à bancada do laboratório.

Ao Laboratório de Imunologia do InCor, especialmente o Dr Edécio Cunha Neto e Prof. Dr Jorge Kalil pela orientação, oportunidades e pelo uso do laboratório para a dosagem de citocinas, fazendo com que um clínico de aproximasse mais das áreas básicas.

Ao Prof Dr José Eduardo Krieger e Dr Alexandre Costa Pereira, pelas opiniões, amizade e pela análise do polimorfismo genético do TNF deste estudo.

Ao Dr. José Soares Junior e à Dra. Mariza Izaki pela realização das ventriculografias radioisotópicas que complementaram este estudo.

Ao Prof. Dr. José Lazaro de Andrade, Dr. Wilson Matias e em especial ao Dr Marcelo Vieira pela realização dos exames ecocardiográfios deste estudo.

À Fundação de amparo à pesquisa do Estado de São Paulo ( FAPESP ), pelo financiamento através do auxílio-pesquisa 00 / 09472-2 


\section{Agradecimento Institucional}

À Liga de Combate à Febre Reumática, em especial seus discutidores, diretores atuais e passados, acadêmicos e ex-acadêmicos. Através da Liga, que freqüento desde o terceiro ano médico, tive a oportunidade de descobrir meu amor pelos doentes e pela cardiologia. A Liga é exemplo de ensino médico e fornece indubitavelmente oportunidade ímpar de aprendizado, em qualquer estágio da carreira médica. 
Índice

Lista de Abreviaturas

Resumo

6

Abstract

8

1) Introdução

10

2) Objetivo

29

3) Casuística e métodos

30

4) Análise estatística

5) Resultados

6) Discussão

79

7) Conclusões

97

8) Referências bibliográficas

99

Anexos 


\section{Lista de abreviaturas}

IAo - Insuficiênia aórtica crônica importante

TNF - Fator de necrose tumoral - alfa

TNFRI - Receptor de TNF tipo I

TNFRII - Receptor de TNF tipo II

STNFRI - Receptor solúvel de TNF tipo I

sTNFRII - Receptor solúvel de TNF tipo II

IL-6 - Interleucina-6

IL-6R - Receptor solúvel de interleucina-6

II-1 $\beta$ - Interleucina 1-beta

IL1-RA - Antagonista do receptor de interleucina-1

ET-1 - Endotelina-1

DDVE - Diâmetro diastólico do ventrículo esquerdo

DSVE - Diâmetros sistólico do ventrículo esquerdo

FE -Fração de ejeção

$\mathrm{AE}$ - Diâmetro do átrio esquerdo

Ao - Diâmetro da aorta

Eco - Ecocardiografia

NYHA - New York Heart Association

$\mathrm{CF}$ - Classe funcional

FR - Febre Reumática 
Resumo 
SPINA, G. S. - Níveis de citocinas proinflamatórias e seus antagonistas em pacientes com insuficiência aórtica crônica importante. São Paulo, 2004. Tese ( doutorado ) - Faculdade de Medicina da Universidade de São Paulo

Introdução: As citocinas proinflamatórias estão implicadas na fisiopatologia da insuficiência cardíaca secundária à miocardiopatia dilatada ou isquêmica, mas existem poucos dados sobre o comportamento destes mediadores em doença valvar.

Determinamos o comportamento destes mediadores em pacientes com insuficiência aórtica crônica importante ( IAo ).

Materal e métodos:Analisamos 89 portadores de Insuficiência Aórtica crînica importante, média etária de $33,6 \pm 11,5$ anos, $84,6 \%$ sexo masculino, $60 \%$ assintomáticos, todos de etiologia reumática. Os pacientes foram submetidos a avaliação clínica e ecocardiográfica. Os valores médios foram: diâmetro diastólico (DD) do ventrículo esquerdo ( VE ) de $71,9 \pm 8,3 \mathrm{~mm}$ e o diâmetro sistólico ( DS ) do VE de $50,4 \pm 9,3 \mathrm{~mm}$, e a fração de ejeção ( FE ) do VE de $0,64 \pm 0,11$. Realizamos a dosagem de Fator de Necrose Tumoral ( TNF ), seus receptores solúveis tipo I e II ( sTNFRI e sTNFR II ), Interleucina-6 ( IL-6 ), seu receptor ( IL-6R), interleucina 1-beta ( IL-1 $\beta$ ), seu antagonista ( IL1-RA ) e endotelina-1 ( ET-1 ). Comparamos com níveis séricos de controles saudáveis. Conjuntamenete analisamos o polimorfismo genético do gene do TNF, localizado a -308 pares de bases do sítio de iniciação.

Resultados: Os níveis séricos de TNF forma significativamente maiores em pacientes com IAo do que em controles normais ( $92,65 \pm 110,24 \mathrm{pg} / \mathrm{ml}$ contra 1,67 $\pm 1,21$ em controles normais, $p<0,001$ ). Tiveram comportamentos similares os níveis séricos de sTNFRI ( $894,75 \pm 348,87 \mathrm{pg} / \mathrm{ml}$ vs $521,42 \pm 395.13 \mathrm{pg} / \mathrm{ml}$ em controles, $\mathrm{p}=0,007$ ) e IL-6 ( $7,17 \pm 7,78 \mathrm{pg} / \mathrm{ml}$ vs $0,81 \pm 0,38 \mathrm{pg} / \mathrm{ml}, \mathrm{p}=0,0001)$. Observamos correlação significativa entre níveis de sTNFRII e DDVE ( $r=-0,329, p=0,038)$ e DSVE ( $r=-0,352, p=0,027)$. Não observamos relação de níveis séricos de citocinas com sintomas. As outras citocinas não guardaram relação com parâmetros de gometria e função ventricular. A presença do alelo 2 do polimorfismo genético do TNF associou-se a paciente assintomáticos com IAo.

Conclusão: Demonstramos níveis elevados de citocinas proinflamatórias em pacientes com IAo em relação a controles normais. Os níveis de sTNFRII diminuem com o aumento dos diâmetros ventriculares. A presença do alelo 2 do polimorfismo -308 do TNF asocia-se a pacientes assintomáticos com IAo. 
Abstract 
SPINA, G.S. - Proinflamatory cytokine and antagonists levels in patients with chronic severe aortic regirgitation. São Paulo, 2004. Thesis ( doutorado ) - Faculdade de Medicina da Universidade de São Paulo

Background - Proinflamatory cytokines are implied in the phisiopatology of heart failure secoundary to ischaemic or idiophatic dilated cardiomiopathy, but there are few studies regarding these mediators in valular heart disease. We determined the behaivour of proinflamatory cytokines and their antagonists in patients with chronic severe aortic regurgitation ( IAo )

Methods - We analised 89 patients with IAo mean age $33.6 \pm 11.5$ years, $84.6 \%$ male, 60\% asymptomatic, all of rheumatic etiology. Patients were evaluated clinnicaly and by echocardiography. Mean values were : left ventricular ( LV ) diastolic diameter (DD) $71.9 \pm 8.3 \mathrm{~mm}$, LV systolic diameter ( SD ) 50.4 $\pm 9.3 \mathrm{~mm}$ and ejection fraction $0.64 \pm 0.11$. We made the plasma dosages of tumor necrosis factor-alpha ( TNF), its soluble receptors type I and II ( STNFRI and STNFR II ), Interleukin 6 ( IL-6 ) and its receptor ( IL-6R ), Interleukin 1-beta ( IL-1 $\beta$ ), its antagonist ( IL1-RA ) and endothelin-1 ( ET-1 ). Plasma levels were compared to healthy controls. We also analysed the TNF gene polimorphism, located at 308 base pairs from the initation site.

Results - Plasma TNF levels were significantly increased in IAo patients in telation to normal controls $(92.65 \pm 110.24 \mathrm{pg} / \mathrm{ml}$ vs $1.67 \pm 1.21 \mathrm{pg} / \mathrm{ml}$ in controls, $p<0.001)$. Similar behaivour was observed with IL-6 $(7.17 \pm 7.78 \mathrm{pg} / \mathrm{ml}$ in IAo patients vs $0,81 \pm 0,38 \mathrm{pg} / \mathrm{ml}$ in controls , $p=0.0001)$ and sTNFRI $(894.75 \pm 348.87 \mathrm{pg} / \mathrm{ml}$ vs $521.42 \pm 395.13 \mathrm{pg} / \mathrm{ml}$ in controls, $p=0,007$ ). We observed and significant relation between sTNFRII levels and LVDD ( $r=-$ $0,329, p=0,038$ ) e LVSD ( $r=-0,352, p=0,027$ ). Levels of cytokines were similar in asymptomatic and sympromatic patients and the other cytokines had no relation to ventricular diameters or function. Presence of the alele 2 of the -308 TNF polimorphism was associated to asymptomatic patients.

Conclusion - We showed increased plasma levels of proinflamatory cytokines in patients with IAo in relation to normal controls. There was an decrease of STNFRII levels with increase in ventricular diameters. The presence of the alele 2 of the -308 TNF polimorphism was associated to asymtomatic patients. 


\section{I ntrodução}


A insuficiência aórtica ( IAo ) é valvopatia de evolução lenta , característica do modelo reumático no qual há uma complexa remodelação ventricular esquerda representada por alterações nos compartimentos muscular, intersticial, vascular e neurohormonal. Estes mecanismos adaptativos mantêm o paciente assintomático por um período de tempo longo, mas são exauridos ao longo de anos ou décadas. A resultante final é a insuficiência cardíaca, que requer diagnóstico e terapêutica precisas, e influencia o prognóstico. ${ }^{1}$

Evidentes obscuridades persistem na compreensão da progressão clínica, desde o momento da lesão anatômica até a manifestação da insuficiência cardíaca . De modo semelhante, na síndrome insuficiência cardíaca ( ICC ), ainda não são conhecidos os determinantes que levam à progressão da doença.

Há aproximadamente 50 anos, a fisiopatologia da insuficiência cardíaca era atribuída à excessiva retenção de sódio e água, o chamado modelo cardiorrenal ${ }^{2}$, justificando condutas de restrição hidrossalina, diuréticos e digitálicos. Nos anos 60, a pesquisa foi direcionada à redução da função de bomba do ventrículo esquerdo e às mudanças hemodinâmicas, perfazendo o modelo hemodinâmico,que explicava sintomas tanto da insuficiência cardíaca retrógrada ( dispnéia, edema ) quanto de ICC anterógrada ( fadiga, intolerância ao exercício ) ${ }^{3}$.

A utilização de vasodilatadores que reduzem a pré e a pós-carga ${ }^{3,4}$ e de drogas inotrópicas positivas ${ }^{6,7}$ trouxe a oportunidade para testar esta teoria. Entretanto, estas abordagens não diminuíram a mortalidade por insuficiência cardíaca, apesar de melhora nos parâmetros hemodinâmicos e na sintomatologia ${ }^{8,9}$. Embora tais modelos ofereçam 
modalidades de tratamento que são utilizadas até hoje, não conseguiram prover uma explicação ou impedir a progressão da insuficiência cardíaca.

As duas últimas décadas testemunharam o surgimento do modelo neurohumoral ${ }^{10}$, 11 segundo o qual moléculas biologicamente ativas inicialmente produzem homeostase, mas têm consequências deletérias a longo prazo. Destacam-se entre estes mecanismos o sistema renina-angiotensiva-aldosterona e o sistema adrenégico de importância fisiopatológica comprovada. A antagonização destes sistemas com fármacos como betabloqueadores e inibidores da enzima conversora da angiotensina favorecem a remodelação ventricular esquerda, com redução de mortalidade e alívio dos sintomas. ${ }^{12,}$ ${ }^{13} \mathrm{O}$ antagonismo do sistema renina-angiotensina também demonstrou efeitos benéficos em pacientes com insuficiência aórtica ${ }^{14}$.

Recentemente pesquisas revelaram um papel importante de respostas inflamatórias locais e sistêmicas, no que se convencionou chamar de "hipótese das citocinas". Esta hipótese não implica que as citocinas causem a insuficiência cardíaca per se, mas sim que o aumento de expressão de citocinas contribui para as manifestações cardíacas e sistêmicas da insuficiência cardíaca. ${ }^{15}$

Citocina é termo aplicado a um grupo de peptídeos de relativo baixo peso molecular (geralmente 15 a 30 Kd ), altamente potentes e pleiotrópicos, secretadas por grande variedade de células, inclusive cardiomiócitos, em resposta a diferentes estímulos, incluindo estresse mecânico. O pioneirismo em cardiologia coube a LEVINE e cols ${ }^{16}$ que demonstraram pela primeira vez aumento dos níveis séricos do fator de necrose tumoral - alfa (TNF), uma citocina proinflamatória, em pacientes com insuficiência cardíaca secundária a miocardiopatia dilatada idiopática. Desde então TNF, Interleucina 6 ( IL-6 ) e interleucina 1-beta ( IL-1ß ) foram identificados em concentrações elevadas em pacientes com insuficiência cardíaca secundária a miocardiopatia dilatada ${ }^{10,}$ 
11, 12, 14 . Inicialmente relacionadas ao sistema imunológico podem ser secretadas mesmo na ausência de ativação deste. ${ }^{10}$

Evidência da importância das citocinas na insuficiência cardíaca é a capacidade destas modularem a função cardiovascular e reproduzirem o fenótipo da insuficiência cardíaca, através de uma variedade de mecanismos, como a capacidade de provocar disfunção ventricular esquerda ${ }^{17}$, edema pulmonar ${ }^{18,19}$, cardiomiopatia $^{20}$ e redução de fluxo sanguíneo da perna em humanos ${ }^{21}$.

Experimentalmente níveis elevados de citocinas provocam remodelação ventricular esquerda, $^{22}$ alterações no metabolismo miocárdico $23,24,25$, anorexia, caquexia $26,27,28$ desacoplamento de receptores ßadrenégicos da adenilato-ciclase ${ }^{29}$, alterações no metabolismo mitocondrial ${ }^{30,31}$ e ativação do programa genético fetal ${ }^{32}$, que fazem parte fazem parte do fenótipo da insuficiência cardíaca.

Interessante destacar que as citocinas comportam-se como marcadores de pior prognóstico em pacientes com insuficiência cardíaca secundária a miocardiopatia dilatada idiopática ou isquêmica, de modo independente de outros fatores como sexo, idade, classe funcional, fração de ejeção e nível de sódio sérico. $33,34,35,36,37$ Comprovando este aspecto, o estudo de Framigham, em pacientes idosos sem infarto do miocárdio prévio, níveis séricos elevados de citocinas identificam pacientes de alto risco para desenvolvimento de insuficiência cardíaca $^{38}$, de modo que podem sinalizar tanto gravidade da insuficiência cardíaca quanto identificar pacientes com insuficiência cardíaca incipiente mas já com pior prognóstico . 
1.1) Origem das citocinas na insuficiência cardíaca

A exata origem da superprodução de citocinas na insuficiência cardíaca permanece desconhecida. Há pelo menos três hipóteses: ( 1 ) Ativação do sistema imunitário, em resposta a um estímulo ainda desconhecido, ( 2 ) Elaboração pelo coração em resposta a certos estresses, mecânicos ou químicos, com extravazamento desta produção aumentada para a circulação sistêmica e ( 3 ) hipoperfusão sistêmica de tecidos. ${ }^{10}$

Várias evidências demonstram que o sistema imune é uma fonte importante de produção de citocinas em insuficiência cardíaca. Estudos apontaram alterações de imunidade celular e humoral na insuficiência cardíaca de etiologia não valvar ${ }^{39,40}$. Os níveis séricos de neopterina, um marcador de ativação de macrófagos, estão elevados em pacientes com insuficiência cardíaca ${ }^{41,42}$ e estas células são conhecidos como uma das maiores fontes produtoras de citocinas ${ }^{43}$. Há evidências de que provavelmente o TNF estimule a produção de neopterina pelos macrófagos. ${ }^{10}$

Há evidências experimentais ${ }^{44}$ e clínicas ${ }^{45}$ que os cardiomiócitos adultos são capazes de produzir TNF quando submetidos a estiramento ou sobrecarga hemodinâmica. Cardiomiócitos normais não possuem RNA mensageiro para TNF- $\alpha$ em seu citossol, mas quando submetidos a uma sobrecarga hemodinâmica podemos detectar RNA mensageiro para esta citocina no citoplasma. Deste modo, o miocárdio pode ser uma fonte importante de produção de citocinas proninflamatórias na insuficiênca cardíaca e os níveis séricos elevados destas seriam um extravazamento da produção miocárdica para a periferia. Há controvérsia sobre esta teoria, com autores que identificaram gradientes transmiocárdicos de citocinas ${ }^{46}$ e outros que não identificaram tal gradiente . ${ }^{47,48}$

Uma variante interessante desta teoria é que provavelmente há uma intercomunicação entre o sistema cardiovascular e o sistema imune. As citocinas 
proinflamatórias que são produzidas pelo coração,como o TNF- $\alpha$ e a IL-6 poderiam extravazar do coração para a periferia, estimulando células mononucleares a sintetizar citocinas proinflamatórias ${ }^{49}$. Além disso, o estresse mecânico também aumenta a expressão de moléculas de adesão, como o fator quimiotático e ativador de monócitos ( MCAF ) no endotélio. Tal fator pode contribuir para o recrutamento de macrófagos, que posteriormente seriam ativados pelas citocinas oriundas do miocárdio ${ }^{50,51}$ Desta forma, os monócitos e o sistema imune amplificariam sistemicamente a produção miocárdica de citocinas.

ANKER e cols ${ }^{52}$ propuseram que a congestão venosa e edema de alças intestinais consequente à insuficiência cardíaca, aumentaria a permeabilidade do epitélio intestinal, causando translocação bacteriana e/ou aumento da absorção de endotoxinas na corrente sanguínea. As endotoxinas estimulam monócitos a produzir citocinas proinflamatórias. Entretanto, esta hipótese não explica os níveis elevados de citocinas em pacientes com insuficiência cardíaca incipiente ou em pacientes oligossintomáticos.

Procurando estudar de forma completa o sistema das citocinas concentramos esforços naquelas que estão, segundo a literatura, mais envolvidas com a remodelação ventricular esquerda, ou seja, o TNF, a IL-1 $\beta$ e a IL-6 ${ }^{53}$, juntamente com seus receptores endógenos solúveis ou antagonistas, a fim de melhor compreender tal sistema. 
1.2 ) Efeitos cardiovasculares conhecidos das diversas citocinas

\subsection{1) Fator de necrose tumoral- $\alpha$ ( TNF)}

Embora as mudanças complexas que ocorrem no coração durante a remodelação ventricular esquerda na insuficiência aórtica tenham sido descritas mecanicamente ou anatomicamente, há muitas outras alterações que ocorrem durante tal processo na biologia do cardiomiócito. Há um aumento de volume dos miócitos e mudanças no compartimento intersticial e vascular, que levam às alterações de geometria de câmaras e da arquitetura do coração. Muitas destas alterações podem ser explicadas pelos efeitos conhecidos do TNF. Entre os efeitos do TNF que podem estar diretamente envolvidos com a remodelação ventricular na insuficiência aórtica podemos citar alterações na biologia do miócito, como hipertrofia, anormalidades de contração e expressão de genes fetais, alterações na matriz extracelular, promovendo fibrose e degradação da matriz e alterações na própria população de miócitos, com indução de apoptose $^{54}$.

O TNF deriva seu nome da observação que tal proteína tem potente atividade antitumoral, tanto in vitro quanto in vivo. ${ }^{55,56}$ Apresenta uma grande variedade de ações biológicas, além de seus efeitos citotóxicos, como influência no crescimento ou diferenciação em diversos tipos celulares, incluindo miócitos cardíacos 57, 58, 59 Inicialmente tidas como apenas secretadas apenas por células do sistema imune, sabemos hoje que todas as células nucleadas no miocárdio, inclusive o próprio cardiomiócito ${ }^{45}$. , têm capacidade de produção de TNF em resposta a diversos 
estímulos, inclusive com resposta a sobrecargas pressóricas ou de volume ao ventrículo esquerdo. É possível relatar que tal produção de citocinas pode ocorrer mesmo na completa ausência de ativação do sistema imunológico. ${ }^{60}$

Através de estudos recentes, podemos afirmar que a estimulação de cardiomióctos isolados pelo TNF provoca ao menos três mudanças importantes para o processo de remodelação ventricuclar esquerdo : ( 1 ) hipertrofia de cardiomiócitos ${ }^{57}$, ( 2 ) morte celular progressiva por apoptose ${ }^{61}$ e ( 3 ) alterações contráteis e na expressão de genes fetais ${ }^{62,63}$.

Sabemos que há alterações na quanltidade de colágeno na IAo e oTNF pode mediar estas alterações na matriz extracelular por sua ação via metaloproteinases da matriz ${ }^{64}$. As metaloproteinases podem contribuir para a dissolução do colágeno tipo I e aumento do colégeno tipo III que ocorre na IAo ${ }^{65}$, fazendo com que os miócitos fiquem menos unidos e resultando em diminuição da força de contração do coração

Devemos enfatizar que o TNF é uma molécula de meia-vida curta, estimada em 14 a 18 minutos, pois estudos com TNF marcado mostraram que é distribuído primariamente para os receptores de TNF no fígado e na pele, aonde é rapidamente degradado. ${ }^{66}$ Desta forma, os níveis séricos permanentemente elevados nos pacientes com Insuficiência cardíaca mostram que há uma biosíntese continuada desta citocina. 


\subsection{2) Receptores solúveis de TNF tipo I e II}

Os efeitos do TNF são mediados por dois receptores, um de mais baixa afinidade, de 55kd, chamado de receptor de TNF tipo I ( TNFR I ) e um receptor de $75 \mathrm{kd}$ de alta afinidade, definido como receptor de TNF tipo II ( TNFR II ). A transdução do sinal se dá quando ocorre uma ligação entre receptores vizinhos, após a ligação do trímero de TNF, induzindo uma oligomerização dos receptores. Os receptores de TNF são bastante semelhantes em suas porções extracelulares, caracterizados por possuírem motivos ricos em cisteína ${ }^{67}$. Entretanto, os domínios intracelulares do TNFR I e TNFRII são bastante diferentes, sugerindo que cada receptor tem uma via de sinalização e assim ações celulares diferentes.

Ambos os tipos de receptores já foram identificados no miocárdio humano, tanto em corações normais ${ }^{68}$. quanto em miocárdio de portadores de insuficiência cardíaca ${ }^{69}$. Estudos sugerem que a forma de TNF ligada à membrana sinalizaria predominantemente pelo receptor TNFRII, enquanto que o TNF trimérico, solúvel, de 51kd se ligaria preferencialmente ao TNFRI ${ }^{70}$.

É importante notar ao examinar o sistema das citocinas que a atividade biológica depende também não só da concentração da citocina de interesse, mas também da concentração de receptores solúveis ou antagonistas circulantes para essa dada citocina. ${ }^{11}$ Os receptores solúveis de TNF tipo I e tipo II podem servir como antagonistas à ação do TNF bloqueando sua ligação a receptores celulares ou como agonistas, agindo como sistemas-tampão e impedindo a monomerização e conseqüente degradação dos trímeros de TNF e assim aumentando a sua meia-vida ${ }^{71}$. Estes 
receptores também indicam a atividade tecidual da citocina, já que muitos destes receptores solúveis são secretadosem resposta à ação tecidual destas. ${ }^{10}$

Por terem menor variabilidade que os níveis séricos de TNF, os níveis séricos de receptores solúveis de TNF tipo I e II ( STNFRI e sTNFRII ) constituem ferramentas mais sensíveis para estudos em insuficiência cardíaca, inclusive com valor prognóstico, como é o caso dos receptores solúveis de TNF tipo ${ }^{36}$.

A maioria dos efeitos deletérios do TNF parece se dar através da ativação do TNFRI, enquanto que a ativação do TNFRII tem um papel protetor. A ativação do TNFRI é responsável por mediar os efeitos inotrópicos negativos ${ }^{68}$ do TNF através da ativação da via da esfingomielinase neutra ${ }^{72}$ e via óxido nítrico ${ }^{73}$ e induzindo também apoptose em cardiomiócitos. Ao contrário, a ativação do TNFRII parece ser proteger o miócito contra isquemia e lesão por hipóxia ${ }^{74}$, não tendo efeito na contração celular.

A ativação do TNFRII leva à ativação do fator associado ao receptor de TNF tipo 2, que desencadeia uma série de eventos transcricionais, que geralmente são descritos como respostas protetoras e não apoptóticas, levando ao crescimento celular, proliferação e protegendo contra a ativação de eventuais mecanismos deletérios ativados pelos receptores tipo I. ${ }^{75}$ 
1.2.3) Polimorfismo genético do fator de necrose tumoral- $\alpha$

Polimorfismos genéticos podem influenciar o comportamento das citocinas na insuficiência cardíaca. Um das mais estudados é a mutação na região promotora do gene do TNF, a -308 pares de bases do sítio de iniciação, que constitui uma mutação pontual, com substituição de guanina ( $\mathrm{G}$ ) por adenina ( $\mathrm{A}$ )

A mutação em questão tornaria o gene mais predisposto à transcrição, e assim aumentaria a expressão do gene do TNF ${ }^{76}$.

Este polimorfismo já foi associado a aumento dos níveis de TNF após circulação extracorpórea e maior morbidade ${ }^{77}$ e também predispõe à disfunção miocárdica não-isquêmica em uma população caucasiana ${ }^{78}$. Há relatos como o de ITO e cols ${ }^{79}$, que notaram maior freqüência do alelo 2 do genótipo -308 em pacientes com miocardiopatia dilatada se comparado com controles normais. Entretanto, tal autor não encontrou relação entre o genótipo e níveis séricos de citocinas. 


\subsection{4) Interleucina-6 ( IL-6 )}

A interleucina-6 é uma importante parte da resposta do coração ao estiramento miocárdico, sendo um dos mecanismos que fazem a transdução de sinal da distensão miocárdica à hipertrofia. A IL-6 liga-se em seus receptores ( IL6R ), induzindo a fosforilação da proteína gp130 via Janus quinase (JAK ) e ativa uma importante via de sinalização que leva à hipertrofia miocárdica ${ }^{80}$, chamada de via de ativação JAK / STAT ( transdutor de sinal e ativador da transcrição )..A atívação da gp 130 parece ser importante na transição entre hipertrofia compensatória e falência cardíaca ${ }^{81}$

Resssalta-se que a IL-6 tem importante valor prognóstico em insuficiência cardíaca secundária à miocardiopatia dilatada ou isquêmica. Estudos ${ }^{82}$ têm associado níveis maiores que $5 \mathrm{pg} / \mathrm{ml}$ a maior mortalidade em tais pacientes. O nível de corte associado com maior mortalidade varia de acordo com o estudo, sendo em alguns de $6,97 \mathrm{pg} / \mathrm{ml}^{36}$ e em outros de $4,4 \mathrm{pg} / \mathrm{ml}^{83}$. 


\subsection{5) Interleucina 1-beta (IL-1 $\beta)$}

A interleucina-1 $\beta$ é descrita como tendo importante papel na hipertofia miocárdica. Em modelos experimentais de hipertrofia ventricular, a IL-1 $\beta$ tem níveis elevados à medida que progride a hipertrofia ventricular,e aumenta de maneira expressivamente quando se iniciam os sinais de insuficiência cardíaca.

Sassayama e cols ${ }^{51}$ observaram a correlação da quantidade de RNA mensageiro para IL-1 $\beta$ e a massa ventricular, através de um mecanismo independente de óxido nítrico, asssociada com expressão de genes fetais e diminuição de genes reguladores de cálcio ${ }^{84}$.Por outro lado, Cain e cols ${ }^{85}$ demonstraram os efeitos miocardiodepressores da IL-1 $\beta$, induzindo disfunção ventricular in vitro, juntamente com o TNF, provavelmente através mecanismo óxido nítrico (NO) - dependente ${ }^{73,86}$, podendo contribuir com a deterioração hemodinâmica que se observa nas fases finais da insuficiência aórtica.

Os mecanismos biológicos responsáveis por esse efeito cardiodepressor das citocinas são, entre outros: a) um aumento na atividade da óxido-nítrico sintase (NOS) constitutiva do músculo cardíaco ${ }^{73}$, b) aumento da NOS indutível ( iNOS) com consequente aumento na produção de $\mathrm{NO}$ e peroxinitrito ${ }^{87}$.

A IL-1 $\beta$ pode independentemente desacoplar receptores beta-adrenégicos no miocárdio, ${ }^{88}$ e ativar metaloproteinases da matriz extracelular, promovendo assim fibrose intersticial. ${ }^{51}$ 
A ação da IL-1 $\beta$ como desencadeante de hipertrofia ventricular também é vista em doenças na qual esta citocina é produzida como resposta à infecção. Recentemente PETERSEN e cols ${ }^{89}$ demonstraram que sobrenadante de células infectadas com $T$. cruzi podiam induzir hipertrofia em cardiomiócitos isolados, de modo que a IL-1 $\beta$ pode ser uma das causadoras da hipretrofia ventricular e fibrose observadas na doença de Chagas. 
Outro mediador importante na remodelação ventricular e na insuficiência cardíaca é a endotelina-1 ( ET-1 ), que não é uma citocina, mas uma proteína de 21 resíduos de aminoácidos. É um peptídeo vasoconstritor produzido pelo endotélio, que possui múltiplas ações no sistema cardiovascular. Além dos efeitos vasoconstritores, é importante na regulação hemodinâmica na insuficiência cardíaca, assim como é importante no remodelamento vascular e miocárdico. ${ }^{90} \mathrm{~A}$ síntese da endotelina-1 é estimulada por muitos fatores de estresse cardiovascular, como citocinas, neurohormônios, trombina e estresse mecânico. ${ }^{91}$

A ET-1 faz parte de uma família grande de peptídeos correlatos. É secretada do endotélio quando seu precussor, a endotelina-1-grande é clivada pela enzima conversora de endotelina. As ações da endoletina são complexas, agindo via dois receptores, determinados de $\mathrm{ET}(\mathrm{A})$ e $\mathrm{ET}(\mathrm{B})$. A ativação de receptores $\mathrm{ET}(\mathrm{A})$ induz vasoconstrição, enquanto que estimula a produção de óxido nítrico, tendo um papel regulatório de vasoconstrição. ${ }^{92}$ Estudos demonstram que a ET-1 pode estimular produção de TNF e assim contribuir para a ativação do sistema das citocinas na ICC ${ }^{93}$ Além disso níveis de ET-1 elevados tem sido associados a maior mortalidade em pacientes com insuficiência cardíaca. ${ }^{94}$

Pesquisas atuais de remodelação ventricular têm enfatizado a importância dos aspectos neurohumorais nos mecanismos de adaptação e desadaptação do ventrículo esquerdo.Considerando que a remodelação ventricular esquerda na insuficiência aórtica é uma das mais acentuadas dentre todas as doenças cardiovasculares, presume-se que tais mecanismos de remodelação ventricular esquerda estejam bastante ativos.Desta forma as citocinas proinflamatórias podem estar envolvidas não apenas na remodelação ventricular, mas também no 
desenvolvimento da disfunção ventricular esquerda que caracteriza as fases avançadas da insuficiência aórtica.

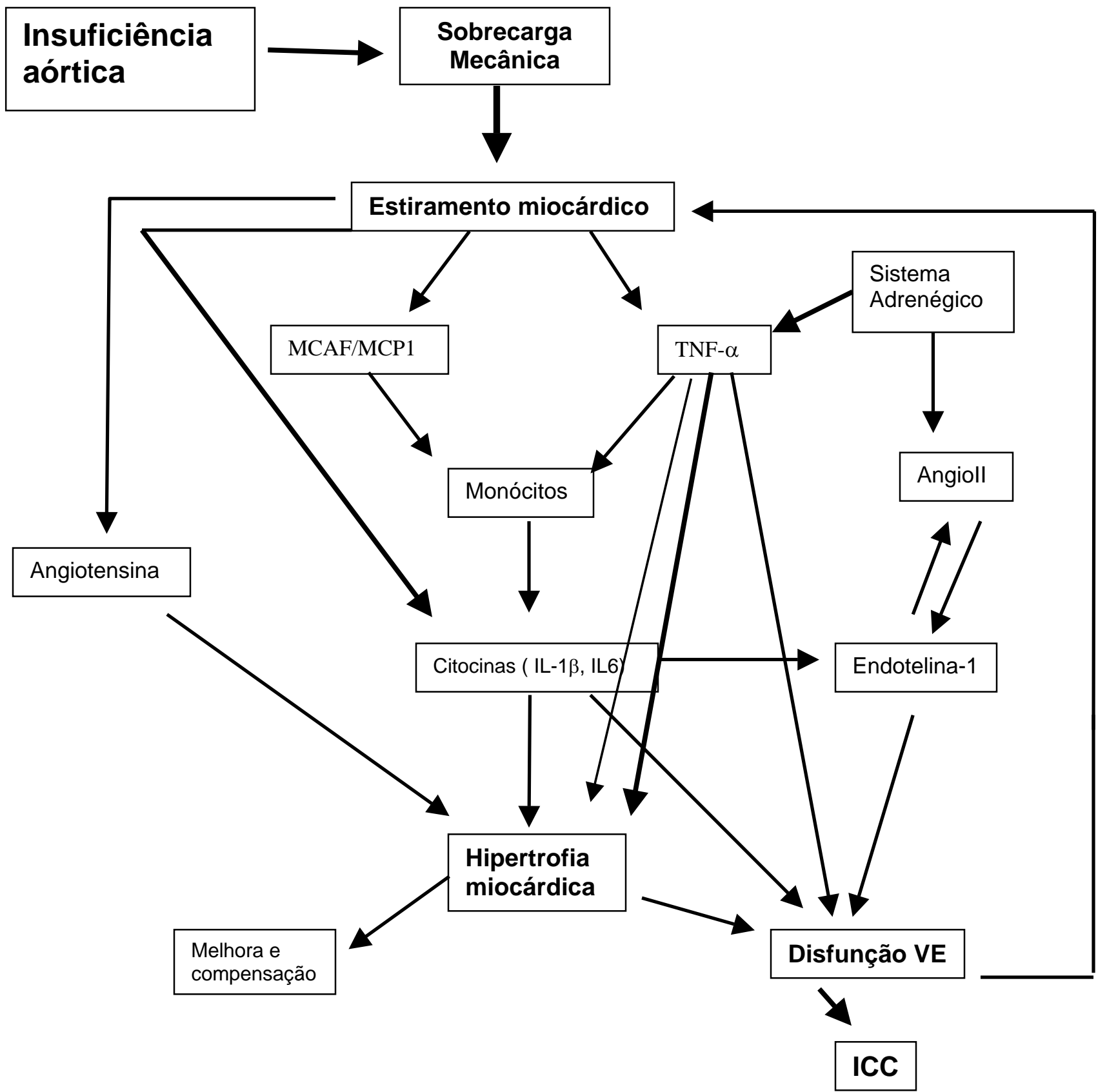

Figura 1 
Figura 1 - Modelo proposto para a ativação do sistema das citocinas na insuficiência aórtica. A distensão miocárdica ativa vários sistemas de segundo mensageiro e diretamente induz expressão de protooncogenes, síntese proteica e estimula a liberação autócrina de angiotensina II. A angiotensina também promove a liberação de endotelina de miócitos. O miocárdio hipertrofiado passa por várias mudanças fisiológicas e bioquímicas até que se estabelece a ICC, com acentuada ativação do sistema reninaangiotensina-aldosterona para tentar manter a homeostase interna, sendo que como potente vasoconstritor a angiotensina contribui para aumentar a pós-carga . A distensão mecânica induz a expressão de fatores quimiotáticos para macrófagos e a síntese de TNF- $\alpha$ pelo miocárdio, o que faz com que monócitos sejam recrutados e estimulados a produzir citocinas como a IL-1 $\beta$ e IL-6 entre outras, que promovem o crescimento de miócitos e remodelação ventricular esquerda. Estas citocinas são também responsáveis por induzir disfunção cardíaca. A IL-1 também estimula a produção de endotelina, que também é miocardiodepressora. ( modificado de Sassayama e cols ${ }^{51}$ ) ( Legenda: MCAF/MCP1 = Fator quimeotático para monócitos / proteína quimeotática para monócitos, IL-1 $\beta=$ Interleucina 1 beta , TNF- $\alpha$ - Fator de necrose tumoral-alfa , Angioll - angiotensina II, IL-6 - Interleucina 6, ICC - Insuficiência cardíaca. ) 
Assim podemos postular que o complexo sistema das citocinas proinflamatórias está envolvido de maneira importante na resposta miocárdica ás sobrecargas de volume e de pressão, como é o caso da insuficiência aórtica, podendo ser um mecanismo de influência na transição da hipertrofia compensatória para a instablização clínica. A transição da hipertrofia compensada para a insuficiência cardíaca pode ser um resultado da modulação da estrutura e função dos cardiomiócitos não só pelas condições de sobrecarga mecânica mas também por processos neurohumorais sistêmicos ou locais.

Com estas evidências torna-se de fundamental importância o estudo do sistema das citocinas para a compreensão dos mecanismos que influenciam a adaptação do ventrículo esquerdo à insuficiência aórtica. Este sistema poderia ser um dos mecanismos responsáveis pela adaptação inicial à sobrecarga de volume-pressão, se manteria com pouca atividade na fase assintomática, em que temos diminuição da tensão da parede do ventrículo esquerdo e estaria muito ativado na fase sintomática e final da doença, em que novamente temos uma tensão elevada da parede ventricular esquerda, contribuindo para sua deterioração e rápida instalação de disfunção ventricular.

O sistema das citocinas proinflamatórias foi pouco estudado em doenças valvares, havedo quatro estudos na literatura, em estenose mitral ${ }^{95}$, estenose aórtica ${ }^{96}$ e Insuficiência mitral ${ }^{45,96}$. Apenas um destes estudos ${ }^{45}$ analisou pacientes reumáticos

Até hoje nenhum estudo analisou o perfil de citocinas na valvopatia que promove a mais expressiva remodelação ventricular, que é a insuficiência aórtica. Assim, de forma inédita na literatura estudamos o perfil de citocinas proinflamatórias em pacientes com insuficiência aórtica. 


\section{Objetivo}


2)- Objetivo

O objetivo primário é analisar níveis de citocinas proinflamatórias e seus antagonistas, relacionando-os com alterações morfológicas, através do ecodopplercardiograma e funcionais ( presença ou não de sintomas ) em uma população de pacientes com insuficiência aortica crônica importante.

Como objetivo secundário analisamos o polimorfismo genético do TNF, e relacionarmos com os níveis de citocinas, sintomas, geometria e função ventricular. 
Casuística e métodos 


\section{3)- Casuística e métodos}

\section{1) População: avaliação clínica}

A população do estudo foi constituída de pacientes portadores de insuficiência aórtica crônica importante em acompanhamento no Ambulatório da Equipe de Cardiopatias Valvares do Instituto do Coração do Hospital das Clínicas da Faculdade de Medicina da Universidade de São Paulo ( HC-FMUSP ). O diagnóstico de insuficiência aórtica crônica importante obedeceu aos critérios de Spagnuolo e cols ${ }^{97}$ modificados, ou seja presença de índice cardiotorácico $>0.50$, sobrecarga ventricular esquerda ao eletrocardiograma, pressão de pulso $\geq 80 \mathrm{mmHg}$ e pressão arterial diastólica $\leq 60$ mmHg. Para cada paciente foi realizada avaliação clínica e laboratorial completa, assim como a dosagem plasmática do perfil de citocinas proinflamatórias. Desta forma foi realizado um estudo transversal.

O protocolo de pesquisa foi aprovado pela comissão científica e de ética do Instituto do Coração e pela comissão de ética em pesquisa do Hospital das Clínicas sob o número 1691/00/52 e foi financiada pela fundação de amparo à pesquisa do Estado de São Paulo ( FAPESP ), protocolo auxílio-pesquisa 00 / 09472-2.

Foram excluídos os pacientes que apresentavam as seguintes características: a) idade inferior a 18 anos ou superior a 60 anos; b) presença de fibrilação atrial; c) presença de outra valvopatia; d) presença de outra cardiopatia associada e) sinais de atividade reumática, clínicos e laboratoriais f) outras patologias concomitantes como infecções, insuficiência renal, neoplasias e doenças autoimunes ou inflamatórias. Quanto a valvopatias associadas, apenas a insuficiência mitral quantificada ecocardiograficamente no máximo como discreta foi tolerada. 
Pacientes em uso de beta-bloqueadores ou inibidores da enzima de conversão da angiotensina tiveram estes fármacos suspensos três dias antes da coleta dos exames laboratoriais, já que estes podem influenciar os níveis séricos de citocinas proinflamatórias. Para os pacientes que faziam uso de profilaxia secundária para Febre Reumática, a coleta de sangue foi realizada com intervalo mínimo de semana após a aplicação intramuscular.

Foi analisado um grupo controle de doze indivíduos sem cardiopatia ou outras doenças,com média de idade de $40 \pm 9,5$ anos, selecionados dentre voluntários saudáveis no Instituto do Coração - HCFMUSP

Seguindo os critérios acima descritos, a casuística foi composta de 89 pacientes. A média de idade foi de 33.64\$11.51 anos, com 76 ( $85,3 \%$ ) pacientes do sexo masculino. Todos pacientes eram portadores de valvopatia de origem reumática. 0 diagnóstico de Febre Reumática foi realizado pela história clínica ou por achado de valvopatia compatível com Febre Reumática à ecocardiografia, especialmente a presença de fusão comissural em valva mitral ou o "domo" de valva mitral no modo bidimensional, corte paraesternal longitudinal. A tabela 1 demonstra as características demográficas da população estudada.

Dentro da população estudada, 54 pacientes estavam assintomáticos ( 60 \% ) e 35 ( $40 \%$ ) sintomáticos. Quando divididos por classes funcionais, temos que 54 ( $60 \%$ ) estavam em classe funcional I da New York Heart Association ( NYHA ), 25 ( 28\% ) em classe funcional II, 9 ( $10 \%$ ) em classe funcional III e um paciente ( $1,1 \%$ ) em classe funcional IV. Tabela 2. 48 pacientes ( 52,7 \% ) estavam em uso de penicilina benzatina como profilaxia secundária na dose de 1.200.000 UI por via intramuscular a cada 21 dias como profilaxia secundária para a Febre Reumática. Vinte e um ( 23\% ) medicados com digoxina 0,25 mg/dia, 10 ( $10,9 \%$ ) com furosemide 40mg / dia, e 8 ( $8,8 \%$ ) com diuréticos tiazídicos. Nos onze ( $12 \%$ ) pacientes medicados com captopril, o fármaco foi 
suspenso três dias antes da coleta. Dezenove ( 20,9\% ) não utolizavam qualquer tipo de medicação.

\begin{tabular}{|l|l|l|}
\hline & Assintomáticos & Sintomáticos \\
\hline Idade & $32.57 \pm 10.49$ & $35.41 \pm 12.96$ \\
\hline Altura & $170.01 \pm 9.52$ & $169.44 \pm 8.21$ \\
\hline Peso & $71.55 \pm 13.45$ & $68.31 \pm 9.83$ \\
\hline
\end{tabular}

Tabela 1 - Variáveis Gerais

\begin{tabular}{|l|l|l|l|l|}
\hline & CFI & CF II & CF III & CF IV \\
\hline $\mathrm{n}$ & 54 & 25 & 9 & 1 \\
$(\%)$ & $(60)$ & $(28)$ & $(10,0)$ & $(1,1)$ \\
\hline
\end{tabular}

Tabela 2 - Distribuição da amostra por classes funcionais. 
Os pacientes selecionados foram avaliados clinicamente, sendo anotados dados sobre etiopatogenia, tempo de conhecimento da valvopatia e sintomas ( dispnéia ), defindos em classes funcionais, obedecendo os critérios da NYHA. Foi realizado exame físico completo, com ênfase para pressão arterial, frequência cardíaca, ausculta cardíaca e pulmonar, presença de hepatomegalia e edema de membros inferiores. Todas as classificações quanto a classe funcional foram feitas pelo mesmo examinador, o qual não tinha informações sobre exames comolementares durante a avaliação.

3.3) Exames não-invasivos:

Todos os pacientes foram submetidos ao ecodopplercardiograma, sendo observados os valores de diâmetro diastólico, diâmetro sistólico, fração de encurtamento, massa, relação volume-massa, diâmetro do átrio esquerdo e diâmetro da aorta. O intervalo entre a avaliação clínica, com realização das coletas de sangue e a avaliação ecocardiográfica foi sempre inferior a dois meses. 


\subsection{1) Ecocardiografia}

As interpretações obedeceram às recomendações da Associação Americana de Ecocardiografia.

Foram estudados, particularmente:

- diâmetro diastólico final da cavidade do VE: DD (mm);

- diâmetro sistólico final da cavidade do VE: DS (mm);

- relação volume diastólico final (VDF) do VE/massa (M) (ml/g), $M(g)$ obtida por meio da fórmula $\left[1,05 \times(D D+E D P+E D S)^{3}-(D D)^{3}\right]+0,6$, onde EDP é a espessura diastólica de parede posterior (mm) e EDS é a espessura diastólica do septo interventricular (mm);

- fração de ejeção do VE pelo método de Teicholtz - valor normal FEECO > 0,55

Nos 89 pacientes analisados a espessura média do septo foi de $10.26 \pm 1.56 \mathrm{~mm}$, a espessura média da parede posterior foi de 10.18 $\pm 1.47 \mathrm{~mm}$. O diâmetro diastólico médio do ventrículo esquerdo foi de $71.78 \pm 8.43 \mathrm{~mm}$, o diâmetro sistólico médio do ventrículo esquerdo foi de $50.38 \pm 9.27 \mathrm{~mm}$ e a fração de ejeção média calculada pela ecocardiografia foi de $0.64 \pm 0.11$. O diâmetro médio da aorta foi de $38.40 \pm 5.42 \mathrm{~mm}$ enquanto que o diâmetro médio do átrio esquerdo foi de $39.91 \pm 5.10 \mathrm{~mm}$. A massa média do ventrículo esquerdo avaliada pela ecocardiografia foi de $232.88 \pm 71.48 \mathrm{~g}$ e a relação volume-massa média foi de $0.94 \pm 0.25 \mathrm{~mm}$. A tabela 3 resume as características ecocardiográficas da população estudada. 


\begin{tabular}{|l|l|}
\hline Variável & Média \pm desvio-padrão \\
\hline Septo $(\mathrm{mm})$ & $10,26 \pm 1,56$ \\
\hline PP ( mm ) & $10,18 \pm 1,47$ \\
\hline DDVE ( mm) & $71,78 \pm 8,43$ \\
\hline DSVE ( mm) & $50,38 \pm 9,27$ \\
\hline FE & $0,64 \pm 0,11$ \\
\hline AO (mm) & $38,40 \pm 5,42$ \\
\hline AE (mm ) & $39,91 \pm 5,10$ \\
\hline Massa (g) & $232,88 \pm 71,48$ \\
\hline V/M (g ) & $0,94 \pm 0,25$ \\
\hline
\end{tabular}

Tabela 3 - Médias e desvios-padrão das variáveis ecocardiográficas. S = septo PP = parede posterior DDVE = diâmetro diastólico do ventrículo esquerdo DSVE= diâmetro sistólico do ventrículo esquerdo FE = fração de ejeção do ventrículo esquerdo avaliada pela ecocardiografia $\mathrm{AO}=$ diâmetro da aorta $\mathrm{AE}=$ diâmetro do átrio esquerdo MASSA = massa do ventrículo esquedo, estimada pela ecocardiografia $\mathrm{V} / \mathrm{M}=$ Relação volumemassa estimada pela ecocardiografia.

A tabela 4 relaciona as variáveis ecocardiográficas de pacientes sintomáticos e assintomáticos. 


\begin{tabular}{|l|l|l|}
\hline & Assintomáticos & Sintomáticos \\
\hline Septo $(\mathrm{mm})$ & $10.18 \pm 1.34$ & $10.36 \pm 1.85$ \\
\hline PP (mm ) & $10.11 \pm 1.31$ & $10.25 \pm 1.69$ \\
\hline DDVE ( mm ) & $70.01 \pm 7.60$ & $74.61 \pm 8.98$ \\
\hline DSVE ( mm ) & $47.74 \pm 6.77$ & $54.80 \pm 10.86$ \\
\hline Aorta (mm) & $38.29 \pm 4.92$ & $38.83 \pm 5.95$ \\
\hline Átrio esquerdo (mm) & $39.37 \pm 4.92$ & $40.69 \pm 5.39$ \\
\hline Fração de ejeção & $0.67 \pm 0.06$ & $0.58 \pm 0.13$ \\
\hline Massa ( g ) & $226.4 \pm 58.75$ & $243.66 \pm 88.84$ \\
\hline V / M ( ml/g ) & $0.89 \pm 0.15$ & $1.02 \pm 0.35$ \\
\hline
\end{tabular}

Tabela 4 - Variáveis ecocardiográficas, distribuição em relação a sintomas. Legenda : $\mathrm{PP}=$ parede posterior, $\mathrm{DDVE}=$ diâmetro diastólico do ventrículo esquerdo, $\mathrm{DSVE}=$ diâmetro sistólico do ventrículo esquerdo $\mathrm{V} / \mathrm{M}$ = relação volume $/$ massa.

Definindo-se como disfunção ventricular esquerda valor de fração de ejeção menor que 0,55 pelo ecocardiografia, 77 pacientes ( 84,6 \% ) possuíam fração de ejeção normal e 14 ( 15,4 \%) possuíam disfunção ventricular esquerda, ou seja, fração de ejeção menor que 0,55 . 
3.4) Protocolo de coleta de sangue:

O sangue para o estudo foi colhido da veia antecubital, em tubos contendo EDTA ( para as análises de plasma) e em tubos secos estéreis ( para as análises de soro). Pacientes em uso de inibidores da enzima conversora de angiotensina tiveram estes fármacos suspensos 72 horas antes da coleta. Os tubos foram imediatamente imersos em gelo imediatamente após a coleta e então centrifugados a $4^{\circ} \mathrm{C}$ por 15 minutos a 1,000g para as análises de plasma ou deixados para coagular por 1 hora antes de centrifugação a $4^{\circ} \mathrm{C}$ por 10 minutos a 1,000g para as análises de soro. . As amostras foram aliquotadas separadamente e congeladas imediatamente $\mathrm{a}-80^{\circ} \mathrm{C}$ para análise posterior.

3.5) Dosagem :

Quando são avaliados os níveis séricos das citocinas proinflamatórias, é de grande importância que sejam medidos os níveis de seus respectivos moduladores endógenos solúveis ${ }^{98,99}$ para uma completa avaliação da atividade biológica destas. Assim realizamos a dosagem dos níveis plasmáticos do TNF e dos receptores solúveis de TNF tipo I ( sTNFRI ) e tipo II ( sTNFRII ), IL-6, receptor solúvel de IL-6 ( IL6R), IL-1 $\beta$ e seu antagonista, o antagonista do receptor de IL-1 (IL1-RA ). Para uma melhor compreensão do sistema das citocinas proinflamatórias foi realizada também a dosagem dos níveis séricos de endotelina-1.

As dosagens plasmáticas foram feitas por ELISA quimioluminescente automatizado ( Immulite ${ }^{\circledR}$, DPC ) para o TNF, IL-1 $\beta$ e IL-6 e ELISA com kits específicos comerciais de alta sensibilidade ( Quantikine ${ }^{\circledR}$, RND systems ) para o sTNFRI, sTNFRII, 
IL6R e IL1RA e kit específico de ELISA ( Parameter ${ }^{\circledR}$, RND systems ) para a endotelina-1 .

Além destas dosagens séricas, DNA genômico foi extraído de sangue total através de técnica de extração por sal, gerando amostras que também foram aliquotadas e estocadas a $-800 \mathrm{C}$. Tais amostras destinam-se a análises genéticas dos pacientes, sendo que já foi realizada a análise do polimorfismo genético do TNF, dados que foram incuídos no presente estudo. O polimorfismo estudado se localiza na região promotora do gene à 308 pares de bases do sítio de iniciação, e constitui uma mutação pontual, com substituição de guanina ( $G$ ) por adenina ( A ).. A genotipagem foi realizada através da amplificação por reação de PCR de sequências flanqueando a região polimórfica e digestão enzimática com endonuclease Not-1 . Os produtos da digestão foram analisados através de eletroforese em gel de agarose e visualizados através de coloração com brometo de etídeo.

Denominamos o polimorfismo como alelo 1 quando há a presença de guanina na posição -308, e como alelo 2 quando a posição está com adenina . 


\section{4) Análise estatística}

4.1)Analise descritiva:

Para as variáveis quantitativas (idade, DDVE, DSVE, FE,...) esta análise foi realizada através da observação dos valores mínimos e máximos, e do cálculo de médias e desvios-padrão e medianas. Para as variáveis qualitativas (presença ou não de determinado parâmetro) foram calculadas freqüências absolutas e relativas.

\section{2) Analise comparativa:}

Para se testar a homogeneidade de grupos em relação as proporções foi utilizado o teste qui-quadrado ${ }^{100}$ e o teste exato de Fisher, que é indicado para a comparação de proporções quando caselas de respostas apresentam freqüências esperadas menor do que $5^{100}$.

Para a comparação entre média de dois grupos independentes foi utilizado o teste $\mathrm{t}$ de Student ${ }^{100}$; quando a normalidade dos dados foi rejeitada utilizou-se o teste nãoparamétrico de Mann-Whitney ${ }^{100}$.

Para a comparação entre média de três grupos independentes foi utilizada a Análise de Variância a um fator e as comparações múltiplas foram realizadas através do teste de Bonferroni $^{100}$; quando a normalidade dos dados foi rejeitada utilizou-se o teste não-paramétrico de Kruskal-Wallis com comparações múltiplas realizadas através do teste de Dunn ${ }^{100}$.

Para o estudo da correlação entre duas variáveis foi utilizado o coeficiente de correlação de Pearson ${ }^{100}$. 
Em algumas análises as variáveis: IL6, IL-6R, TNF- $\alpha$, sTNFRI, sTNFR II, IL-1 $\beta$, IL-1RA e endotelina foram analisadas através da transformação logarítmica, para obtermos a normalidade dos dados.

Todos os testes foram realizados admitindo-se nível de significância de 5\%. ${ }^{100}$ 


\section{Resultados}




\section{5) Resultados}

5.1 ) Níveis plasmáticos de Fator de necrose tumoral-alfa ( TNF)

Foram realizadas dosagens séricas do TNF em 89 pacientes. Os níveis plasmáticos médios de TNF foram de 92.65 $\pm 110.24 \mathrm{pg} / \mathrm{ml}$, sendo significantemente mais elevados que em controles normais ( média de $1.67 \pm 1.21 \mathrm{pg} / \mathrm{ml}$ ) , $p=0,0001$. Não observamos diferença entre os níveis de TNF entre pacientes assintomáticos e sintomáticos ( $p=0.887$ ) como podemos notar na tabela 5 e 6 e na figura 2.

\begin{tabular}{|l|l|l|l|}
\hline & $\begin{array}{l}\text { Controles } \\
\mathrm{N}=12\end{array}$ & $\begin{array}{l}\text { IAo } \\
\mathrm{n}=89\end{array}$ & $p$ \\
\hline TNF $(\mathrm{pg} / \mathrm{ml})$ & $1,67 \pm 1,21$ & $92,65 \pm 110,24$ & \\
\hline logTNF & $0,26 \pm 0,73$ & $3,81 \pm 1,30$ & 0,0001 \\
\hline
\end{tabular}

Tabela 5 - Comparação entre níveis séricos de TNF em pacientes com insuficiência aórtica ( IAo ) e controles normais. TNF = fator de necrose tumoral alfa. LogTNF Transformação logarítmica das concentrações de TNF. 


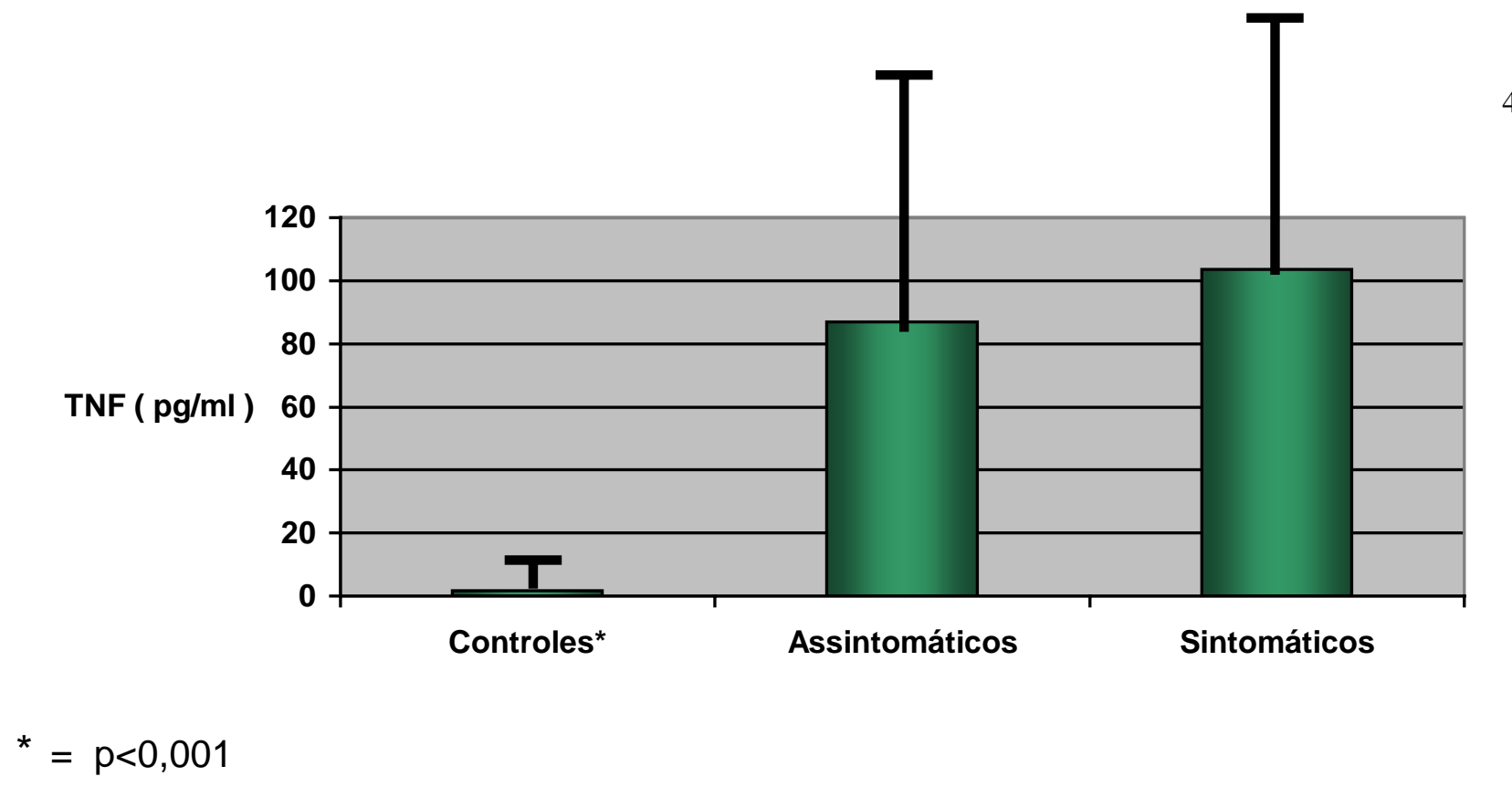

\begin{tabular}{|l|l|l|l|l|}
\hline & Controles & Assintomáticos & Sintomáticos & $p$ \\
& $\mathrm{~N}=12$ & $\mathrm{n}=53$ & $\mathrm{n}=35$ & \\
\hline TNF $(\mathrm{pg} / \mathrm{ml})$ & $1,67 \pm 1,21$ & $86,91 \pm 85,21$ & $103,49 \pm 141,43$ & \\
\hline LogTNF & $0,26 \pm 0,73$ & $3,84 \pm 1,23$ & $3,80 \pm 1,42$ & $<0,001$ \\
\hline
\end{tabular}

análise de variância a um fator

Tabela 6 e figura 2 - Comparação entre níveis de TNF em controles, pacientes assintomáticos e sintomáticos. TNF $=$ fator de necrose tumoral alfa. logTNF transformação logarítmica das concentrações de TNF.

Pela análise de variância a um fator, observamos que os grupos controle, assintomáticos e sintomáticos diferem significativamente $(p<0,001)$. Através do teste de Bonferroni observamos que o grupo controle difere significativamente dos demais grupos $(p<0.05)$

Separando os pacientes por classes funcionais, não notamos diferença entre os níveis plasmáticos de pacientes em CFI, CFII e CF III e IV ( $p=0,899$ ). Tabela 7. 


\begin{tabular}{|l|l|l|l|l|}
\hline & CFI & CFII & CFIII / IV & $p$ \\
$n=53$ & $n=26$ & $n=9$ & \\
\hline TNF $(\mathrm{pg} / \mathrm{ml})$ & $86,92 \pm 85,22$ & $110,02 \pm 158,07$ & $84,63 \pm 79,99$ & \\
\hline logTNF & $3,84 \pm 1,24$ & $3,74 \pm 1,54$ & $3,97 \pm 1,07$ & 0,899 \\
\hline
\end{tabular}

análise de variância a um fator

Tabela 7 - Relação entre os níveis plasmáticos de TNF e classes funcionais. TNF = fator de necrose tumoral alfa. logTNF - transformação logarítmica das concentrações de TNF.

Analisando a relação entre fração de ejeção do ventrículo esquerdo e níveis plasmáticos de TNF não observamos relação com os grupos definidos pela fração de ejeção. Tabela 8. 


\begin{tabular}{|c|c|c|c|c|}
\hline & & $\operatorname{TNF}(\mathrm{pg} / \mathrm{ml})$ & $\log T N F$ & $p$ \\
\hline \multirow[t]{2}{*}{ FE } & $\begin{array}{l}\geq 0,55 \\
n=75\end{array}$ & $88,68 \pm 110,73$ & $3,77 \pm 1,28$ & \\
\hline & $\begin{array}{l}<0,55 \\
n=14\end{array}$ & $113,84 \pm 109,06$ & $4,00 \pm 1,45$ & 0,545 \\
\hline
\end{tabular}

análise de variância a um fator

Tabela 8 - Relação entre níveis plasmáticos de TNF e função ventricular, aferida pela ecocardiografia. TNF = fator de necrose tumoral alfa. LogTNF - transformação logarítmica das concentrações de TNF. FE = fração de ejeção pela ecocardiografia.

Não observamos relação entre níveis plasmáticos de fator de necrose tumoral - alfa e diâmetro diastólico do ventrículo esquerdo $(r=-0,013, p=0,93)$, diâmetro sistólico do ventrículo esquerdo ( $r=-0,005 p=0,97$ ) e fração de ejeção pela ecocardiografia ( $r$ $=0,008, p=0,95)$.

Dividindo os diâmetros ventriculares em categorias, definidas pela linha de corte de 75mm para o diâmetro diastólico e 55mm para o diâmetro sistólico, não obtivemos correlação entre diâmetros e níveis plasmáticos de TNF. Tabela 9. 
49

\begin{tabular}{|c|c|c|c|c|}
\hline & & TNF ( $\mathrm{pg} / \mathrm{ml})$ & logTNF & $p$ \\
\hline \multirow[t]{2}{*}{$\begin{array}{l}\text { DDVE } \\
(\mathrm{mm})\end{array}$} & $\begin{array}{l}\geq 75 \\
n=33\end{array}$ & $87,64 \pm 85,95$ & $3,82 \pm 1,30$ & \\
\hline & $\begin{array}{l}<75 \\
n=56\end{array}$ & $95,60 \pm 122,97$ & $3,81 \pm 1,31$ & 0,970 \\
\hline \multirow[t]{2}{*}{$\begin{array}{l}\text { DSVE } \\
(\mathrm{mm})\end{array}$} & $\begin{array}{l}\geq 55 \\
n=22\end{array}$ & $88,60 \pm 91,98$ & $3,78 \pm 1,36$ & \\
\hline & $\begin{array}{l}<55 \\
n=66\end{array}$ & $95,27 \pm 116,61$ & $3,84 \pm 1,28$ & 0,844 \\
\hline
\end{tabular}

Tabela 9 - Níveis de TNF em relação a grupos de pacientes definidos pelos diâmetros ventriculares. TNF = fator de necrose tumoral alfa. LogTNF - transformação logarítmica das concentrações de TNF, DDVE = diâmetro diastólico do ventrículo esquerdo, DSVE = diâmetro sistólico do ventrículo esquerdo. 
5.2) Níveis plasmáticos de receptores solúveis de TNF tipo I ( sTNFR I )

Nos 40 pacientes analisados, os níveis plasmáticos médios de receptores solúveis de TNF tipo I ( sTNFR I ) foram de $894.75 \pm 348.87$ pg / ml. Tais níveis foram significantemente maiores do que aqueles do grupo controle ( 521,42 $\pm 395,13 \mathrm{pg} / \mathrm{ml})$, $p=0,0078$ Os níveis plasmáticos de sTNFR I não foram diferentes entre pacientes sintomáticos e assintomáticos. Tabela 10, 11 e figura 3.

\begin{tabular}{|l|l|l|l|}
\hline & Controles & IAo & \\
& $\mathrm{N}=12$ & $\mathrm{n}=89$ & $p$ \\
\hline sTNFR I $(\mathrm{pg} / \mathrm{ml})$ & $521,42 \pm 395,13$ & $894,75 \pm 348,87$ & \\
\hline logsTNFR I & $5,96 \pm 0,81$ & $6,72 \pm 0,37$ & 0,0078 \\
\hline
\end{tabular}

Teste $\mathrm{t}$

Tabela10 - Níveis séricos de sTNFRI em pacientes com Insuficiência aórtica ( IAo ) e controles normais. sTNFR I = receptor solúvel de TNF tipo I, LogsTNFR I = transformação logarítmica dos níveis de receptor solúvel de TNF tipo I. 


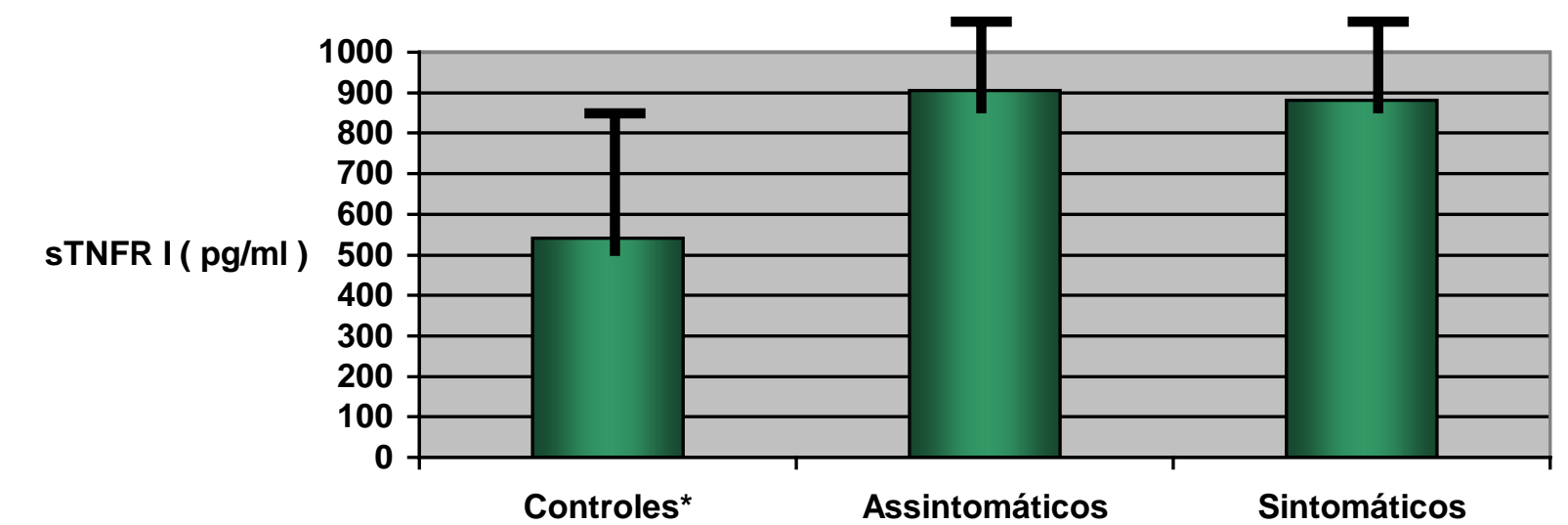

$*=p<0,05$

\begin{tabular}{|l|l|l|l|l|}
\hline & Controles & Assintomáticos & Sintomáticos & $p$ \\
& $\mathrm{~N}=12$ & $\mathrm{n}=21$ & $\mathrm{n}=19$ & \\
\hline sTNFR I $(\mathrm{pg} / \mathrm{ml})$ & $521,42 \pm 395,13$ & $906,82 \pm 299,62$ & $881,41 \pm 404,47$ & \\
\hline logsTNFR I & $5,96 \pm 0,81$ & $6,75 \pm 0,36$ & $6,70 \pm 0,39$ & $<0,001$ \\
\hline
\end{tabular}

análise de variância a um fator

Tabela 11 e figura 3 - Níveis de receptores solúveis de TNF tipo I em controles, pacientes sintomáticos e assintomáticos. STNFR I = receptor solúvel de TNF tipo I, LogsTNFR I = transformação logarítmica dos níveis de receptor solúvel de TNF tipo I.

Pela análise de variância a um fator, observamos que os grupos controle, assintomáticos e sintomáticos diferem significativamente $(p<0,001)$. Através do teste de Bonferroni observamos que o grupo controle difere significativamente dos demais grupos $(p<0.05)$

Separando os pacientes por classes funcionais, não notamos diferença entre os níveis plasmáticos de pacientes em CFI, CFII e CF III e IV $(p=0.485)$. Tabela 12 


\begin{tabular}{|l|l|l|l|l|}
\hline & CFI & CFII & CFIII / IV & $p$ \\
& $n=21$ & $n=10$ & $n=9$ & \\
\hline STNFR I $(\mathrm{pg} / \mathrm{ml})$ & $906,82 \pm 299,62$ & $768,91 \pm 253,53$ & $1006,41 \pm 512,24$ & \\
\hline logsTNFR I & $6,75 \pm 0,37$ & $6,61 \pm 0,26$ & $6,8 \pm 0,49$ & 0,893 \\
\hline
\end{tabular}

análise de variância a um fator

Tabela 12 - Níveis de receptores solúveis de TNF tipo I e classes funcionais. STNFR I = receptor solúvel de TNF tipo I, LogsTNFR I = transformação logarítmica dos níveis de receptor solúvel de TNF tipo I.

Analisando a relação entre fração de ejeção do ventrículo esquerdo e níveis plasmáticos de sTNFRII, não observamos relação com os grupos definidos pela fração de ejeção. Tabela13.

\begin{tabular}{|l|l|l|l|l|}
\hline \multicolumn{2}{|l|}{} & STNFR I $(\mathrm{pg} / \mathrm{ml})$ & logsTNFR I & $p$ \\
\hline FE & $\geq 0,55$ & $922,17 \pm 373,55$ & $6,75 \pm 0,40$ & \\
$n=31$ & & & \\
\cline { 2 - 5 } & $<0,55$ & $800,31 \pm 238,97$ & $6,65 \pm 0,27$ & 0,487 \\
$n=9$ & & & \\
\hline
\end{tabular}

Tabela 13 - Relação entre níveis plasmáticos de sTNFR I e função ventricular, aferida pela ecocardiografia. STNFR I = receptor solúvel de TNF tipo I, LogsTNFR I = transformação logarítmica dos níveis de receptor solúvel de TNF tipo I.

FE eco = fração de ejeção pela ecocardiografia. 
Não observamos relação entre níveis plasmáticos de fator de necrose tumoral alfa e diâmetro diastólico do ventrículo esquerdo ( $r=-0,08, p=0,60)$, diâmetro sistólico do ventrículo esquerdo ( $r=-0,139 p=0,39$ ), fração de ejeção pela ecocardiografia $(r=0,166, p=0,30)$.

Dividindo os diâmetros ventriculares em categorias, definidas pela linha de corte de $75 \mathrm{~mm}$ para o diâmetro diastólico e 55mm para o diâmetro sistólico, também não obtivemos correlação entre diâmetros e níveis plasmáticos de TNF. Tabela 14.

\begin{tabular}{|l|l|l|l|l|}
\hline \multicolumn{2}{|l|}{} & STNFR I ( pg / ml ) & logsTNFR I & $p$ \\
\hline $\begin{array}{l}\text { DDVE } \\
(\mathrm{mm})\end{array}$ & $\geq 75$ & $875,78 \pm 309,45$ & $6,72 \pm 0,35$ & \\
& $\mathrm{n}=20$ & & & \\
\cline { 2 - 5 } & $<75$ & $913,72 \pm 391,54$ & $6,74 \pm 0,41$ & 0,863 \\
$\mathrm{n}=20$ & & & \\
\hline $\begin{array}{l}\text { DSVE } \\
(\mathrm{mm})\end{array}$ & $\geq 55$ & $861,80 \pm 311,80$ & $6,70 \pm 0,35$ & \\
& $\mathrm{n}=14$ & & & \\
\cline { 2 - 5 } & $<55$ & $914,82 \pm 379,47$ & $6,74 \pm 0,40$ & 0,754 \\
& $\mathrm{n}=25$ & & & \\
\hline
\end{tabular}

Tabela 14 - Níveis de sTNFR I em relação a grupos de pacientes definidos pelos diâmetros ventriculares. sTNFR I = receptor solúvel de TNF tipo I, LogsTNFR I = transformação logarítmica dos níveis de receptor solúvel de TNF tipo I, DDVE = diâmetro diastólico do ventrículo esquerdo, DSVE = diâmetro sistólico do ventrículo esquerdo. 
5.3) Níveis plasmáticos de receptores solúveis de TNF tipo II ( sTNFR II )

Nos 40 pacientes analisados, os níveis plasmáticos médios de receptores solúveis de TNF tipo II ( sTNFR II ) foram de $1879.65 \pm 596.12$ pg / ml. Os níveis plasmáticos de sTNFR II não foram diferentes entre pacientes sintomáticos e assintomáticos. Tabela15.

\begin{tabular}{|l|l|l|l|}
\hline & $\begin{array}{l}\text { Assintomáticos } \\
\mathrm{N}=21\end{array}$ & $\begin{array}{l}\text { Sintomáticos } \\
\mathrm{N}=19\end{array}$ & $P$ \\
\hline STNFR II ( pg / ml ) & $1868,75 \pm 530,54$ & $1891,68 \pm 675,93$ & \\
\hline logsTNFR II & $7,49 \pm 0,27$ & $7,49 \pm 0,3$ & 0,992 \\
\hline
\end{tabular}

Tabela 15 - Níveis de receptores solúveis de TNF tipo II em pacientes sintomáticos e assintomáticos. sTNFR $\|=$ receptor solúvel de TNF tipo $\|$, LogsTNFR $\|=$ transformação logarítmica dos níveis de receptor solúvel de TNF tipo II.

Separando os pacientes por classes funcionais, também não notamos diferença entre os níveis plasmáticos de pacientes em CFI, CFII e CF III e IV ( $p=0.893)$. Tabela 16. 


\begin{tabular}{|l|l|l|l|l|}
\hline & CFI & CFII & CFIII / IV & $P$ \\
\hline STNFR II ( pg / ml ) & $1868,76 \pm 530,55$ & $1805,94 \pm 473,3$ & $1986,97 \pm 869,8$ & \\
& & & 3 & \\
\hline logsTNFR II & $7,50 \pm 0,27$ & $7,47 \pm 0,26$ & $7,53 \pm 0,35$ & 0,893 \\
\hline
\end{tabular}

análise de variância a um fator

Tabela 16 - Níveis de receptores solúveis de TNF tipo II e classes funcionais. STNFR II = receptor solúvel de TNF tipo II, LogsTNFR II = transformação logarítmica dos níveis de receptor solúvel de TNF tipo II.

Analisando a relação entre fração de ejeção do ventrículo esquerdo e níveis plasmáticos de sTNFRII, não observamos relação com os grupos definidos pela fração de ejeção tanto pela ecocardiografia quanto pela ventriculografia radioisotópica. Houve, entretanto tendência não significativa ( $p=0,076$ ) a níveis maiores de sTNFR II em pacientes com fração de ejeção aferida pela ecocardiografia maior que 0,55. Tabela 17.

\begin{tabular}{|l|l|l|l|l|}
\hline \multicolumn{2}{|l|}{} & STNFR II (pg / ml ) & LogsTNFR II & $P$ \\
\hline FE & $\geq 0,55$ & $1959,32 \pm 619,5$ & $7,54 \pm 0,28$ & \\
$n=31$ & & & \\
\cline { 2 - 5 } & $<0,55$ & $1605,21 \pm 428,9$ & $7,35 \pm 0,26$ & 0,076 \\
$n=9$ & & & \\
\hline
\end{tabular}

análise de variância a um fator

Tabela 17 - Relação entre níveis plasmáticos de sTNFR II e função ventricular, aferida pela ecocardiografia. sTNFR $\|=$ receptor solúvel de TNF tipo II, LogsTNFR II = transformação logarítmica dos níveis de receptor solúvel de TNF tipo II.

FE = fração de ejeção pela ecocardiografia. 
Não foi observada correlação entre os níveis de sTNFR II e a fração de ejeção, medida pela ecocardiografia $(r=0,219, p=0,17)$.

Dividindo-se os diâmetros ventriculares em categorias, definidas pela linha de corte de $75 \mathrm{~mm}$ para o diâmetro diastólico e $55 \mathrm{~mm}$ para o diâmetro sistólico, observamos correlação entre diâmetros e níveis plasmáticos de sTNFRII. Pacientes com diâmetro diastólico do ventrículo esquerdo maior que $75 \mathrm{~mm}$ tiveram níveis de sTNFR II significantemente $(p=0.025$ ) menores do que pacientes com diâmetro diastólico menor que este valor, e pacientes com diâmetro sistólico maior que 55mm tiveram de modo semelhante níveis significantemente $(p=0.034)$ menores de sTNFR II que aqueles com diâmetro sistólico menor 55 mm. Tabela 18.

\begin{tabular}{|l|l|l|l|l|}
\hline \multicolumn{2}{|l|}{} & STNFR II ( pg / ml ) & logsTNFR II & $P$ \\
\hline DDVE & $\geq 75$ & $1673,57 \pm 372,40$ & $7,39 \pm 0,22$ & \\
\cline { 2 - 5 } & $n=20$ & & & \\
\cline { 2 - 5 } & $<75$ & $2085,72 \pm 708,05$ & $7,59 \pm 0,30$ & 0,025 \\
$(\mathrm{~m}=20$ & $\geq 55$ & $1608,67 \pm 327,13$ & $7,36 \pm 0,20$ & \\
\cline { 3 - 5 } & $n=14$ & & & 0,034 \\
\cline { 2 - 5 } & $<55$ & $2010,15 \pm 668,70$ & $7,56 \pm 0,29$ & \\
\hline
\end{tabular}

análise de variância a um fator

Tabela 18 - Níveis de sTNFR II em relação a grupos de pacientes definidos pelos diâmetros ventriculares. STNFR $\|=$ receptor solúvel de TNF tipo II, LogsTNFR $\|=$ transformação logarítmica dos níveis de receptor solúvel de TNF tipo II, DDVE = diâmetro diastólico do ventrículo esquerdo, DSVE = diâmetro sistólico do ventrículo esquerdo. 
Foi observada correlação significativa, entretanto, entre os níveis plasmáticos de STNFR II e o diâmetro diastólico do ventrículo esquerdo $(r=-0,329, p=0,038)$ e $o$ diâmetro sistólico do ventrículo esquerdo ( $r=-0,352, p=0,027$ ), como pode ser visto nas figuras 4 e 5 


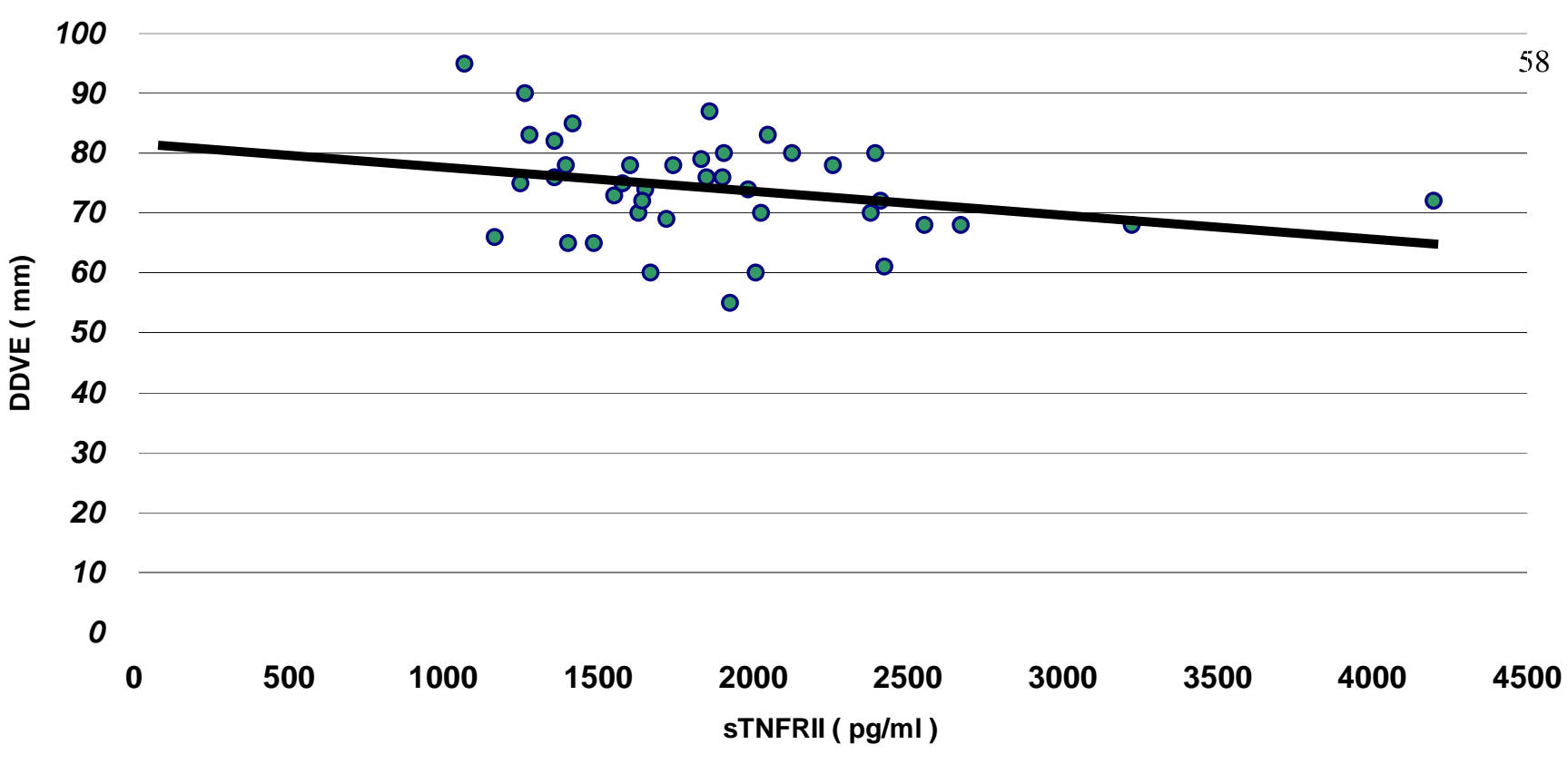

Relação entre sTNFRII e DSVE

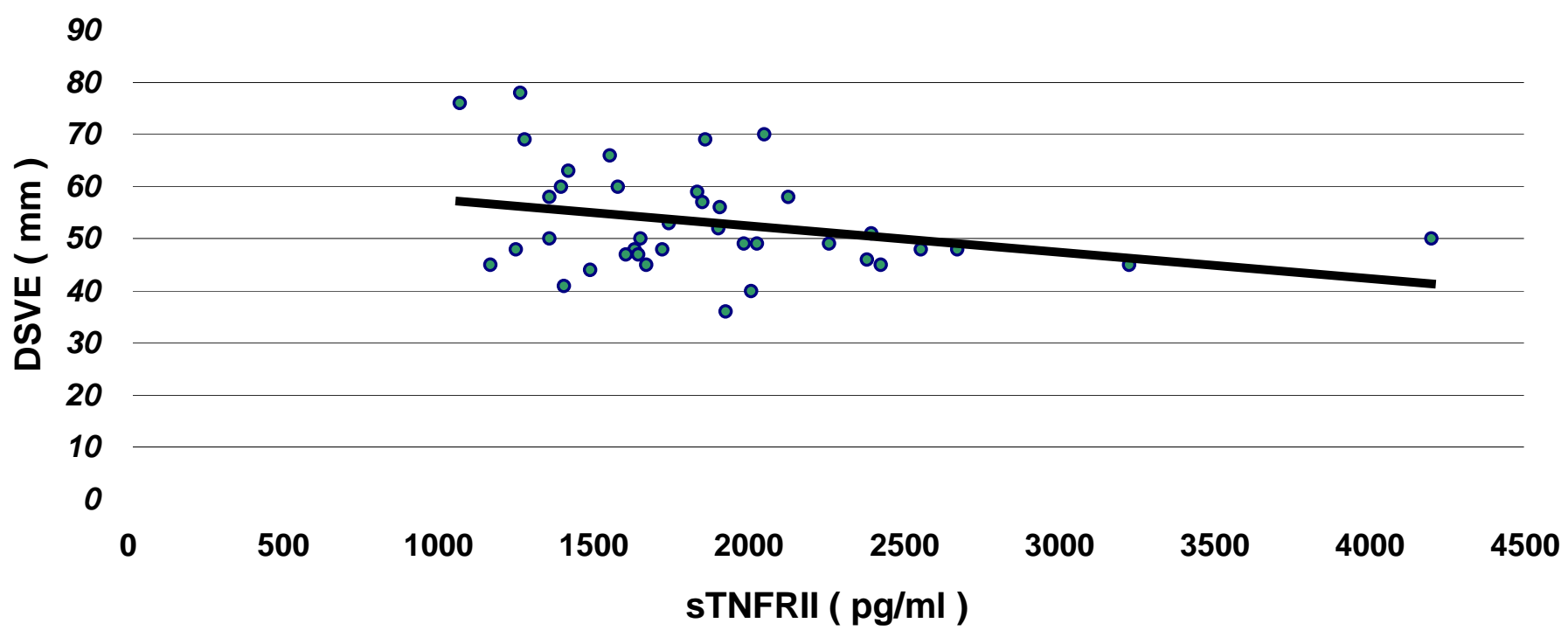

Figuras 4 e 5 - Gráficos de regressão mostrando a correlação entre os níveis de sTNFRII e DDVE $(r=-0,329, p=0,038)$ e entre sTNFRII e DSVE $(r=-0,352, p=0,027$ ). sTNFR II = receptor solúvel de TNF tipo II, DDVE = diâmetro diastólico do ventrículo esquerdo, DSVE = diâmetro sistólico do ventrículo esquerdo. 
5.4) Polimorfismo genético do Fator de Necrose Tumoral-alfa

Após análise genética de 88 pacientes, 66 ( $75 \%)$ pacientes foram identificados para o polimorfismo estudado como genótipo 1/1, 19 ( 21,6 \% ) foram identificados como 1/2 e 3 ( 3,4 \% ) como genótipo 2/2. Houve associação significativa ( $p=0,035$ ) entre o genótipo e a sintomatologia dos pacientes. Tabela 19

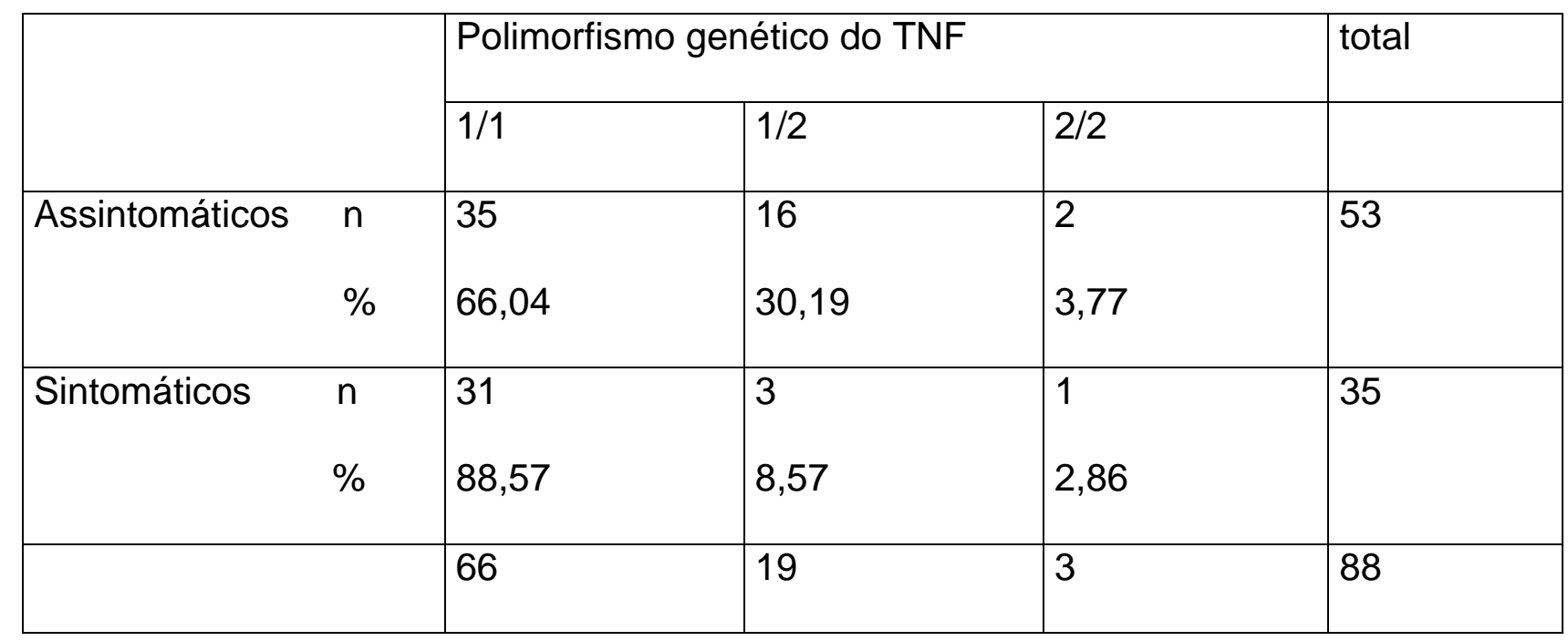

$P=0,035$, teste exato de Fisher.

Tabela 19 - Relação entre sintomatologia e variantes genéticas do TNF.

Ao dividirmos os pacientes em classes funcionais da NYHA, em CF I, CF II e Cf II e IV notamos que persiste associação significativa ( $p=0,048$ ) entre genótipo e sintomas. Tabela 20.

Entre os pacientes assintomáticos, encontramos $66 \%$ de genótipo $1 / 1,30 \%$ de genótipo $1 / 2$ e $4 \%$ de genótipo $2 / 2$, enquanto que entre pacientes sintomáticos 
encontramos $88 \%$ de genótipo $1 / 1,9 \%$ de genótipo $1 / 2$ e $3 \%$ de genótipo $2 / 2$, uma associação significante $(p=0.035)$

\begin{tabular}{|c|c|c|c|c|c|}
\hline & \multicolumn{3}{|c|}{ Polimorfismo genético do TNF } & \multirow[t]{2}{*}{ total } \\
\hline & & $1 / 1$ & $1 / 2$ & $2 / 2$ & \\
\hline CF I & $\begin{array}{l}\mathrm{n} \\
\%\end{array}$ & $\begin{array}{l}35 \\
66,04\end{array}$ & $\begin{array}{l}16 \\
30,19\end{array}$ & $\begin{array}{l}2 \\
3,77\end{array}$ & 53 \\
\hline CF II & $\begin{array}{l}\mathrm{n} \\
\%\end{array}$ & $\begin{array}{l}23 \\
88,46\end{array}$ & $\begin{array}{l}3 \\
11,54\end{array}$ & $\begin{array}{l}0 \\
0,00\end{array}$ & 35 \\
\hline CF III / IV & $\begin{array}{l}\mathrm{n} \\
\%\end{array}$ & $\begin{array}{l}8 \\
88,89\end{array}$ & $\begin{array}{l}0 \\
0,00\end{array}$ & $\begin{array}{l}1 \\
11,11\end{array}$ & 88 \\
\hline & & 66 & 19 & 3 & 88 \\
\hline
\end{tabular}

$P=0,048$, teste exato de Fisher.

Tabela20- Relação entre classes funcionais e variantes genéticas do TNF.

Pelo teste não-paramétrico de Kruskal-Wallis não observamos diferença entre os grupos definidos pelo genótipo em relação a idade $(p=0,711)$, peso $(p=0,096)$, altura $(p=0,65)$ e pelo teste exato de Fisher, não houve diferença em relação ao sexo entre os grupos $(p=0,580)$.

Analisando as variáveis ecocardiográficas e de ventriculografia radioisotópica, notamos que os grupos definidos pela variante genética estudada de TNF possuíam valores semelhantes. Observamos tendência não significante $(p=0,055)$ de diferenças 
de massa miocárdica entre os genóripos, com tendência de massas maiores no grupo com genótipo 2/2. Tabela 21.

\begin{tabular}{|l|l|l|l|l|}
\hline & \multicolumn{2}{|l|}{ Polimorfismo genético do TNF } & \\
\hline & $1 / 1$ & $1 / 2$ & $2 / 2$ \\
$n=66$ & $n=19$ & $n=3$ & \\
\hline Septo ( mm) & $10,30 \pm 1,69$ & $10,05 \pm 1,02$ & $11,33 \pm 1,15$ & 0,328 \\
\hline PP (mm) & $10,19 \pm 1,58$ & $10,00 \pm 1,00$ & $11,33 \pm 1,15$ & 0,268 \\
\hline AE ( mm) & $39,54 \pm 5,12$ & $39,73 \pm 5,04$ & $43,66 \pm 1,52$ & 0,288 \\
\hline Ao (mm) & $38,19 \pm 5,42$ & $39,42 \pm 5,11$ & $35,66 \pm 3,51$ & 0,45 \\
\hline DDVE (mm) & $72,12 \pm 8,56$ & $69,31 \pm 7,84$ & $74,66 \pm 4,50$ & 0,311 \\
\hline DSVE (mm) & $50,98 \pm 9,35$ & $47,36 \pm 8,26$ & $52,00 \pm 6,08$ & 0,239 \\
\hline FE eco & $0,63 \pm 0,11$ & $0,67 \pm 0,08$ & $0,65 \pm 0,07$ & 0,385 \\
\hline Massa ( g ) & $232,03 \pm 77,81$ & $217,5 \pm 39,07$ & $306,66 \pm 28,86$ & 0,055 \\
\hline V/M ( ml/g ) & $0,95 \pm 0,27$ & $0,90 \pm 0,15$ & $0,82 \pm 0,13$ & 0,639 \\
\hline
\end{tabular}

teste não-paramétrico de Kruskal-Wallis

Tabela 21 - Correlação entre as variáveis ecocardiográficas e da ventriculografia radioisotópica com a variante genética estudada do TNF. PP = espessura da parede posterior do ventrículo esquerdo, DDVE = diâmetro diastólico do ventrículo esquerdo, DSVE = diâmetro sistólico do ventrículo esquerdo, FEeco = fração de ejeção do ventrículo esquerdo avaliada pela ecocardiografia, V/M - Relação volume/massa. 
Analisando os níveis séricos de citocinas proinflamatórias em relação aos grupos definidos pelo polimorfismo genético estudado, notamos que os grupos são semelhantes, com exceção do antagonista do receptor de IL1 ( IL1-RA ), que apresentou distrinuição diferente entre os grupos, apresentando maiores concentrações no grupo com polimorfismo 1/2 ( $p=0,016$, teste não-parmétrico de Mann-Whitney ). Tabela 22.

\begin{tabular}{|c|c|c|c|c|}
\hline & Polimorfismo & ético do TNF & & \\
\hline $\begin{array}{l}\text { N } \\
\text { n para TNF e IL-6 } \\
\text { n para restantes }\end{array}$ & $\begin{array}{l}1 / 1 \\
n=66 \\
n=30\end{array}$ & $\begin{array}{l}1 / 2 \\
n=19 \\
n=6\end{array}$ & $\begin{array}{l}2 / 2 \\
n=3 \\
n=3\end{array}$ & $p$ \\
\hline $\begin{array}{r}\text { TNF } \quad \mathrm{pg} / \mathrm{ml} \\
\\
\log \end{array}$ & $\begin{array}{l}97,16 \pm 118,6 \\
3,85 \pm 1,32\end{array}$ & $\begin{array}{l}92,16 \pm 91,1 \\
3,81 \pm 1,37\end{array}$ & $\begin{array}{l}68,56 \pm 90,4 \\
3,58 \pm 1,36\end{array}$ & 0,946 \\
\hline $\begin{array}{c}\text { sTNFR I } \mathrm{pg} / \mathrm{ml} \\
\\
\log \end{array}$ & $\begin{array}{l}882,21 \pm 365,3 \\
6,71 \pm 0,39\end{array}$ & $\begin{array}{l}968,2 \pm 288,9 \\
6,84 \pm 0,30\end{array}$ & $\begin{array}{l}965,04 \pm 406,7 \\
6,80 \pm 0,48\end{array}$ & 0,651 \\
\hline $\begin{array}{c}\text { sTNFR II } \mathrm{pg} / \mathrm{ml} \\
\text { log }\end{array}$ & $\begin{array}{l}1845 \pm 608,3 \\
7,48 \pm 0,28\end{array}$ & $\begin{array}{l}2146 \pm 669,6 \\
7,63 \pm 0,33\end{array}$ & $\begin{array}{l}1702 \pm 404,2 \\
7,42 \pm 0,26\end{array}$ & 0,343 \\
\hline $\begin{array}{r}\mathrm{pg} / \mathrm{ml} \\
\\
\log \end{array}$ & $\begin{array}{l}7,65 \pm 8,29 \\
-3,26 \pm 6,92\end{array}$ & $\begin{array}{l}6,13 \pm 5,42 \\
6,81 \pm 1,90\end{array}$ & $\begin{array}{l}2,93 \pm 5,08 \\
-2,83 \pm 6,81\end{array}$ & 0,613 \\
\hline $\begin{array}{c}\mathrm{pg} / \mathrm{ml} \\
\\
\log \end{array}$ & $\begin{array}{l}32258 \pm 8647 \\
10,35 \pm 0,28\end{array}$ & $\begin{array}{l}39507 \pm 14770 \\
10,52 \pm 0,42\end{array}$ & $\begin{array}{l}39920 \pm 12645 \\
10,56 \pm 0,30\end{array}$ & 0,275 \\
\hline $\begin{array}{r}\text { IL1-RA } \quad \mathrm{pg} / \mathrm{ml} \\
\\
\\
\log \end{array}$ & $\begin{array}{l}43,55 \pm 106,5 \\
-5,52 \pm 6,25\end{array}$ & $\begin{array}{l}313,65 \pm 326,63 \\
0,94 \pm 7,88\end{array}$ & $\begin{array}{l}0,00 \\
-9,21 \pm 0,00\end{array}$ & $0,025^{\star}$ \\
\hline $\begin{array}{r}\text { ET-1 } \quad \mathrm{pg} / \mathrm{ml} \\
\\
\log \end{array}$ & $\begin{array}{l}7,28 \pm 6,68 \\
1,23 \pm 2,23\end{array}$ & $\begin{array}{l}7,37 \pm 7,06 \\
1,33 \pm 1,53\end{array}$ & $\begin{array}{l}3,95 \pm 6,85 \\
-5,32 \pm 6,75\end{array}$ & 0,475 \\
\hline
\end{tabular}

teste não-paramétrico de Kruskal-Wallis * =teste não paramétrico de Mann-Whitney 
Tabela 22 - Correlações entre os níveis séricos de citocinas, seus antagonistas e endotelina-1 e os grupos definidos pela variante genética estudada. TNF = fator de necrose tumoral alfa, sTNFR I = receptor solúvel de TNF tipo I, sTNFR II = receptro solúvel de TNF tipo II, IL-6 = interleucina 6, IL-6R = receptor sulúvel de IL-6, IL1-RA = antagonista do receptor de interleucina 1, ET-1 = endotelina-1, log = transformação logarítmica dos níveis plasmáticos. 
5.5 ) Níveis plasmáticos de Interleucina-6 ( IL-6 )

Foram realizadas dosagens séricas da interleucina-6 ( IL-6 ) em 89 pacientes. Os níveis plasmáticos médios de IL-6 foram de $7,17 \pm 7,78$ pg/ml, significantemente mais altos do que em controles normais $(0,91 \pm 0,38 \mathrm{pg} / \mathrm{ml}), p=0,0001$. Tabela 23 .

Não observamos diferença entre os níveis de II-6 entre controles normais, pacientes assintomáticos e sintomáticos como podemos notar na tabela 24 .

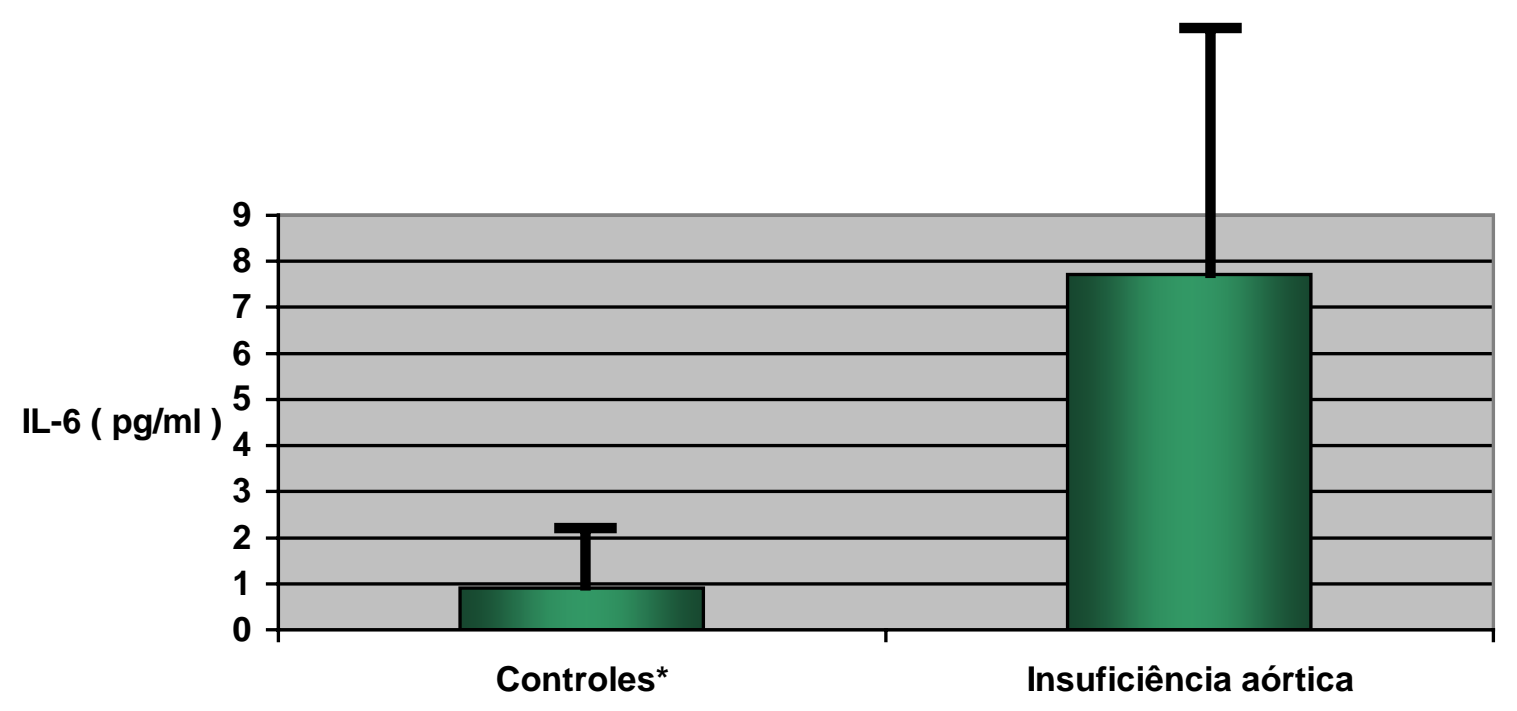

$*=p=0,0001$

\begin{tabular}{|l|l|l|l|}
\hline & $\begin{array}{l}\text { Controles } \\
\mathrm{N}=12\end{array}$ & $\begin{array}{l}\mathrm{IAO} \\
\mathrm{n}=89\end{array}$ & $p$ \\
\hline $\mathrm{IL}-6(\mathrm{pg} / \mathrm{ml})$ & $0,91 \pm 0,38$ & $7,17 \pm 7,78$ & \\
\hline logIL-6 & $0,43 \pm 0,12$ & $6,90 \pm 0,72$ & 0,0001 \\
\hline
\end{tabular}


Tabela 23 e figura 6 - Níveis de IL-6 em controles normais e pacientes com insuficiência aórtica ( IAo ). IL-6 = Interleucina 6. LogIL-6 - Transformação logarítmica das concentrações de IL-6.

\begin{tabular}{|l|l|l|l|l|}
\hline & $\begin{array}{l}\text { Controles } \\
\mathrm{N}=12\end{array}$ & $\begin{array}{l}\text { Assintomáticos } \\
\mathrm{N}=53\end{array}$ & $\begin{array}{l}\text { Sintomáticos } \\
\mathrm{N}=36\end{array}$ & $p$ \\
\hline IL-6 $(\mathrm{pg} / \mathrm{ml})$ & $0,91 \pm 0,38$ & $6,55 \pm 7,36$ & $8,29 \pm 8,37$ & \\
\hline loglL-6 & $0,43 \pm 0,12$ & $-2,26 \pm 6,70$ & $-1,86 \pm 6,74$ & 0,269 \\
\hline
\end{tabular}

análise de variância a um fator

Tabela 24 - Comparação entre níveis de IL-6 em pacientes sintomáticos e assintomáticos. IL-6 = Interleucina 6. LogIL-6 - Transformação logarítmica das concentrações de IL-6.

Separando os pacientes por classes funcionais, também não notamos diferença entre os níveis plasmáticos de pacientes em CFI, CFII e CF III / IV ( $p=0,899)$. Tabela 25. 


\begin{tabular}{|l|l|l|l|l|}
\hline & CFI & CFII & CFIII / IV & $p$ \\
\hline IL-6 $(\mathrm{pg} / \mathrm{ml})$ & $6,55 \pm 7,37$ & $7,08 \pm 6,74$ & $11,46 \pm 11,46$ & \\
\hline logIL-6 & $-2,27 \pm 6,71$ & $-1,81 \pm 6,71$ & $-1,93 \pm 7,20$ & 0,982 \\
\hline
\end{tabular}

análise de variância a um fator

Tabela 25 - Relação entre os níveis plasmáticos de IL-6 e classes funcionais. IL-6 = interleucina - 6, loglL-6 = transformação logarítmica das concentrações de IL-6.

Analisando a relação entre fração de ejeção do ventrículo esquerdo e níveis plasmáticos de IL-6 não observamos relação com os grupos definidos pela fração de ejeção. Tabela 26.

\begin{tabular}{|l|l|l|l|l|}
\hline \multicolumn{2}{|l|}{} & IL-6 $(\mathrm{pg} / \mathrm{ml})$ & loglL-6 & $p$ \\
\hline $\mathrm{FE}$ & $\geq 0,55$ & $7,36 \pm 7,88$ & $-4,13 \pm 8,01$ & \\
\cline { 3 - 5 }$=77$ & & & & \\
\cline { 2 - 5 } & $<0,55$ & $6,08 \pm 7,38$ & $-5,70 \pm 8,42$ & 0,594 \\
& & & & \\
\hline
\end{tabular}

análise de variância a um fator

Tabela 26 - Relação entre os níveis plasmáticos de IL-6 e função ventricular, aferida pela ecocardiografia. IL-6 = interleucina -6 , $\log \mathrm{IL}-6=$ transformação logarítmica das concentrações de IL-6. FE = fração de ejeção pela ecocardiografia. 
Não observamos relação entre níveis plasmáticos de fator de interleucina-6 e diâmetro diastólico do ventrículo esquerdo $(r=-0,101, p=0,33)$, diâmetro sistólico do ventrículo esquerdo $(r=-0,012 p=0,90)$, fração de ejeção pela ecocardiografia $(r=0,13, p=0,42)$.

Dividindo os diâmetros ventriculares em categorias, definidas pela linha de corte de 75mm para o diâmetro diastólico e 55mm para o diâmetro sistólico, não obtivemos correlação entre diâmetros e níveis plasmáticos de IL-6. Tabela 27.

\begin{tabular}{|l|l|l|l|l|}
\hline \multicolumn{2}{|l|}{} & IL-6 $(\mathrm{pg} / \mathrm{ml})$ & loglL-6 & $p$ \\
\hline \multirow{2}{*}{$\begin{array}{l}\text { DDVE } \\
\mathrm{mm})\end{array}$} & $\geq 75$ & $7,29 \pm 8,90$ & $-4,01 \pm 7,10$ & \\
& $\mathrm{n}=34$ & & & \\
\cline { 2 - 5 } & $<75$ & $7,10 \pm 7,12$ & $-3,00 \pm 6,81$ & 0,467 \\
$\mathrm{n}=57$ & & & \\
\hline $\begin{array}{l}\text { DSVE } \\
(\mathrm{mm})\end{array}$ & $\geq 55$ & $7,74 \pm 9,03$ & $-3,85 \pm 7,16$ & \\
& $n=22$ & & & \\
\cline { 2 - 5 } & $<55$ & $7,00 \pm 7,46$ & $-3,34 \pm 6,89$ & 0,767 \\
\hline
\end{tabular}

Tabela 27- Níveis de IL-6 em relação a grupos de pacientes definidos pelos diâmetros ventriculares. IL-6 = interleucina -6 , logIL-6 = Transformação logarítmica das concentrações de IL-6, DDVE = diâmetro diastólico do ventrículo esquerdo, DSVE = diâmetro sistólico do ventrículo esquerdo. 
5.6) Níveis plasmáticos dos receptores solúveis de IL-6 (IL-6R)

Nos 40 pacientes analisados, os níveis plasmáticos médios de receptores solúveis de IL-6 ( IL-6R ) foram de $34018.6 \pm 10078.9$ pg / ml. Os níveis plasmáticos de IL-6R não foram diferentes entre pacientes sintomáticos e assintomáticos. Tabela 28.

\begin{tabular}{|l|l|l|l|}
\hline & Assintomáticos & Sintomáticos & $p$ \\
$\mathrm{n}=21$ & $\mathrm{~N}=19$ & \\
\hline IL-6R $(\mathrm{pg} / \mathrm{ml})$ & $33556,4 \pm 12457,6$ & $34529,4 \pm 6865,6$ & \\
\hline Log IL-6R & $10,35 \pm 0,36$ & $10,43 \pm 0,20$ & 0,428 \\
\hline
\end{tabular}

análise de variância a um fator

Tabela 28 - Níveis de receptores solúveis de IL-6 em pacientes sintomáticos e assintomáticos. IL-6R = receptor solúvel de IL-6, LogIL-6R = transformação logarítmica dos níveis de receptor solúvel de IL-6.

Separando os pacientes por classes funcionais, não notamos diferença entre os níveis plasmáticos de pacientes em CFI, CFII e CF III / IV ( $p=0.743)$. Tabela 29. 


\begin{tabular}{|l|l|l|l|l|}
\hline & CFI & CFII & CFIII / IV & $p$ \\
& $\mathrm{n}=21$ & $\mathrm{n}=10$ & $\mathrm{n}=9$ & \\
\hline IL-6R $(\mathrm{pg} / \mathrm{mI})$ & $33556,4 \pm 12457,6$ & $768,91 \pm 253,53$ & $34295,6 \pm 6975,1$ & \\
\hline Log IL-6R & $10,36 \pm 0,37$ & $10,43 \pm 0,19$ & $10,44 \pm 0,22$ & 0,743 \\
\hline
\end{tabular}

análise de variância a um fator

Tabela 29 - Níveis de receptores solúveis de IL-6 e classes funcionais. IL-6R = receptor solúvel de IL-6, LoglL-6R = transformação logarítmica dos níveis de receptor solúvel de IL-6.

Analisando a relação entre fração de ejeção do ventrículo esquerdo e níveis plasmáticos de IL-6R, não observamos relação com os grupos definidos pela fração de ejeção pela ecocardiografia. Tabela 30.

\begin{tabular}{|l|l|l|l|l|}
\hline \multicolumn{2}{|l|}{} & IL-6R $(\mathrm{pg} / \mathrm{ml})$ & Log IL-6R & $p$ \\
\hline FE & $\geq 0,55$ & $34936,3 \pm 11155,5$ & $10,41 \pm 0,33$ & \\
$n=31$ & & & & \\
\cline { 2 - 5 } & $<0,55$ & $30857,7 \pm 3748,1$ & $10,33 \pm 0,12$ & 0,494 \\
$n=9$ & & & \\
\hline
\end{tabular}

Tabela 30 - Relação entre níveis plasmáticos de IL-6R e função ventricular, aferida pela ecocardiografia IL-6R = receptor solúvel de IL-6, LogIL-6R = transformação logarítmica dos níveis de receptor solúvel de IL-6, FE = fração de ejeção pela ecocardiografia. 
Não observamos relação entre níveis plasmáticos receptores solúveis de IL-6 e diâmetro diastólico do ventrículo esquerdo $(r=-0,05, p=0,72)$, diâmetro sistólico do ventrículo esquerdo ( $r=-0,04 p=0,79$ ), fração de ejeção pela ecocardiografia ( $r=0,153, p=0,34)$.

Dividindo os diâmetros ventriculares em categorias, definidas pela linha de corte de $75 \mathrm{~mm}$ para o diâmetro diastólico e 55mm para o diâmetro sistólico, também não obtivemos correlação entre diâmetros e níveis plasmáticos de IL-6. Tabela 31.

\begin{tabular}{|c|c|c|c|c|c|}
\hline & & IL-6R(pg & & logIL-6R & $p$ \\
\hline $\begin{array}{l}\text { DDVE } \\
(\mathrm{mm})\end{array}$ & $\begin{array}{l}\geq 75 \\
n=20\end{array}$ & $\begin{array}{l}32888,84 \\
6955,47\end{array}$ & \pm & $10,37 \pm 0,22$ & \\
\hline & $\begin{array}{l}<75 \\
n=20\end{array}$ & $\begin{array}{l}35148,41 \\
12547,90\end{array}$ & \pm & $10,40 \pm 0,36$ & 0,771 \\
\hline $\begin{array}{l}\text { DSVE } \\
(\mathrm{mm})\end{array}$ & $\begin{array}{l}\geq 55 \\
n=14\end{array}$ & $\begin{array}{l}31853,26 \\
5281,89\end{array}$ & \pm & $10,42 \pm 0,35$ & \\
\hline & $\begin{array}{l}<55 \\
n=25\end{array}$ & $\begin{array}{l}35521,59 \\
11944,85\end{array}$ & \pm & $10,35 \pm 0,19$ & 0,443 \\
\hline
\end{tabular}

Tabela 31 - Níveis de IL-6 em relação a grupos de pacientes definidos pelos diâmetros ventriculares. IL-6R = receptores solúveis de interleucina -6 , loglL-6R = Transformação logarítmica das concentrações de IL-6, DDVE = diâmetro diastólico do ventrículo esquerdo, DSVE = diâmetro sistólico do ventrículo esquerdo. 
5.7) Níveis plasmáticos de interleucina-1 $\beta(I L-1 \beta)$

Em todos os 89 pacientes analisados, os níveis de interleucina-1 $\beta$ estiveram abaixo dos limites de detecção ( $5 \mathrm{pg} / \mathrm{ml}$ ). Desta forma não foi possível estabelecer correlações para seus níveis plasmáticos. 
5.8) Níveis plasmáticos do antagonista do receptor de IL-1 (IL-1RA)

Nos 40 pacientes analisados, os níveis plasmáticos médios do antagonista do receptor de IL1 ( IL1-RA ) foram de 79.80£179.40 pg / ml. Os níveis plasmáticos de IL1-RA não foram diferentes entre pacientes sintomáticos e assintomáticos. Tabela 32.

\begin{tabular}{|l|l|l|l|}
\hline & $\begin{array}{l}\text { Assintomáticos } \\
\mathrm{n}=21\end{array}$ & $\begin{array}{l}\text { Sintomáticos } \\
\mathrm{N}=19\end{array}$ & $p$ \\
\hline IL1-RA ( pg / ml ) & $134,06 \pm 230,2$ & $19,83 \pm 60,01$ & \\
\hline loglL1-RA & $-2,99 \pm 7,38$ & $-6,48 \pm 5,46$ & 0,10 \\
\hline
\end{tabular}

análise de variância a um fator

Tabela 32 - Níveis do antagonista do receptor de IL1 em pacientes sintomáticos e assintomáticos. IL1-RA = antagonista do receptor de IL1, LogIL1-RA = transformação logarítmica dos níveis do antagonista do receptor de IL1.

Separando os pacientes por classes funcionais, não houve diferença entre os níveis plasmáticos de pacientes em CFI, CFII e CF III / IV ( $p$ = 0.164). Tabela 33. 


\begin{tabular}{|l|l|l|l|l|}
\hline & CFI & CFII & CFIII / IV & $p$ \\
$n=21$ & $n=10$ & $n=9$ & \\
\hline IL1-RA ( pg / ml ) & $906,82 \pm 299,62$ & $768,91 \pm 253,53$ & $1006,41 \pm 512,24$ & \\
\hline logIL1-RA & $6,75 \pm 0,37$ & $6,61 \pm 0,26$ & $6,8 \pm 0,49$ & 0,893 \\
\hline
\end{tabular}

análise de variância a um fator

Tabela 33 - Níveis de antagonista do receptor de IL-1 e classes funcionais. IL1-RA = antagonista do receptor de IL1, LogIL1-RA = transformação logarítmica dos níveis do antagonista do receptor de IL1.

Analisando a relação entre fração de ejeção do ventrículo esquerdo e níveis plasmáticos do IL1-RA, não observamos relação com os grupos definidos pela fração de ejeção pela ecocardiografia . Tabela 34.

\begin{tabular}{|l|l|l|l|l|}
\hline \multicolumn{2}{|l|}{} & IL1-RA $(\mathrm{pg} / \mathrm{ml})$ & logIL1-RA & $p$ \\
\hline FE & $\geq 0,55$ & $79,32 \pm 186,84$ & $-5,05 \pm 6,64$ & \\
$\mathrm{n}=31$ & & & \\
\cline { 2 - 5 } & $<0,55$ & $81,46 \pm 161,17$ & $-3,32 \pm 7,12$ & 0,502 \\
$n=9$ & & & \\
\hline
\end{tabular}

análise de variância a um fator

Tabela 34 - Relação entre níveis plasmáticos de IL1-RA e função ventricular. IL1-RA = antagonista do receptor de IL1, LogIL1-RA = transformação logarítmica dos níveis do antagonista do receptor de IL1, FE = fração de ejeção pela ecocardiografia. 
Não observamos relação entre níveis plasmáticos de fator do antagonista do receptor de IL1 e diâmetro diastólico do ventrículo esquerdo ( $r=0,228, p=0,15$ ), diâmetro sistólico do ventrículo esquerdo ( $r=-0,09 p=0,55)$, fração de ejeção pela ecocardiografia $(r=0,093, p=0,56)$.

Dividindo os diâmetros ventriculares em categorias, definidas pela linha de corte de 75mm para o diâmetro diastólico e 55mm para o diâmetro sistólico, não obtivemos correlação entre grupos de diâmetros e níveis plasmáticos de IL1-RA. Tabela 35.

\begin{tabular}{|l|l|l|l|l|}
\hline \multicolumn{2}{|l|}{} & IL1-RA $(\mathrm{pg} / \mathrm{ml})$ & logIL1-RA & $p$ \\
\hline DDVE & $\geq 75$ & $106,28 \pm 172,57$ & $-2,92 \pm 7,21$ & \\
& $\mathrm{n}=20$ & & & \\
\cline { 2 - 5 } & $<75$ & $53,33 \pm 186,57$ & $-6,39 \pm 5,80$ & 0,102 \\
\hline DSVE & $n=20$ & & & \\
$(\mathrm{~mm})$ & $\mathrm{n}=14$ & $94,31 \pm 185,41$ & $-3,39 \pm 7,07$ & \\
\cline { 2 - 5 } & $<55$ & & & 0,435 \\
& $n=25$ & $74,87 \pm 182,39$ & $-5,18 \pm 6,61$ & \\
\hline
\end{tabular}

análise de variância a um fator

Tabela 35 - Níveis de IL1-RA em relação a grupos de pacientes definidos pelos diâmetros ventriculares. IL1-RA = antagonista do receptor de IL1, LogIL1-RA = transformação logarítmica dos níveis do antagonista do receptor de IL1, DDVE = diâmetro diastólico do ventrículo esquerdo, DSVE = diâmetro sistólico do ventrículo esquerdo. 
5.9) Níveis plasmáticos de endotelina-1 ( ET-1)

Nos 40 pacientes analisados, os níveis plasmáticos médios de endotelina-1 (

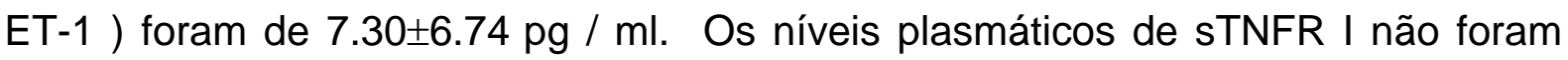
diferentes entre pacientes sintomáticos e assintomáticos. Tabela 36.

\begin{tabular}{|l|l|l|l|}
\hline & $\begin{array}{l}\text { Assintomáticos } \\
\mathrm{n}=21\end{array}$ & $\begin{array}{l}\text { Sintomáticos } \\
\mathrm{n}=19\end{array}$ & $p$ \\
\hline ET-1 $(\mathrm{pg} / \mathrm{ml})$ & $7,01 \pm 5,11$ & $7,61 \pm 8,32$ & \\
\hline LogET-1 & $1,14 \pm 2,56$ & $0,39 \pm 3,60$ & 0,449 \\
\hline
\end{tabular}

análise de variância a um fator

Tabela 36 - Níveis de endotelina-1 em pacientes sintomáticos e assintomáticos. ET-1 = endotelina-1, logET-1 = transformação logarítmica dos níveis de endotelina-1.

Separando os pacientes por classes funcionais, também não notamos diferença entre os níveis plasmáticos de pacientes em CFI, CFII e CF III e IV ( p = 0.639 ). Tabela 37. 


\begin{tabular}{|l|l|l|l|l|}
\hline & CFI & CFII & CFIII / IV & $p$ \\
& $n=21$ & $n=10$ & $n=9$ & \\
\hline ET-1 $(\mathrm{pg} / \mathrm{ml})$ & $7,01 \pm 5,11$ & $7,42 \pm 5,51$ & $7,84 \pm 11,02$ & \\
\hline LogET-1 & $1,15 \pm 2,57$ & $0,79 \pm 3,58$ & $-0,04 \pm 3,79$ & 0,639 \\
\hline
\end{tabular}

análise de variância a um fator

Tabela 37 - Níveis de endotelina-1 e classes funcionais. ET-1 = endotelina-1, logET-1 = transformação logarítmica dos níveis de endotelina-1.

1.

Não encontramos correlação entre os grupos definidos pela fração de ejeção pela ecocardiografia e os níveis de ET-1 ( $p=0,82$ ). Tabela 38.

\begin{tabular}{|l|l|l|l|l|}
\hline \multicolumn{2}{|l|}{} & ET-1 $(\mathrm{pg} / \mathrm{ml})$ & LogET-1 & $p$ \\
\hline FE & $\geq 0,55$ & $6,86 \pm 5,61$ & $0,85 \pm 2,91$ & \\
$n=31$ & & & \\
\cline { 2 - 5 } & $<0,55$ & $8,79 \pm 10,00$ & $0,59 \pm 3,81$ & 0,827 \\
$n=9$ & & & \\
\hline
\end{tabular}

análise de variância a um fator

Tabela 38 - Relação entre níveis plasmáticos de endotelina-1 e função ventricular, aferida pela ecocardiografia. ET-1 = endotelina-1, logET-1 = transformação logarítmica dos níveis de endotelina-1, FE = fração de ejeção pela ecocardiografia.

Não observamos relação entre níveis plasmáticos de endotelina-1 e diâmetro diastólico do ventrículo esquerdo $(r=-0,08, p=0,62)$, diâmetro sistólico do ventrículo 
esquerdo $(r=-0,034 p=0,83)$, fração de ejeção pela ecocardiografia $(r=0,126, p=$ $0,43)$.

Dividindo os diâmetros ventriculares em categorias, definidas pela linha de corte de $75 \mathrm{~mm}$ para o diâmetro diastólico e $55 \mathrm{~mm}$ para o diâmetro sistólico, também não obtivemos correlação entre diâmetros e níveis plasmáticos de ET-1. Tabela 39.

\begin{tabular}{|c|c|c|c|c|}
\hline & & ET-1 ( pg / ml ) & LogET-1 & $p$ \\
\hline \multirow[t]{2}{*}{$\begin{array}{l}\text { DDVE } \\
(\mathrm{mm})\end{array}$} & $\begin{array}{l}\geq 75 \\
n=20\end{array}$ & $6,84 \pm 7,44$ & $0,91 \pm 2,62$ & \\
\hline & $\begin{array}{l}<75 \\
n=20\end{array}$ & $7,76 \pm 6,12$ & $0,67 \pm 3,54$ & 0,806 \\
\hline \multirow[t]{2}{*}{$\begin{array}{l}\text { DSVE } \\
(\mathrm{mm})\end{array}$} & $\begin{array}{l}\geq 55 \\
n=14\end{array}$ & $7,06 \pm 8,51$ & $0,68 \pm 3,06$ & \\
\hline & $\begin{array}{l}<55 \\
n=25\end{array}$ & $7,73 \pm 5,68$ & $1,25 \pm 2,43$ & 0,523 \\
\hline
\end{tabular}

análise de variância a um fator

Tabela 39 - Níveis de endotelina-1 em relação a grupos de pacientes definidos pelos diâmetros ventriculares. ET-1 = endotelina-1, logET-1 = transformação logarítmica dos níveis de endotelina-1, DDVE = diâmetro diastólico do ventrículo esquerdo, DSVE = diâmetro sistólico do ventrículo esquerdo. 
5.10) Correlações entre níveis séricos de citocinas.

Foi realizada a correlação pelo método de Pearson entre os níveis séricos das citocinas, seus antagonistas e da endotelina-1, após transformação logarítmica. Observou-se correlação significativa ( $r=0,411, p=0,008$ ) entre os níveis de receptores solúveis de TNF tipo I e II. Não observamos outras correlações entre o restante das variáveis. Tabela 40. 


\begin{tabular}{|c|c|c|c|c|c|c|c|}
\hline & & $\log T N F$ & logsTNFRI & logSTNFRII & LoglL-6R & LogIL1-RA & LogET1 \\
\hline LogIL-6 & $\begin{array}{l}r \\
p\end{array}$ & $\begin{array}{l}-0,017 \\
0,91 \\
39\end{array}$ & $\begin{array}{l}-0,282 \\
0,07 \\
40\end{array}$ & $\begin{array}{l}0,013 \\
0,9337 \\
40\end{array}$ & $\begin{array}{l}-0,133 \\
0,41 \\
40\end{array}$ & $\begin{array}{l}-0,10 \\
0,53 \\
40\end{array}$ & $\begin{array}{l}0,139 \\
0,38 \\
40\end{array}$ \\
\hline LogTNF & $p$ & & $\begin{array}{l}-0,06 \\
0,71 \\
39\end{array}$ & $\begin{array}{l}-0,161 \\
0,32 \\
39\end{array}$ & $\begin{array}{l}0,095 \\
0,56 \\
39\end{array}$ & $\begin{array}{l}-0,091 \\
0,58 \\
39\end{array}$ & $\begin{array}{l}0,06 \\
0,71 \\
39\end{array}$ \\
\hline LogsTNFRI & $\mathrm{p}$ & & & $\begin{array}{l}0,411 \\
0,0083 \\
40\end{array}$ & $\begin{array}{l}0,212 \\
0,19 \\
40\end{array}$ & $\begin{array}{l}0,076 \\
0,64 \\
40\end{array}$ & $\begin{array}{l}-0,175 \\
0,27 \\
40\end{array}$ \\
\hline LogSTNFRII & $r$ & & & & $\begin{array}{l}0,180 \\
0,26 \\
40\end{array}$ & $\begin{array}{l}0,130 \\
0,42 \\
40\end{array}$ & $\begin{array}{l}-0,088 \\
0,58 \\
40\end{array}$ \\
\hline LogIL-6R & $n$ & & & & & $\begin{array}{l}0,120 \\
0,45 \\
40\end{array}$ & $\begin{array}{l}-0,07 \\
0,66 \\
40\end{array}$ \\
\hline LogIL1-RA & $n$ & & & & & & $\begin{array}{l}0,238 \\
0,14 \\
40\end{array}$ \\
\hline
\end{tabular}

Tabela 40 -Relação entre os níveis plasmáticos das citocinas estudadas. logTNF = transformação logarítmica dos níveis de fator de necrose tumoral alfa, logsTNFR I = transformação logarítmica dos níveis de receptor solúvel de TNF tipo I, logsTNFR II = transformação logarítmica dos níveis de receptor solúvel de TNF tipo II, loglL-6 = transformação logarítmica dos níveis de interleucina 6 , log $\mathrm{LL}-6 \mathrm{R}=$ transformação 
logarítmica dos níveis de receptor solúvel de IL-6, logIL1-RA = transformação logarítmica dos níveis de antagonista do receptor de interleucina 1, logET-1 = transformação logarítmica dos níveis de endotelina-1. 
Discussão 


\section{6) Discussão}

\section{1) Considerações gerais}

Os estudos sobre citocinas proinflamatórias asociam estes peptídeos, antes tidos como exclusivos mediadores de respostas imunológicas, ao processo de remodelação ventricular. Portanto, a participação das citocinas deve ser obrigatoriamente apreciada na fisiopatologia da ICC, aliás como originalmente demonstrado por LEVINE e cols. ${ }^{16}$ Não postulamos que o sistema das citocinas seja o único grupo de mediadores intimamente ligados à resposta miocárdica ao estresse mecânico. Não obstante, suas extensas interações com outros sistemas neurohumorais, como o sistema reninaangiotensina e o sistema adrenégico ${ }^{101}$ coloca-o em uma alta hierarquia dentre os mecanismos que contribuem para a adaptação - e subseqüente desadaptação - do miocárdio frente ás sobrecargas de volume.

Estudamos uma ampla e homogênea população de pacientes com insuficiência aórtica crônica importante ( IAo ), representativa das várias fases da história natural da doença, do assintomático ao sintomático, do paciente com diâmetros ainda aquém dos tidos pela literarura como indicativos de tratamento cirúrgico ${ }^{102}$ aos pacientes na fase final da evolução da doença, já com disfunção ventricular esquerda e muito sintomáticos, com o objetico de rastrear o comportamento do sistema das citocinas.

Postulamos que os níveis séricos de citocinas corresponderiam a marcadores do grau de remodelação ventricular que ocorre na IAo no modelo reumático da doença . Por esta razão, nossa casuística integrou dois tipos de doença inflamatória (febre reumática $+I C C^{11}$ ), de modo que uma questão primeira fez-se obrigatória : a eventual influência da Febre Reumática sobre os níveis séricos de citocinas . 
A análise de níveis de citocinas proinflamatórias em pacientes com cardiopartia reumática crônica, que é o caso de nossos pacientes, mostrou que o TNF ou a IL-1 plasmáticos não eram diferentes de controles normais, e que na Febre Reumática só havia alteração periférica nos níveis de citocinas durante as primeiras semanas da atividade reumática ${ }^{103}$. Apenas um estudo analisou níveis de citocinas plasmáticas em pacientes com Febre Reumática e doença valvar. CHANG e cols ${ }^{95}$ analisaram pacientes com estenose mitral, e demonstraram que níveis de citocinas se normalizaram após valvoplastia por cateter balão. Como os níveis de citocinas não eram diferentes nos pacientes pós-valvoplastia e controles, concluímos que a cardiopatia reumática crônica não provoca aumento de níveis de citocinas séricas per se, e que provavelmente a presença de citocinas na periferia reflete eventos ligados à remodelação ventricular.

O perfil de nossos pacientes condiz com a realidade observada em nosso meio, com predominância de jovens ( média etária 33.64₫11.51 anos ) reumáticos. Os dados ecocardiográficos além de confirmar o diagnóstico de insuficiência aórtica crônica importante permitem apreciar a acentuada remodelação ventricular esquerda a que ocorre em resposta à sobrecarga de volume-pressão.

Ainda hoje a literatura se baseia nas características anatômicas do ventrículo para caracterizar em que fase da evolução natural da doença o paciente de encontra, e tais parâmetros tem sido usados inclusive para predizer a resposta dos pacientes ao tratamento cirúrgico ${ }^{102}$. O desafio da pesquisa em valvopatia tem sido usar eventuais mecanismos moleculares e celulares que estejam envolvidos na resposta às sobrecargas para o diagnóstico e estadiamento da doença ${ }^{104}$. 
6.2) Fator de Necrose Tumoral ( TNF ), seus receptores solúveis e polimorfismo genético

Os níveis de TNF observados em nossa casuística foram de 92.65£110.24 pg/ml, valores significantemente mais elevados do que no grupo controle ( $p=0,001$ ). São níveis elevados também se comparados a valores da literatura, nos quais o percentil 95 para indivíduos normais é de 3,8 pg/ml. ${ }^{105}$ Observamos grande variabilidade nos níveis de TNF, de maneira semelhante a outros estudos ${ }^{98}$ Assim como outros autores ${ }^{105,} 37$, encontramos que os dados para as citocinas proinflamatórias não estavam normalmente distribuídas, desta forma utilizamos a transformação logarítimica para análise.

A estimulação de cardiomiócitos in vitro com TNF provoca hipertofia, com aumento da síntese protéica de sarcômeros ${ }^{57} \mathrm{Em}$ experimentos em animais, concentrações de TNF habitualmente encontradas na insuficiência cardíaca provocam também hipertrofia miocárdica ${ }^{106}$. Em uma situação em que há talvez a maior resposta hipertrófica observada na cardiologia, a via bioquímica que leva à hipertrofia pela ativação do TNF estaria bastante ativa, o que poderia também explicar os altos níveis encontrados. Além disso o TNF induz mudanças na matriz extracelular, com ativação de metaloproteinases da matriz que podem causar degradação de fibras colágenas e substituição de colágeno I por III. Assim, muitos dos aspectos do fenótipo da insuficiência aórtica, como hipertrofia, dilatação ventricular e fibrose ${ }^{107}$ podem ser explicados pelos efeitos conhecidos do TNF.

Os níveis de TNF encontrados em nossos pacientes são mais elevados que em outros estudos, tanto em pacientes com insuficiência cardíaca secundária a miocardiopatia dilatada ou isquêmica, quanto em pacientes com doença valvar. ORAL e cols encontraram níveis de TNF de 3,59 $\pm 1,81 \mathrm{pg} / \mathrm{ml}$, enquanto que KAPADIAe cols

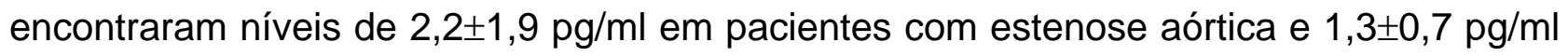


em pacientes com insuficiência mitral. Alguns autores como FERRARI ${ }^{98}$ encontraram níveis de TNF semelhantes aos nossos ( 33,52 $\pm 13.12 \mathrm{pg} / \mathrm{ml})$, mas apenas em pacientes com miocardiopatia dilatada em classe funcional IV.

Não encontramos correlação significante dos níveis plasmáticos de TNF com sintomas ou classe funcional. Em vista dos níveis plasmáticos de TNF estarem elevados de forma semelhante, independentemente de classes funcionais podemos postular que a grande distensão miocárdica que ocorre na insuficiência aórtica provocaria um intenso estiramento de fibras cardíacas, causando assim estímulo constante e duradouro para a produção do TNF. Há evidências experimentais ${ }^{44}$ e clínicas ${ }^{45}$ que o estiramento provocado pelas sobrecargas volêmicas e de pressão fazem com que o cardiomiócito produza RNA mesageiro para TNF. A IAo, com seu aumento de pressão de pulso e característicos diferenciais de pressão gera grandes estresses ao miocárdio, havendo grande distensão de miócitos. Esta distensão intensa e mantida poderia servir como estímulo à secreção de grandes quantidades de TNF, de maneira sustentada, o que faria com que todo paciente com IAo mesmo assintomático, tivesse altos níveis desta citocina.

A maioria dos estudos que envolvem TNF e insuficiência cardíaca secundária a miocardiopatia dilatada idiopática ou isquêmica mostram que há uma relação entre classe funcional e aumento de níveis séricos de TNF, 17, 98, 105, 108.

Em doenças valvares como a insuficiência mitral e a estenose aórtica também foram vistas correlações entre níveis de TNF e a sintomatologia, qualificada por classes funcionais $^{96}$.

Em nossa casuística, não encontramos correlação entre TNF e índices de geometria ventricular, como diâmetros ventriculares ou função. Na IAo podemos ter níveis permanentemente elevados de TNF por se tratar de uma remodelação de maiores proporções do que a observada na insuficiência mitral por estar aoociada a sobrecargas 
de pressão e de volume ${ }^{109}$, o que a diferencia de outras valvopatias. A falta de correlação dos níveis de TNF com diâmetro ou função ventricular também pode ser atribuída à grande variabilidade nos resultados dos níveis plasmáticos de TNF.

Em doença valvar, ORAL e cols ${ }^{45}$ demonstraram, haver correlação entre níveis séricos de citocinas e diâmetros e função ventricular na insuficiência mitral. Já KAPADIA e cols ${ }^{96}$ demonstraram que sobrecargas pressóricas como a estenose aórtica acarretam maior expressão de citocinas proinflamatórias do que sobrecargas de volume, como da insuficiência mitral. Os altos níveis de TNF em nossos pacientes podem refletir este resultado, pois podemos supor que na IAo os estresses mecânicos e de estiramento miocárdico sejam ainda maiores que na estenose aórtica.

ORAL e cols ${ }^{45}$ conseguiram correlacionar níveis de citocinas com geometria ventricular em pacientes com insuficiência mitral.

Em nossa amostra, observamos níveis de sTNFRI de $894.75 \pm 348.87 \mathrm{pg} / \mathrm{ml}$, significantemente maiores que em grupo controle ( $p=0,001)$ e sTNFR II de 1879.65 $\pm 596.12 \mathrm{pg} / \mathrm{ml}$. São valores semelhantes aos observados na literatura em pacientes com insuficiência cardíaca secundária a miocardiopatia dilatada ou isquêmica. Ao contrário de observações da literarura em insuficiência cardíaca de etiologia não valvar, não encontramos aumento dos níveis de receptores endógenos solúveis com a piora da classe funcional.

Analisando o estudo de RAUCCHAUS e cols ${ }^{36}$ em pacientes com insuficiência cardíaca de origem não-valvar observamos que nossos pacientes estão em média no segundo quartil ( entre 820 e 1096 pg/ml ) com relação ao TNF, tendo já um risco relativo de 3,2 de mortalidade em relação a indivíduos com TNFRI abaixo de 820 pg/ml. No mesmo estudo, níveis de sTNFRII maiores que 2913 pg/ml também indicaram pior prognóstico em insuficiência cardíaca. Entretanto, devemos ter cuidado com comparações entre este estudo e o presente, pois tratam-se de doenças diferentes. 
Em doença valvar, ORAL e cols ${ }^{45}$ encontraram níveis de sTNFRI de $975 \pm 344$ $\mathrm{pg} / \mathrm{ml}$ e TNFRII de $2156 \pm 889 \mathrm{pg} / \mathrm{ml}$ em pacientes com insuficiência mitral, ou seja, níveis discretamente mais elevados que os encontrados em nossos pacientes, e KAPADIA e cols. ${ }^{96}$ encontrou níveis médios de sTNFRI de $1614 \pm 884 \mathrm{pg} / \mathrm{ml}$ e sTNFRII de 4559 \pm 2389 em pacientes com estenose aórtica, enquanto que pacientes com insuficiência mitral os níveis foram de $1060 \pm 270$ para o sTNFRI e $3201 \pm 838$ para o sTNFRII. De forma semelhantes aos estudos com pacientes com insuficiência cardíaca, os pacientes nestes estudos estavam em classes funcionais mais avançadas e tiveram maiores níveis de receptores endógenos solúveis.

Ressalta-se, em nossa casuística os níveis de sTNFRII mostraram correlação com os diâmetro sistólico $(p=-0,352, p=0,027)$ e diastólico $(p=-0,329, p=0,038)$. Tal correlação se mantém, ao separarmos os pacientes em grupos definidos pelos diâmetros ventriculares, com níveis de sTNFRII mais baixos em pacientes com diâmetros ventriculares mais acentuados. Ademais, observamos tendência não significativa $(p=$ 0,076 ) a níveis mais elevados de sTNFRII em pacientes com função normal do que naqueles com fração de ejeção menor que 0,55.

Desta forma, o sTNFRII parece ser marcador de remodelação ventricular em pacientes com IAo, estando mais elevado em pacientes com diâmetros ventriculares menores. Na fase inicial da insuficiência aórtica temos altos níveis de TNF, mas também com níveis mais elevados de sTNFRII. A diminuição nos níveis de sTNFRII que é observada à medida que avançamos na história natural da doença e temos maiores diâmetros ventriculares, pode levar a uma maior atividade do TNF e assim maior remodelação ventricular. Devemos lembrar que o sTNFRII é o receptor de maior afinidade ao TNF, e sua capacidade de neutralizar os efeitos deletérios deste é tão acentuada, que faz com que tenha até aplicação clínica. O Etrancept, droga anti-TNF usada para doeças como artrite reumatóide e espondilite anquilosante é um receptor de 
TNF tipo II recombinante. Desta forma nas fases iniciais da IAo os efeitos deletérios do TNF sobre a função ventricular poderiam estar parcialmente antagonizados pelo sTNFRII, e à medida que os níveis deste caem, os miócitos ficariam mais expostos à ação do TNF, com progressiva dilatação e disfunção ventricular.

ORALe cols ${ }^{45}$ encontraram boa correlação entre volumes e função ventricular e níveis de citocinas proinflamatórias em pacientes com insuficiência mitral, obtendo correlação positiva de quase todos os índices geométricos e de função ventricular com níveis séricos de citocinas.

Assim, delineamos que os pacientes com IAo parecem ter um perfil único de TNF e receptores, com altos níveis de TNF e baixos níveis de receptores endógenos solúveis. É interessante notar que em quase todos os estudos em insuficiência cardíaca de etiologia não-valvar ${ }^{37}$ os níveis de receptores solúveis de TNF aumentam com o avançar da história natural da doença, e na IAo ao menos o sTNFRII parece estar em concentrações menores nos pacientes com avançada remodelação ventricular. Em pacientes com insuficiência mitral, como os que ilustram o estudo de ORAl e cols ${ }^{45}$, os níveis maiores de receptores solúveis talvez indiquem uma menor remodelação ventricular, já que protegeriam o miocárdio das ações maléficas do TNF. 


\subsection{1) Polimorfismo genético do TNF}

O presente estudo foi o primeiro a analisar o polimorfismo genético localizado a -308 pares e bases do sítio de iniciação do TNF em doença valvar. Os resultados mostraram uma distribuição com predomínio do alelo 1, com $75 \%$ dos pacientes sendo identificados como $1 / 1,21,6 \%$ como $1 / 2$ e $3,4 \%$ como $2 / 2$. Tal freqüência é semelhante àquela encontrada em outros estudos, tanto em insuficiência cardíaca de origem não valvar, ${ }^{110}$ quanto em outras patologias. ${ }^{111}$

De forma surpreendente, no presente estudo notamos uma associação significativa ( $p=0,035$ ) entre o polimorfismo estudado e a classificação de pacientes como assintomáticos ou sintomáticos. De forma semelhante, ao separarmos os pacientes em classes funcionais, continuamos notando uma associação significante ( $p=0,048$ ) entre o polimorfismo e a classificação em classes funcionais da NYHA. Uma observação interessante é que a presença do alelo 2 está ligada a pacientes assintomáticos. Na tabela 20, podemos notar que quando analisamos os 9 pacientes em classe III / IV que foram submentidos à análise genética, 8 ( 88,89\% ) possuíam o genótipo 1/1.

Além disso, entre pacientes assintomáticos, encontramos 66\% de genótipo $1 / 1,30 \%$ de genótipo $1 / 2$ e $4 \%$ de genótipo $2 / 2$, enquanto que entre pacientes sintomáticos encontramos $88 \%$ de genótipo $1 / 1,9 \%$ de genótipo $1 / 2$ e $3 \%$ de genótipo 2/2, uma associação significante $(p=0.035$ ). Desta forma, a presença de um alelo tipo 2 parece conferir aos pacientes uma melhor adaptação à sobrecarga de volume-pressão da IAo.

É interessante analisar que não há diferenças de diâmetros ou função entre os grupos definidos pelo genótipo, de forma que o mecanismo de tal proteção a 
sintomas deve se operar em nível celular ou molecular, de modo que pode não ser refletido em medidas macroscópicas.

Postulamos que a presença de um alelo que produza maior quantidade de TNF pode permitir uma melhor adaptação do miocárdio à sobrecarga volêmica, fazendo com que haja uma remodelação mais acentuada, com maior complacência e assim melhor capacidade de acomodar o volume regurgitante, desta forma tornando o paciente assintomático. Há situações estudadas em que a presença do alelo 2 é maléfica ${ }^{79}$, mas como em qualquer sistema biológico, há também vantagens na presença deste gene. Tomando um exemplo extremo, ratos com nocaute do gene do TNF tem maior mortalidade por miocardite viral ${ }^{99}$ e o TNF também pode proteger miócitos de lesão isquêmica ${ }^{63}$. Assim a insuficiência aórtica seria situação em que a presença de gene que tem maior produção de TNF seria adaptativa, levando a uma remodelação ventricular mais eficaz.

Observamos que os três grupos definidos pela variante genética estudada tinham perfis de citocinas semelhantes, com exceção do antagontsta do receptor de IL-1 ( IL1-RA ), cujos níveis foram significantemente ( $p=0,025$ ) mais elevados em pacientes com o genótipo 1/2. Ora, ao antagonizar os efeitos da II-1, que é descrita como causadora de disfunção miocárdica diretamente e de hipertrofia e remodelação ventricular ${ }^{85}$ o IL1-RA pode ser considerado uma citocina cardioprotetora, e seu aumento condiz com uma população de pacientes mais assintomáticos. Não propomos que o polimorfismo estudado tenha direta relação com os níveis elevados de IL1-RA, mas sim que tal polimorfismo possa predispor mecanismos bioquímicos e interações que resultem em um aumento de IL1-RA.

Não observamos relação entre o genótipo e produção aumentada de TNF ou de outras citicinas, com exceção do IL1-RA supra citado. Em estudo envolvendo pacientes com insuficiência cardíaca secundária à miocardiopatia dilatada, KUBOTA 
e cols não encontraram correlação entre genótipo e produção aumentada de citocinas em uma população de pacientes oriundos do estudo VEST. ${ }^{110}$ 
6.3) Interleucina-6 ( IL-6) e seu receptor solúvel ( IL-6R)

Os níveis médios de IL-6 em nossos pacientes foram de $7.17 \pm 7.78 \mathrm{pg} / \mathrm{ml}$, níveis significantemente mais elevados que em grupo controle ( $p=0,001)$. Estudos ${ }^{82}$ em insuficiência cardíaca de etiologia não-valvar tem associado níveis maiores que $5 \mathrm{pg} / \mathrm{ml}$ a maior mortalidade. O nível de corte associado com maior mortalidade varia de acordo com o estudo, sendo em alguns de $6.97 \mathrm{pg} / \mathrm{ml}{ }^{36}$ e em outros de $4,4 \mathrm{pg} / \mathrm{ml}$ ${ }^{83}$. Desta forma, os pacientes de nossa casuística apresentavam níveis elevados de IL-6, os quais, em pacientes com insuficiência cardíaca secundária a miocardiopatia isquêmica ou idiopática já se traduzem em pior prognóstico.

De forma semelhante ao TNF não observamos diferenças entre os níveis plasmáticos de IL-6 entre os pacientes sintimáticos e assintomáticos mesmo ao dividimos os pacientes por classe funcional. Assim este sistema parece estar ativado desde a fase assintomática da insuficiência aórtica, à semelhança do TNF.

Dos estudos envolvendo IL-6 e doenças valvares apenas dois realizaram dosagens de IL-6 : ORAL e cols encontraram níveis de IL-6 de 7,80 $\pm 9,70$ pg/ml em pacientes com insuficiência mitral e CHANG e cols ${ }^{95}$ encontraram níveis de 7.52 $\pm 7.05 \mathrm{pg} / \mathrm{ml}$ em pacientes com estenose mitral. Assim este estudo encontrou níveis de IL-6 semelhantes aos observados na literatura em outras valvopatias.

Não encontramos correlação dos níveis de IL-6 com função ou diâmetros ventriculares, ao contrário do descrito por ORALve cols ${ }^{45}$ para a insuficiência mitral. Tal fato provavelmente se deve à grande remodelação ventricular decorrente da sobrecarga de volume-pressão da IAo, fazendo com que os mecanismos que levam à hipertrofia estejam ativados de forma mais intensa. 
Quanto aos níveis de II-6R, a média encontrada em nosso estudo foi de $34018.6 \pm 10078.9 \mathrm{pg} / \mathrm{ml}$. ORALe cols ${ }^{45}$ relatam valores semelhantes em pacientes

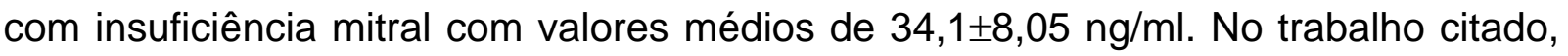
tais níveis não diferiram de uma população controle. TESTA e cols ${ }^{105}$ relatam como percentil 95 para indivíduos normais o valor de 51ng /ml.

De forma semelhante à II-6, não observamos correlação entre níveis plasmáticos de IL-6R e sintomas, classe funcional, diâmetros ou função ventricular.

Assim sendo podemos observar que pacientes com insuficiência aórtica, mesmo assintomática, possuem níveis de IL-6 comparáveis a uma população de pacientes com insuficiência cardíaca com mortalidade elevada. Esta informação provavelmente também se deve à intensa remodelação ventricular existente na IAo , e pode indicar que esta valvopatia associa-se a uma intensa ativação do sistema da gp130, o qual está intimamente envolvido nos mecanismos moleculares que levam à hipertrofia miocárdica . 
6.4 ) Interleucina 1-beta( IL-1 $\beta$ ) e antagonista do receptor de IL-1 (IL1-RA)

Gostaríamos de ressaltar que este é o primeiro estudo a aferir os níveis séricos de IL-1 $\beta$ e de II1-Ra em patologia valvar. Entretanto, não encontramos em nenhum paciente níveis de IL-1 $\beta$ maiores do que $5 \mathrm{pg} / \mathrm{ml}$, que é o limite de detecção do kit utilizado. Resultado similar foi observado por FERRARI e cols ${ }^{95}$ em insuficiência cardíaca de etiologia não-valvar e AUKURST e cols ${ }^{17}$, em pacientes semelhantes que do mesmo modo notaram níveis indetectáveis ou próximos a controles de IL-1 $\beta$.

Ambos os estudos citados ${ }^{17,95}$ acima notaram aumento do IL1-RA, o qual pode estar elevado independentemente da IL-1 $\beta$. O antagonista do receptor de IL-1 é um antagonista natural, secretado em geral por macrófagos e que pode antagonizar as açòes da IL-1ß. Em estudos em insuficiência cardíaca não valvar, os níveis de IL1-RA aumentam de acordo com a progressão em classes funcionais. Tal observação não foi reproduzida em nosso estudo. Também não encontramos correlação entre níveis de IL1RA e geometria ou função ventricular.

Os níveis indetectáveis de IL-1 podem sugerir que tal citocina tenha um efeito mais autócrino ou parácrino, não chegando a "exravasar" para a circulação periférica de modo semelhante a outras citocinas.

Como discutido anteriormente, é relevante notar que grupo definido como genótipo de TNF 1/2 teve níveis significantemente mais altos de IL1-Ra do que o grupo com genótipo TNF 1/1, conforme podemos ver na tabela 22. Este achado inédito provavelmente relaciona-se a remodelação ventricular mais favorável que é observada no grupo heterozigoto para o polimorfismo estudado. 
Os níveis médios de endotelina-1 em nosso estudo foram de $7.30 \pm 6.74$ pg / ml. Estudos em insuficiênca cardíaca de etiologia não-valvar mostram pior prognóstico de pacientes com esta patologia e níveis séricos de ET-1 acima de $5 \mathrm{pg} / \mathrm{ml}$. Desta forma, os níveis séricos de nossos pacientes já se enquadrariam no grupo com pior prognóstico. Há um estudo que determinou os níveis de ET-1 em estenose mitral (3.66 $\pm 2.20 \mathrm{pg} / \mathrm{ml})$, mas sempre correlacionando estes níveis com hipertensão pulmonar e sua resposta à correção cirúrgica ${ }^{112}$.

De modo semelhante aos outros mediadores, não encontramos diferenças entre os níveis de ET-1 entre pacientes sintomáticos e assintomáticos e entre as diferentes classes funcionais. Também não obtivemos correlação entre níveis de ET1 e geometria e função ventricular.

O fato de termos níveis de ET-1 elevados ainda na fase assintomática da insuficiência aórtica reforça o conceito de que a fase assintomática da IAo já se vale de mecanismos compensatórios que estão presentes apenas nas fases mais avançadas da insuficiência cardíaca de etiologia não-valvar. A lenta e progressiva predominância de substâncias vasoconstritoras, como a ET-1, ao longo da progressão da IAo pode ser um dos determinantes da passagem da fase assintomática para a sintomática. 


\section{6) Considerações finais}

O objetivo maior da pesquisa em insuficiência aórtica é encontrar o "gatilho" que levaria ao desenvolvimento de sintomas, um marcador que determinaria a passagem da fase assintomática para a sintomática. O presente estudo inicia uma nova linha de pesquisa na busca não em parâmetros anatômicos, mas tentando rastrear a remodelação ventricular através de substâncias que fazem a transdução de sinal em direção à hipertrofia e à dilatação em resposta à sobrecarga de volumepressão da IAo .

Neste grupo de pacientes com insuficiência aórtica crônica importante, representativo das diversas fases da evolução natural da doença, notamos um perfil único de citocinas proinflamatórias e seus antagonistas endógenos. Destacamos em nosso trabalho em perfil em alguns aspectos diferente de pacientes com insuficiência cardíaca de etiologia não-valvar e mesmo em outras lesões valvares. A diferença mais acentuada se dá na relação entre os níveis de citocinas e a classe funcional de nossos pacientes, e mostra que um paciente assintomático pode ter níveis de citocinas proinflamatórias semelhantes a um paciente muito sintomático.

Esta importante informação provavelmente reflete a intensa atividade dos mecanismos responsáveis pela remodelação ventricular esquerda desde o início da doença, e mostra que a fase assintomática da IAo pode não ser tão silenciosa como poderíamos imaginar. O paciente assintomático com IAo tem uma intensa e contínua atividade de remodelação ventricular, que contribui para mantê-lo assintomático mas que provavelmente tem papel na evolução natural da doença, progredindo de forma lenta, mas inexorável, em direção aos sintomas. 
O sTNFRII parece ser um marcador de remodelação ventricular em pacientes com IAo, correlacionando-se com aumento dos diâmetros. Estes dados podem dar substrato para que no futuro o acompanhamento de pacientes com IAo não seja apenas clínico e com monitoramento de parâmetros anatômicos, como os diâmetros ou função ventricular esquerda, mas também que também estejamos atentos a atividade de citocinas e outros aspectos neurohumorais.

Um aspecto intrigante do presente estudo é a associação do genótipo do TNF com sintomas em pacientes com IAo. O presente estudo é o primeiro a estudar este polimorfismo em pacientes com doença valvar. Pacientes com insuficiência aórtica podem ter sintomas variados com diâmetros e função ventricular muito semelhantes. O polimorfismo genético do TNF poderia ser um marcador de pacientes que responderiam de modo mais eficiente à sobrecarga de volume-pressão e que assim permaneceriam mais tempo assintomáticos.

Com o estudo genético abriu-se a atraente possibilidade de antevermos o comportamento clínico do paciente por seu perfil genético. Assim em um coorte de pacientes com IAo poderíamos determinar um genótipo de pior evolução, como em nosso estudo identificou o genótipo TNF 1/1, e seguirmos estes pacientes com avaliação clínica e laboratorial mais frequente que pacientes com genótipo mais favorável.

É improvável que apenas um polimorfismo seja resposável por toda a complexa diferença fisiopatológica que leva ou não a sintomas na insuficiência aórtica. Como resultado do presente estudo constituímos um banco genético de pacientes com IAo, o qual conta atualmete com mais de 90 indivíduos. Com o estudo de outros polimorfismos como o da Angiotensina e do Receptor de Endotelina podemos no futuro determinar um perfil baseado em vários polimorfismos de 
genéticos que identificaria o paciente com IAo que tem evolução mais desfavorável, permitindo um seguimento diferenciado para este.

Para entendermos melhor a ativação do sistema de citocinas proinflamatórias na insuficiência aórtica devemos continuar a linha de pesquisa atual, agora em duas direções. Primariamente, devemos avaliar o tecido, determinando expressão tecidual de citocinas, sua localização e de RNA mensageiro. Técnicas de medida de quantidade de RNA e hibridização in situ podem dar importantes informações sobre o local de produção e prover informações adicionais sobre a remodelação ventricular esquerda na IAo. Por a IAo se constituir em uma das doenças cardíacas com mais dramática remodelação ventricular, tais técnicas também poderiam prover importantes informações sobre o processo de hipertofia ventricular em geral e adaptação ás sobrecargas de pressão e volume.

Uma outra linha de pesquisa que se abre na IAo é a determinação do perfil de citocinas proinflamatórias após tratamento cirúrgico, a fim de determinar se há normalização destes parâmetros após retirarmos a sobrecarga de volume-pressão ao ventrículo esquerdo. Além disso é interessante o seguimento a longo prazo de pacientes com genótipos de pior evolução a fim de determinar seu real significado clínico. 
Conclusões 


\section{7) Conclusões}

- Os níveis de TNF, sTNFRI e IL-6 estão elevados em pacientes com insuficiência aórtica.

- Os níveis de sTNFRII diminuem com o aumento dos diâmetros ventriculares em pacientes com IAo.

- Pacientes assintomáticos com IAo tem perfil de citocinas proinflamatórias e seus antagonistas semelhantes a pacientes já sintomáticos.

- A presença do alelo 2 do polimorfismo -308 do gene do TNF está associado a pacientes assintomáticos com IAo.

- Pacientes com IAo e genótipo $1 / 2$ do polimorfismo -308 do TNF possuem níveis maiores de IL1-RA

- Pacientes com IAo e genótipo $1 / 1$ do polimorfismo -308 do TNF apresentam maior proporção de pacientes sintomáticos. 


\section{Referências}




\section{8) Referências bibliográficas}

1) Tarasoutchi F, Grinberg M, Spina GS, et al. Ten-year clinicallaboratory follow-up after application of a symptom-based therapeutic strategy to patients with severe chronic aortic regurgitation of predominant rheumatic etiology. $J$ Am Coll Cardiol $2003 ; 41: 1316-24$

2) Brauunwald, E. Congestive heart failure, a half century perspective. Eur Heart $J$ $2001 ; 22$ : 825-36

3) Ross J, Braunwald E. Studies on Starling's law of the heart: the effect of impeding venous return on the performance of the normaland failing human left ventricle. Circulation 1964;30:719-27

4) Cohn JN, Archibald DG, Ziesche $S$ et al. Effect of vasodilator lined therapy on mortality in chronic congestive heart failure: results of a Veterans Administration Cooperation Study (V-Heft). N Engl J Med 1986;314:1547-52

5) Packer M, Rouleau J-L, Swedberg $\mathrm{K}$ et al. Effects of flosequinan on survival in chronic heart failure: preliminary results of the PROFILE corrects endothelial dysfunction and improves exercise capacity in study. Circulation 1993;88(suppl I):301

6) Packer M, Carver JR, Rodeheffer RJ et al. Effect of oral milrinone mortality in severe chronic heart failure. N Engl J Med 1991;325:1468-75

7) Hampton JR, vanVeldhuisen DJ, Kleber FX et al. Randomised study of effect of ibopamine on survival in patients with advanced severe heart failure. Second Prospective Randomised Study of Ibopamine on Mortality and Efficacy (PRIME II) Investigators. Lancet 1997;349:971-7 
8) Packer M, Carver JR, Rodeheffer RJ et al. Effect of oral milrinone mortality in severe chronic heart failure. N Engl J Med 1991;325:1468-75

9) Hampton JR, vanVeldhuisen DJ, Kleber FX et al. Randomised study of effect of ibopamine on survival in patients with advanced severe heart failure. Second Prospective Randomised Study of Ibopamine on Mortality and Efficacy (PRIME II) Investigators. Lancet 1997;349:971-7

10)Kapadia S, Dibbs $Z$, Kurrelmeyer $K$, et al, The role of cytokines in the failing human heart, Cardiology Clinics ; 16 (4) : 645-656, 1998

11)Conraads VM,. Bosmans JM,. Vrints CJ. Chronic heart failure: an example of a systemic chronic inflammatory disease resulting in cachexia International Journal of Cardiology 85 (2002) 33- 49

12)Garg G , Yussuf S. Overview of randomized trials of angiotensin-converting enzyme inhibitors in mortality and morbidity in patients with heart failure. JAMA 1995; 273 : 462

13)Farrell $\mathrm{MH}$, Foody JM, Krumholtz HM. Beta-blockers in heart failure : clinical applications. JAMA $2002 ; 287: 890-7$

14)Banaszewskl, M.; Rydlewska, L.; Sadowska, W.; Rubkiewicz S. Captopril or nifedipine? Comparison of rest and exercise acute effects and long-term therapy in chronic isolated asymptomatic moderate to severe aortic regurgitation. J. Heart Valve Dis., v.7, n.5, p.488-99, 1998

15)Kapadia S, Dibbs Z, Kurrelmeyer K, Kalra D, Seta Y, Wang F, Bozkurt B, Oral H, Sivasubramanian N, Mann DL. The role of cytokines in the failing human heart. Cardiology Clinics, Philadelphia, Saunders; 16 (4) : 645-656, 1998

16)Levine B, Kalman J, Mayer L, Fillit HM, Packer M. Elevated circulating levels of tumor necrosis factor in severe chronic heart failure. N. Eng J Med $1990 ; 323: 236-41$ 
17)Aukurst $P$, Ueland $T$, Lien $E$, Bendtzen $K$ et al. Cytokine network in congestive heart failure sucindary to ischemia or idiopathic dilated cardiomiopathy. American Jourmal of Cardiology $83: 376-382,1999$

18) Millar $A B$, Singer $M$, Meager, et al. Tumor necrosis factor in bronchopulmonary secretions of patients with adult respiratory distress syndrome. Lancet $2: 712-713$, 1989

19)Testa $M$, Yeh $M$, Lee $P$, Fanelli $R$ et al. Circulating levels of cytokines and their endogenous modulators in patients with mild to severe congestive heart failure due to coronary artery disease or hypertension. Journal of the American College of Cardiology 28 (4) : 964-971 , 1996

20)Suffrendini AF, Fromm RE, Parker MM et al. The cardiovascular response of normal humans to the administration of endotoxin. New England Journal of Medicine 321 : $280-287,1989$

21)Semb H, Peterson J, Tavanier J, et al. Multiple effects of tumor necrosis factor on lipoprotein lipase in vivo. Journal of Biological Chemstry $262: 8390-8394,1987$

22)Hegewisch S, Weh HJ, Hossfeld DK. TNF-induced cardiomiopathy. Lancet 2 : 294295 , 1990, Anker SD, Egerer KR, Volk HD et al. Elevated soluble CD14 receptors and altered cytokines in chronic heart failure. American Journal of Cardiology 79 : $1426-1429,1997$

23)Natanson C, Eichenholz PW, Danner RL, et al. Endotoxin and tumor necrosis factor challanges in dogs simulate the cardiovascular profile of human septic shock. Journal of Experimental Medicine 169 : 823-832 , 1989

24)Pagani FD, Baker LS, Hsi C, et al. Left ventricular systolic and diastolic disfunction after infusion of tumor necrosis factor- $\alpha$ in conscious dogs. Journal of Clinical Investigation 90 : 389-398, 1992 
25)Semb H, Peterson J, Tavanier J, et al. Multiple effects of tumor necrosis factor on lipoprotein lipase in vivo. Journal of Biological Chemstry $262: 8390-8394,1987$

26)Oliff $A$, Defeo-Jones $D$, Boyer $M$, et al. Tumors secreting human TNF/cachectin induce cachexia in mice. Cell $50: 555-563,1987$

27) Socher $\mathrm{SH}$, Friedman $A$, Martinez D. Recombinant tumor necrosis factor induces reductions in food intake and body weight in mice. Jourmal of Experimental Medicine $167: 1957-1962,1988$

28)Spiegelman BM, Hotamissligil GS. Through thick and thin: Wasting, obesity, and TNFa. Cell $73: 625-627,1993$

29)Chung MK, Gulick TS, Rotondo RE, et al. Mechanism of action of cytokine onhibition of $\beta$-adrenegic agonist stimulation of cyclic AMP in rat myocytes: Impairiment of signal transduction. Circulation Research 67 : 753-763, 1990

30)Lancaster JR, Laster Sm, Gooding LR. Inhibition of target-cell mitochondrial electron transfer by tumor necrosis factor. FEBS Lett $248: 169-174,1989$

31)Stadler J, Bentz BG, Harbrecht BG, et al. Tumor necrosis factor inhibits hepatocyte mitoochondrial respiration. Annals of Surgery 216 : 539-546, 1992

32)Thaik $\mathrm{CM}$, Claderone $A$, Takahashi $\mathrm{N}$, et al. Interleukin $1 \beta$ modulates the growth and phenotype of neonatal rat myocytes. Journal of Clinical Investigation 96 1093-1099 , 1995

33)Tsutamoto $T$, Hisanaga $T$, Wada $A$ et al. Interleukin- 6 spillover in the peripheral circulation increases with the severity of heartfailure, and the high plasma level of interleukin-6 is an important prognostic predictor in patients with congestive heart failure. J Am Coll Cardiol 1998;31:391-8

34)Maeda K, Tsutamoto $T$,Wada $A$ et al. High levels of plasma brain natriuretic peptide and interleukin-6 after optimized treatment for heart failure are independent risk 
factors for morbidity and mortality in patients with congestive heart failure. J Am Coll Cardiol 2000;36:1587-93

35)Ferrari R, Bachetti $T$, Confortini $R$ et al. Tumor necrosis factor soluble receptor in patients with various degrees of congestive heart failure. Circulation 1995;92:1479-86

36)Rauchhaus $M$, Doehner $W$, Francis DP et al. Plasma cytokine parameters and mortality in patients with chronic heart failure. Circulation 2000;102:3060-7

37)Deswal A, Petersen NJ, Feldman AM, Young JB, White BG, Mann DL. Cytokines and cytokine receptors in advanced heart failure. An analysis of the cytokine database from vesnarinone trial (VEST). Circulation 2001;103:2055-9

38)Vasan RS, Sullivan LM, Roubenoff $R$ et al. Inflamatory markers and risk of heart failure in elderly patients without a prior myocardial infarction: The Framingham studt. Circulation $2003 ; 104: 1486$

39)Anderson J, Carlquist JF, Hammond EH. Deficient natural killer cell activity in patients with idiophatic dilated cardiomiopathy. Lancet $1982 ; 2$ : 1124-1127

40)Anastri AA, Wang YC, Danner DJ et al : Abnormal expression of histocompatibility and mitochondrial antigens by cardiac tissue from patients with myocarditis and dilated cardiomiopathy. Am J Patol ; 1991 ; 139 337-354

41)Kalman J, Levine B, Mayer L et al. Prognostic importance of circulating neopterin levels in heart failure : evidence for monocyte activation in patients with heart failure . Circulation 199082 : III-315

42)Wiedermann $\mathrm{CJ}$, Beimpold $\mathrm{H}$, Harold $\mathrm{M}$ et al. Icreased levels of seric neopterin and descreased production of neutrophil superoxide anions in chronic heart failure with elevated levels of tumor necrosis factor - alpha. J Am Coll Cardiol 1993 ; 22 : 18971901

43)Beutlier B, Cerami A. The biology of cachectin/ TNF - a primary mediator of the host response. Annu Rev Immunol 1989 ; 135 : 234-248 
44)Kapadia SR, Oral H, Lee J, Nakano M, Taffet GE, Mann DL. Hemodynamic regulation of tumor necrosis factor-alpha gene and protein expression in adult feline myocardium. Circ Res 1997;81:187-95

45)Oral H, , Sivasubramanian N, Dyke DB, Mehta RH, Grossman PM, Briesmeister K, Fay WP, Pagani FD, Boilling SF, Mann DL, Starling MR. Myocardial proinflamatory cytokine exoression and left ventricular remodeling in patients with chronic mitral regirgitation. Circulation $2003 ; 107: 831-837$

46)Tsutamoto $T$, Wada $A$, Matsumoto $T$ et al. Relationship between tumor necrosis factor-alpha production and oxidative stress in the failing hearts of patients with dilated cardiomyopathy. J Am Coll Cardiol 2001;37:2086-92

47)Petretta $M$, Condorelli GL, Spinelli $L$ et al. Circulating levels of cytokines and their site of production in patients with mild to severe chronic heart failure. Am Heart $\mathrm{J}$ 2000;140(6): E28

48)Munger MA, Johnson B, Amber IJ, Callahan KS, Gilbert EM. Circulating concentrations of proinflammatory cytokines in mild or moderate heart failure secondary to ischemic or idiopathic dilated cardiomyopathy. Am J Cardiol $1996 ; 77: 723-7$

49)Youker K, Smith CW, Anderson Dc et al. Neutrophil adherence to isolated adult cardiac myocytes : Induction by cardiac lymph collected during ischemia and reperfusion. . J Clin Investn 1992 ; $89: 602-9$

50)Arai KI, Lee F, Miyajima A, Miyatake S, Arai N, Yokota T. Cytokines: coordinators of immune and inflammatory responses. Annu Rev Biochem 1990;59:783-836

51)Sassayama $S$, Matsumori $A$, Kihara $Y$ New insights into the pathophysiological role for cytokines in heart failure . Cardiovascular Research 42 (1999) 557- 564 
52)Anker SD, Egerer KR, Volk H, Kox WJ, Poole-Wilson PA, Coats AJS. Elevated soluble CD14 receptors and altered cytokines in chronic heart failure. Am J Cardiol 1997;79:1426-30

53)Testa M, Teh M, Lee $P$, Fanelli R, Loperfido F, Berman JW, LeJemtel TH. Circulating levels of cytokines and theis endogenous modulators in patients with mild to severe congestive heart failure due to coronary artery disease or hypertension.Journal of the American College of Cardiology, 1996 ; 28 : 4 , p 964.

54)Mann DI. Tumor necrosis factor-induced signal transduction and left ventricular remodeling. Journal of Cardiac failure $2002 ; 8: 6$, p S379

55)Carswell EA, Old LJ, Kassel RL, Green S, Fiore N, Williamson B: An endotoxininduced serum factor that causes necrosis of tumors. Proc Natl Acad Sci U $S A$ $1975 ; 72: 3666-3670$

56)Old LJ: Tumor necrosis factor (TNF). Science 1985;230: 630-632

57)Yokoyama T, Nakano M, Bednarczyk JL, McIntyre BW, Entman ML, Mann DL: Tumor necrosis factor-_ provokes a hypertrophic growth response in adult cardiac myocytes. Circulation 1997;95:1247-1252

58)Yokoyama T, Vaca L, Rossen RD, DuranteW, Hazarika P, Mann DL: Cellular basis for the negative inotropic effects of tumor necrosis factor-alpha in the adult mammalian heart.J Clin Invest 1993;92:2303-2312

59)Gulick TS, ChungMK, Pieper SJ, Lange LG, Schreiner GF: Interleukin 1 and tumor necrosis factor inhibit cardiac myocyte _-adrenergic responsiveness. Proc Natl Acad Sci U S A 1989;86:6753-6757

60)Mann DL. Tumor necrosis factor-induced signal transduction and left ventricular remodeling. Journal of Cardiac failure $2002 ; 8: 6$, p S379

61)Krown KA, Page MT, Nguyen C, Zechner D, Gutierrez V, Comstock KL, Glembotski CC, Quintana PJE, Sabbadini RA: Tumor necrosis factor alpha-induced apoptosis in 
cardiac myocytes: involvement of the sphingolipid signaling cascade in cardiac cell death. J Clin Invest 1996; 98:2854-2865

62)Kubota T, McTiernan CF, Frye CS, Slawson SE, Koretsky AP, Demetris AJ, Feldman AM: Dilated cardiomyopathy in transgenic mice with cardiac specific overexpression of tumor necrosis factor-alpha. Circ Res 1997;81:627-635

63)Kubota T, Bounoutas GS, Miyagishima M, Kadokami T, Sanders VJ, Bruton C, Robbins PD, McTiernan CF, Feldman AM: Soluble tumor necrosis factor receptor abrogates myocardial inflammation but not hypertrophy in cytokine-induced cardiomyopathy. Circulation 2000; 101:2518-2525

64)Li YY, FengYQ, Kadokami T, McTiernan CF, Draviam R, Watkins SC, Feldman AM: Myocardial extracellular matrix remodeling in transgenic mice overexpressing tumor necrosis factor alpha can be modulated by anti tumor necrosis factor alpha therapy. Proc Natl Acad Sci U S A 2000;97:12746-12751

65)Borer J., Truter PHD, Herrold E, Falcone D, Pena M, et al. Myocardial fibrosis in chronic aortic regurgitation. Molecular and cellular responses to volume overloaded. Circulation 2002; 105: 1837-1842

66) BeuterB, Cerami A. The biology of cachectin / TNF - a primary mediator of the host response. Annu. Rev, Immunol $1989 ; 7: 234-248$

67)Bazzoni F, Butler B. The tumor necorsis factor ligand and receoptor families. New England Journal of Medicine, 1996 ; 334 : 24 , p 1717

68)Torre-Amione G, Kapadia S, Lee J, Bies RD, Lebovitz R, Mann DL: Expression and functional significance of tumor necrosis factor receptors in human myocardium. Circulation 1995;92:1487-1493

69)Torre-Amione G, Kapadia S, Lee J, Durand JB, Bies RD, YoungJB, Mann DL: Tumor necrosis factor- $\alpha$ and tumor necrosis factor receptors in the failinghuman heart. Circulation 1996;93:704-711 
70)Grell M, Douni E, Wajant H, Lohden M, Clauss M, Maxeiner B, Georgopoulos S, Lesslauer W, Kollias G, Pfizenmaier K, Scheurich P: The transmembrane form of tumor necrosis factor is the prime activatinglig and of the $80 \mathrm{kDa}$ tumor necrosis factor receptor. Cell 1995;83:793- 802

71)Aderka D, Engelmann $H$, Maor $Y$, Brakebrusch $C$, Wallach D. Stabilization of the bioactivity of tumor necrosis factor by its soluble receptors. Journal of Experinetal Medicine. $1992 ; 175: 323-329$.

72)Oral H, Dorn GW, II, Mann DL: Sphingosine mediates the immediate negative inotropic effects of tumor necrosis factor- $\alpha$ in the adult mammalian cardiac myocyte. $\mathrm{J}$ Biol Chem 1997;272:4836-4842

73)Finkel MS, Oddis CV, Jacob TD,Watkins SC, Hattler BG, Simmons RL. tative inotropic effects of cytokines on the heart mediated by nitric oxide. Science $1992 ; 257: 387-9$

74)Nakano M, Knowlton AA, Dibbs Z, Mann DL: Tumor necrosis factor- $\alpha$ confers resistance to injury induced by hypoxic injury in the adult mammalian cardiac myocyte. Circulation 1998;97:1392-1400

75)Sack MN. Tumor necorsis factor $\alpha$ in cardiovascular biology and the potential role for anti-tumor necrosis factor $\alpha$ thera[y in heart disease. Pharmacology and Therapeutics $2002 ; 94: 123-135$

76)Wilson AG, di Giovine FS, Blakemore AIF, Duff GW. Single base polymorphism in the human tumor necrosis factor alpha (TNFa) gene detectable by Ncol restriction of PCR product. Hum Mol Genet. 1992; 1:353

77) Schroeder S, Borger N, Wrigge H, Welz A, Putensen C, Hoeft A, Stuber F A Tumor Necrosis Factor Gene Polymorphism Influences the Inflammatory Response After Cardiac Operation. Annals of Thoracic Surggery. 2003 Feb;75(2):534-7 
78)Densem CG, Hutchinson IV, Yonan N, Brooks NH Tumour necrosis factor alpha gene polymorphism: a predisposing factor to non-ischaemic myocardial dysfunction?. Heart. 2002 Feb;87(2):153-5

79)Ito M, Takahashi H, Fuse K, Hirono S, Washizuka T, Kato K, Yamazaki F, Inano K, Furukawa T, Komada M, Aizawa Y. Polymorphisms of tumor necrosis factor-alpha and interleukin-10 genes in Japanese patients with idiopathic dilated cardiomyopathy. Japan Heart Journal. 2000 Mar;41(2):183-91

80)Hirano H, Yoshida K, Kishimoto $T$, Taga T. Continuous activation of gp 130, a signaltransducing receptor component for interleukin-6 -related cytokines, causes myocardial hypertrophy in mice. Proc Natl Acad Sci USA 1995;92:4862- 6

81)Takihara KY. Gp-130-mediated pathway and left ventricular remodeling. Journal of Cardiac Failure . 2002, 8 suppl 6 : S374

82)Roig E, OrúsJ, Pare' C, Azqueta M, Filella X, Perez-Villa F, Heras M, Sanz G. Serum Interleukin-6 in Congestive Heart Failure Secondary to Idiopathic Dilated Cardiomyopathy. American Heart Journal ; 37 : 688-690

83)Tsutamoto $T$, Hlisanga $T$, Maeda $K$, Ohnishi M, Fukai $D$, Sawanki M, Kinoshita M. Interleukin-6 Spillover in the Peripheral Circulation Increases With the Severity of Heart Failure, and the High Plasma Level of Interleukin-6 Is an Important Prognostic Predictor in Patients With Congestive Heart Failure J Am Coll Cardiol 1998;31:391- 8

84)Thaik CM, Calderone $A$, Takahashi $N$, Colucci WS. Interleukin $1 \beta$ modulates the growth and phenotype of neonatal rat cardiac myocytes. J.Clin . Invest. $1995 ; 96$ : $1035-41$

85)Cain BS, Meldrum DR, Dinarello CA, Meng $X$ et al, Tumor necrosis factor $\alpha$ and interleukin $1 \beta$ synergistically depress human myocardial function, Critical Care Medicine $27(7): 1309-1316,1999$ 
86)Balligand JL, Ungureanu-Longrois D, Simmons WW, Pimental D et al, Cytokineinduced nitric oxide synthase ( iNOS) expression in cardiac myocites : characterization and regulation of iNOS expression in single cardiac myocites in vitro, Journal of Biological Chemistry 269 : 27580-27588 , 1994

87) Oyama J, Shimokawa $\mathrm{H}$, Cheng $\mathrm{X}$, Fukuyama $\mathrm{N}$ et al, Role of nitric oxide and peroxynitrite in the cytokine-induced sustained myocardial disfunction in dogs in vivo, Journal of Clinical Investigation, 101 : 2207-2214 , 1998

88)Adamopoulos S, Parissis J, Kremastinos D. A glossary of circulating cytokines in chronic heart failure. Eur J Heart Fail 2001;3(5):517

89)Petersen CA, Burleigh BA. Role for interleukin-1 beta in Trypanosoma cruzi-induced cardiomyocyte hypertrophy. Infect Immun. 2003 Aug;71(8):4441-7

90)Teerlink, JR. Reversal of Left Ventricular Remodeling: Role of the Endothelin Pathway. Journal of Cardiac Failure 2002 Vol. 8 No. 6 Suppl, p. S494

91)Luscher TF, Barton M. Endothelins and Endothelin Receptor Antagonists Therapeutic Considerations for a Novel Class of Cardiovascular Drugs Circulation. 2000;102:2434-2440.

92)Sharma $R$, Coats $A$, Anker SD. The role of inflamatory mediators in heart failure: cytokines, nitric oxide and endothelin-1. International Journal of Cardiology. 2000 ; 72 : 175-186

93)Ruetten $\mathrm{H}$, Thiemermmann $\mathrm{C}$. Endothelin-1 stimulates the biosynthesis of tumor necrosis factor from macrophages: ET-receptors signal transduction and inhibition by dexamethasone. J. Phisiol. Pharmacol. 1997 ; 48 : 675-88

94)Wei, Cm, Lerman A, Rodenheffer RJ, McGregor CG, Brandt RR, Wright S, Heublin DM, Kao PC, Edwards WD. Endothelin in human congestive heart failure. Circulation. $1994 ; 89: 1580-6$ 
95)Chang CJ, Hsu LA, Chiang CW, Ko YS, See LC, Shen YC, Ko YL, Kou CT, Lee YS, Pang JH. Percutaneous transvenous mitral valvulotomy normalizes elevated circulating levels of tumor necrosis factor-alpha and interleukin-6 in mitral stenosis with heart failure. American Journal of Cardiology. 2003 Apr 15;91(8):1018-20

96)Kapadia S, Yakoob K, Nader S, Thomas JD, Mann DL, Griffin BP. Elevated levels of tumor necrosis factor-alpha in patients with hemodinamically significant pressure and volume overload. Journal of the American College of Cardiology. $2000 ; 36$ : 208-12

97)Spagnuolo M, Kloth $H$, Taranta A, Doyle E Pasternak B. Natural history of rheumatic aortic regurgitation. Criteria predictive of death, congestive heart failure and angina in young patients. Circulation $44: 368-380,1971$

98)Ferrari R, Bachetti $T$, Confortini $R$, Opasich $C$ et al. Tumor necrosis factor soluble receptors in patients with various degrees of heart failure.Circulation ; 92 (6) :14791486, 1995

99)Matsumori $A$. The use of cytokine inhibitors . A new therapeutic insight into heart failure. International Journal of Cardiology 62 ( suppl 1 ) S3-S12 , 1997

100) Rosner, B. - Fundamentals of Biostatistics - Boston, PWS Publishers, Second edition, 1986, 584pp.

101) Murray DR, Prabhu SD, Chandrasekar B. Chronic $\beta$-adrenegic stimulation induces myocardial proinflamatory cytokine expression. Circulation. $2000 ; 101$ : 2338-2341

102) American College of Cardiology/American Heart Association. Guidelines for the management of patients with valvular heart disease. Circulation 1998;98:1949-84

103) Narin N, Kutukculer N, Ozyurek R, Bakiler AR, Parlar A, Arcasoy M. Lymphocyte subsets and plasma IL-1_, IL-2, and TNF-_concentrations in acute rheumatic fever and chronic rheumatic heart disease. Clin Immunol Immunopathol $1995 ; 77: 172-176$ 
104) Gerber IL, Stewart RAH, Legget ME, West TM, French RL, Sutton TM, Yandle TG, French JK, Richards AM, White HD.Increased Plasma Natriuretic Peptide Levels Reflect Symptom Onset in Aortic Stenosis . Circulation. 2003;107:1884-1890

105) Testa $M$, Teh $M$, Lee $P$, Fanelli $R$, Loperfido F, Berman JW, LeJemtel TH. Circulating levels of cytokines and theis endogenous modulators in patients with mild to severe congestive heart failure due to coronary artery disease or hypertension.Journal of the American College of Cardiology, 1996 ; 28 : 4 , p 964

106) Bozkurt B, Kribbs S, Clubb JrFJ, Michael LH, Didenko VV, Hornsby PJ, Seta Y, Oral H, Spinale FG, Mann DL: Pathophysiologically relevant concentrations of tumor necrosis factor- $\alpha$ promote progressive left ventricular dysfunction and remodelingin rats. Circulation 1998;97:1382-1391

107) Elias, N. Comportamento da finbrose miocárdica em pacientes com Insuficiência Aórtica. Tese de Doutorado, USP, 2002

108) Torre-Amione G, Kapadia S, Benedict C, Oral H, Young JB, Mann DL. Proinflamaory cytokine levels in patients with depressed left ventricular ejection fraction : A report from the studies of lef ventricular disfunction ( SOLVD ). Journal of the American College of Cardiology. $1996 ; 27: 1201-1206$

109) Forman, R.; Firth, B.G.; Barnard, M.S.; Prognostic significance of preoperative left ventricular ejection fraction and valve lesion in patients with aortic replacement. Am. J. Cardiol., v.45, p.1120-5, 1980

110) Kubota T, McNamara DM, Wang JJ, Trost M, McTiernan CF, Mann DL, Feldman AM. Effects of Tumor Necrosis Factor Gene Polymorphisms on Patients With Congestive Heart Failure. Circulation. 1998;97:2499-2501

111) Stuber F, Petersen M, Bokelmann F, Schade U. A genomic polymorphism within the tumor necrosis factor locus influences plasma tumor necrosis factor-a 
concentrations and outcome of patients with severe sepsis. Crit Care Med. $1996 ; 24: 381-384$

112) Zhu ZG, Wang MS, Jiang ZB, Jiang $Z$, Xu SX, Ren $C Y$, Shi MX. The dynamic change of plasma endothelin-1 during the perioperative period in patients with rheumatic valvular disease and secondary pulmonary hypertension. $J$ Thorac Cardiovasc Surg. 1994 Nov;108(5):960-8 


\section{Anexos}


Número

Eppendorf Paciente

1 JBSS

2APP

3 ALR

${ }_{4}$ GMP

$5 \mathrm{MVR}$

6 JWC

7 RAP

8 LHR

9 GVP

10RTC

11 JFS

12 RAS

$13 \mathrm{ACL}$

14WLM

15 LMN

16ES

17 JAM

$18 \mathrm{RPS}$

${ }_{19} \mathrm{CCM}$

20 ERM

21 JNS

$22 \mathrm{MR}$

${ }_{24}$ NPR

$25 \mathrm{GPS}$

${ }_{26} \mathrm{RP}$

${ }_{27} \mathrm{~GB}$

28 PLC

$29 \mathrm{EC}$

30 PAM

31 CFA

$32 \mathrm{VJS}$

33 AVP

$34 \mathrm{MMA}$

35 VSN

37 RSD

38DSE
TNF-alfa

alfa1/1

alfa1/1

alfa1/1

alfa1/1

alfa1/2

alfa1/1

alfa1/2

alfa1/1

alfa1/1

alfa1/1

alfa1/2

alfa1/1

alfa1/1

alfa1/1

alfa1/1

alfa1/1

alfa1/1

alfa1/1

alfa1/2

alfa1/1

alfa1/2

alfa1/1

alfa1/1

alfa1/2

alfa1/2

alfa1/2

alfa1/2

alfa1/1

alfa1/1

alfa1/2

alfa1/2

alfa1/2

alfa1/1

alfa1/1
RGHC

2330883G

5260031J

5108145B

$5285111 \mathrm{H}$

$5120519 \mathrm{H}$

$5125595 \mathrm{G}$

5267207C

2845450B

5211951D

2790928G

5194677C

5028908G

$5275286 \mathrm{~F}$

52324421

52741741

5279565C

5247246d

2665687B

$5085325 \mathrm{G}$

$5157220 \mathrm{~F}$

$5139480 \mathrm{D}$

$5269979 \mathrm{H}$

$5288296 \mathrm{D}$

3216353F

$5275933 \mathrm{G}$

$5279063 \mathrm{C}$

5244319J

$5246529 \mathrm{~K}$

5150611E

$2135253 G$

5296083`K

5246626J

$5033271 G$

$6016108 \mathrm{C}$

2415949K

50286211
IDADE SEXO DISF VE CF

$\begin{array}{lll}31 \mathrm{M} & \mathrm{N} & 1\end{array}$

$\begin{array}{lll}22 \mathrm{M} & \mathrm{N}\end{array}$

$\begin{array}{lll}37 \mathrm{M} & \mathrm{N} & 1\end{array}$

$19 \mathrm{M} \quad \mathrm{N}$

$22 \mathrm{M} \quad \mathrm{N} \quad 1$

$25 \mathrm{M} \quad \mathrm{N} \quad 1$

$22 \mathrm{M} \quad \mathrm{N} \quad 1$

$35 \mathrm{M} \quad \mathrm{N} \quad 2$

$35 \mathrm{M} \quad \mathrm{N} \quad 2$

$42 \mathrm{M} \quad \mathrm{N} \quad 1$

$25 \mathrm{M} \quad \mathrm{N} \quad 1$

$\begin{array}{lll}40 \mathrm{M} & \mathrm{N} & 1\end{array}$

$21 \mathrm{M} \quad \mathrm{N} \quad 2$

$19 \mathrm{M} N \mathrm{~N}$

$\begin{array}{lll}46 \mathrm{M} & \mathrm{N} & 1\end{array}$

$\begin{array}{lll}40 \mathrm{M} & \mathrm{N} & 1\end{array}$

$29 \mathrm{M} \quad \mathrm{N}$

$24 \mathrm{M} \quad \mathrm{N} \quad 1$

$34 \mathrm{M} \quad \mathrm{N} \quad 2$

$50 \mathrm{M} \quad \mathrm{N} \quad 1$

$\begin{array}{lll}57 \mathrm{M} & \mathrm{S} & 2\end{array}$

$52 \mathrm{M} \quad \mathrm{N} \quad 2$

$33 \mathrm{M} \quad \mathrm{S} \quad 2$

$18 \mathrm{M} \quad \mathrm{N} \quad 1$

$53 \mathrm{M} \quad \mathrm{N} \quad 1$

$58 \mathrm{M} \quad \mathrm{S} \quad 2$

$33 \mathrm{M} \quad \mathrm{N} \quad 1$

$\begin{array}{lll}24 \mathrm{~F} & \mathrm{~N} & 1\end{array}$

$\begin{array}{lll}25 \mathrm{~F} & \mathrm{~S} & 2\end{array}$

$\begin{array}{lll}42 \mathrm{~F} & \mathrm{~N} & 1\end{array}$

$42 \mathrm{M} \quad \mathrm{N} \quad 1$

$21 \mathrm{M} \quad \mathrm{N} \quad 1$

$33 \mathrm{M} \quad \mathrm{N} \quad 1$

$27 \mathrm{M}$

$\begin{array}{lll}39 \mathrm{M} & \mathrm{N} & 1\end{array}$

$19 \mathrm{M} \quad \mathrm{N}$ 
Número

Eppendorf Paciente

39 ANA

40 SAM

41 TJS

42 DAR

${ }_{43}$ FSR

${ }_{44}$ ACSA

45MVA

${ }_{46}$ AFS

${ }_{47} \mathrm{CAL}$

48 RM

49 NCS

$50 \mathrm{JAO}$

51 LTS

52 ALD

53 JMSR

54 JBSS

$55 \mathrm{SP}$

${ }_{56}$ ELP

57 VSA

58 VLFS

59 ABBS

60 LSS

61 RGO

62 CAF

63RLS

64 WRVS

${ }_{65}$ CGS

66 JCG

67 JGB

68 GIS

69 EFL

70 LBD

71 NSG

73GGV

$74 \mathrm{MACP}$

${ }_{75} \mathrm{CPS}$
TNF-alfa

alfa1/1

alfa1/1

alfa1/1

alfa1/1

alfa1/1

alfa1/1

alfa1/1

alfa1/1

alfa1/1

alfa1/1

alfa1/1

alfa1/1

alfa1/1

alfa1/1

alfa1/2

alfa1/1

alfa1/2

alfa1/1

alfa1/1

alfa1/2

alfa1/2

alfa1/1

alfa1/1

alfa1/1

alfa2/2

alfa1/1

alfa1/1

alfa1/1

alfa1/1

alfa1/1

alfa1/2

alfa1/1

alfa1/1

alfa1/1

alfa1/2
RGHC

50030021

2776291C

5277016C

3085542A

5245774I

5296898D

5140866E

5036436B

5186431C

2021194i

5298057F

5008487E

$5056917 \mathrm{H}$

5230635K

5112799E

2849210B

3187179F

5247125D

5251821D

5036296C

2880430।

5242270D

5350867F

5078239F

$5041986 \mathrm{H}$

5352187G

$5246209 \mathrm{G}$

5293031J

$5065834 \mathrm{H}$

5109616G

5176349B

5214148F

5350911A

5100248B

5356461।

5279121B
IDADE SEXO DISF VE CF

$54 \mathrm{M} \quad \mathrm{N}$

$30 \mathrm{~F} \quad \mathrm{~N}$

$57 \mathrm{M} \quad \mathrm{N}$

$19 \mathrm{M} \quad \mathrm{N}$

$60 \mathrm{M} \quad \mathrm{N}$

$24 \mathrm{M} \quad \mathrm{S}$

$30 \mathrm{M} \quad \mathrm{N}$

$24 \mathrm{M} \quad \mathrm{N}$

$29 \mathrm{M} \quad \mathrm{N}$

$42 \mathrm{M} \quad \mathrm{N}$

$44 \mathrm{M} \quad \mathrm{N}$

$21 \mathrm{M} \quad \mathrm{N}$

$43 \mathrm{~F}$

$32 \mathrm{M}$

$29 \mathrm{M}$

$31 \mathrm{M}$

$19 \mathrm{M}$

$32 \mathrm{M}$

$28 \mathrm{~F}$

$43 \mathrm{~F}$

$34 \mathrm{M}$

$26 \mathrm{~F}$

$31 \mathrm{M}$

$35 \mathrm{M}$

$21 \mathrm{~F}$

$28 \mathrm{M}$

$18 \mathrm{M}$

$18 \mathrm{M}$

$35 \mathrm{M}$

$55 \mathrm{M}$

$29 \mathrm{M}$

$37 \mathrm{~F}$

$27 \mathrm{M}$

$23 \mathrm{M}$

$32 \mathrm{~F}$

$39 \mathrm{M}$
1

$$
2
$$

1

$$
1
$$$$
3
$$

1

1

2

1

1

1

1

2

1

2( DPC) 
Número

Eppendorf Paciente 76 PCCS

$77 \mathrm{MJS}$

$78 \mathrm{MRF}$

79 VRC

$80 \mathrm{KMAA}$

81 PMC

82 JBMM

$83 \mathrm{DM}$

84 JMBF

85 JAJ

$86 \mathrm{ACO}$

87 VBS

${ }_{88} \mathrm{CM}$

90 DLB

91 JBN

92 RCGA

$93 \mathrm{MCS}$
TNF-alfa

alfa1/1

alfa1/1

alfa1/1

alfa1/1

alfa1/1

alfa1/1

alfa1/1

alfa1/1

alfa1/1

alfa1/1

alfa1/1

alfa1/1

alfa1/1

alfa2/2

alfa2/2

alfa1/1

alfa1/1

\section{RGHC}

53571681

5266540B

5125526E

$5216873 \mathrm{H}$

$5181965 \mathrm{~F}$

5359059E

$5360124 \mathrm{~J}$

5292374J

5354045D

3076493A

51116541

$5362612 \mathrm{G}$

$5350295 a$

$5362337 \mathrm{~h}$

$5364092 \mathrm{~h}$

5364782E

5132105D
IDADE SEXO DISF VE CF

$48 \mathrm{M} \quad \mathrm{S}$

$56 \mathrm{M} \quad \mathrm{S}$

$59 \mathrm{~F} \quad \mathrm{~S}$

$30 \mathrm{M} \quad \mathrm{N} \quad 1$

$28 \mathrm{~F} \quad \mathrm{~N} \quad 1$

$28 \mathrm{M} \quad \mathrm{N} \quad 3$

$54 \mathrm{M} \quad \mathrm{S} \quad 2$

$31 \mathrm{M} \quad \mathrm{S} \quad 2$

$27 \mathrm{M} \quad \mathrm{N} \quad 3$

$22 \mathrm{M} \quad \mathrm{N} \quad 1$

$39 \mathrm{M} \quad \mathrm{S} \quad 2$

$27 \mathrm{M} \quad \mathrm{N} \quad 3$

$\begin{array}{lll}33 \mathrm{M} & \mathrm{N} & 1\end{array}$

$\begin{array}{lll}56 \mathrm{M} & \mathrm{S} & 3\end{array}$

$27 \mathrm{M} \quad \mathrm{N} \quad 1$

$33 \mathrm{M} \quad \mathrm{S} \quad 3$

$31 \mathrm{~F} \quad \mathrm{~N} \quad 3$

.
.

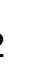
3 1 3 1 3 3 
Paciente PESO ALTURA S PP DDVE DSVE Feeco Ao AE MASSA

JBSS

APP

ALR

GMP

MVR

JWC

RAP

LHR

GVP

RTC

JFS

RAS

ACL

WLM

LMN

ES

JAM

RPS

CCM

ERM

JNS

MR

NPR

GPS

RP

GB

PLC

EC

PAM

CFA

VJS

AVP

MMA

VSN

RSD

$\begin{array}{llll}62 & 164 & 8 & 8\end{array}$

$\begin{array}{llll}57 & 155 & 7 & 7\end{array}$

94

$179 \quad 11 \quad 11$

$\begin{array}{llll}58 & 163 & 8 & 8\end{array}$

$\begin{array}{llll}75 & 185 & 11 & 11\end{array}$

79

63

72

83

72

62

60

60

70

76

90

80

61

83

68

65

74

62

93

78

82

96

78

65

64

$\begin{array}{llll}64 & 168 & 11 & 11\end{array}$

$\begin{array}{llll}70 & 182 & 10 & 10\end{array}$

$\begin{array}{llll}64 & 161 & 10 & 10\end{array}$

$\begin{array}{llll}53 & 160 & 11 & 11\end{array}$

$\begin{array}{llll}47 & 150 & 9 & 9\end{array}$

79

55

73

76

88

75

67

66

77

69

85

64

70

82

81

69

69

71

70

65

68

74

73

79

69

83

77

68

60

75

71

80

68

65

67 $\begin{array}{llll}57 & 0.62 & 43 & 46\end{array}$

35

50

52

58

52

44

42

54

47

63

43

46

58

61

48

48

47

48

43

52

54

66

54

50

70

53

45

49

60

51

51

45

38

50
$0.74 \quad 28 \quad 32$

$0.67 \quad 43 \quad 36$

$0.67 \quad 42 \quad 36$

$0.71 \quad 46 \quad 42$

$0.66 \quad 47 \quad 38$

$0.71 \quad 37 \quad 34$

$0.74 \quad 40 \quad 34$

$0.65 \quad 38 \quad 38$

$0.68 \quad 34 \quad 40$

$0.59 \quad 38 \quad 36$

$0.69 \quad 34 \quad 39$

$0.71 \quad 32 \quad 32$

$0.64 \quad 44 \quad 41$

$0.57 \quad 36 \quad 34$

$\begin{array}{lll}0.66 & 3.8 \quad 3.8\end{array}$

$0.66 \quad 42 \quad 42$

$0.7 \quad 33 \quad 36$

$0.67 \quad 33 \quad 40$

$\begin{array}{lll}0.7 & 37 \quad 42\end{array}$

$0.55 \quad 45 \quad 32$

$0.54 \quad 38 \quad 46$

$0.26 \quad 34 \quad 51$

$0.68 \quad 42 \quad 51$

$0.62 \quad 39 \quad 29$

$0.4 \quad 50 \quad 40$

$0.67 \quad 44 \quad 44$

$0.71 \quad 32 \quad 43$

$0.45 \quad 40 \quad 39$

210

$\begin{array}{llll}0.48 & 36 & 37 & 250\end{array}$

$\begin{array}{llll}0.62 & 39 & 46 & 260\end{array}$

$0.74-37$

$\begin{array}{lll}0.74 & 37 & 37\end{array}$

260

$0.71 \quad 37 \quad 44$

220

$0.8 \quad 28 \quad 41$

$\begin{array}{lll}0.58 & 31 & 47\end{array}$

100

220

210

330

230

240

190

220

170

310

170

220

280

270

210

220

210

260

150

230

140

210

270

270

200

220 10 
Paciente PESO ALtURA S PP DDVE DSVE Feeco Ao AE MASSA

DSE

ANA

SAM

TJS

DAR

FSR

ACSA

MVA

AFS

CAL

RM

NCS

JAO

LTS

ALD

JMSR

JBSS

SP

ELP

VSA

VLFS

ABBS

LSS

RGO

CAF

RLS

WRVS

CGS

JCG

JGB

GIS

EFL

LBD

NSG

GGV

MACP

CPS $\begin{array}{llll}65 & 187 & 10 & 10\end{array}$

$95 \quad 170 \quad 13 \quad 14$

$\begin{array}{llll}57 & 157 \quad 10 \quad 10\end{array}$

$\begin{array}{llll}66 & 172 \quad 13 \quad 13\end{array}$

$69 \quad 175 \quad 8 \quad 8$

$80 \quad 178 \quad 11 \quad 11$

$\begin{array}{llll}68 & 178 \quad 12 \quad 12\end{array}$

$\begin{array}{llll}84 & 171 & 11 & 11\end{array}$

80

$17599 \quad 9$

79

17899

$\begin{array}{llll}85 & 170 & 9 & 9\end{array}$

$\begin{array}{llll}69 & 170 & 9 & 9\end{array}$

$\begin{array}{llll}84 & 162 & 12 & 11\end{array}$

$55 \quad 151 \quad 9 \quad 9$

$\begin{array}{llll}68 & 167 & 10 & 10\end{array}$

$\begin{array}{llll}60 & 170 \quad 10 \quad 10\end{array}$

$\begin{array}{llll}63 & 168 & 7 & 7\end{array}$

$88 \quad 165 \quad 10 \quad 10$

60

73

67

69

65

70

90

47

62

69

60

71

80

100

46

80

60

68
71

78

75

72

50

67

95

73

61

71

68

58

60

62

83

73

68

63

74

65

66

66

62

76

70

75

66

77

83

68

68

80

65

72

74

55

87

\begin{abstract}
52
\end{abstract}
0.6

$41 \quad 34$

$0.75 \quad 42 \quad 43$

210

49

$\begin{array}{lll}0.77 & 39 & 47\end{array}$

330

46

$0.75 \quad 38 \quad 46$

280

45

$0.73 \quad 33 \quad 32$

310

33

$\begin{array}{lll}0.75 & 39 \quad 37\end{array}$

90

42

$0.48 \quad 38 \quad 47$

200

76

57

0.52

$39 \quad 45$

$0.69 \quad 36 \quad 37$

41

52

$0.6 \quad 45 \quad 33$

46

$0.69 \quad 42 \quad 35$

38

$0.71 \quad 42 \quad 31$

$0.7 \quad 33 \quad 42$

$0.75 \quad 29 \quad 36$

$0.42 \quad 33 \quad 44$

$0.79 \quad 40 \quad 40$

$0.71 \quad 35 \quad 44$

$0.78 \quad 36 \quad 40$

$0.69 \quad 43 \quad 33$

$0.78 \quad 34 \quad 36$

$0.66 \quad 34 \quad 42$

$0.68 \quad 41 \quad 39$

$0.66 \quad 35 \quad 45$

$0.59 \quad 43 \quad 38$

$0.63 \quad 43 \quad 38$

$0.73 \quad 36 \quad 45$

$0.74 \quad 31 \quad 43$

440

240

170

180

160

140

190

180

130

250

140

160

210

210

230

200

43

56

50

48

42

$0.65 \quad 36 \quad 44$

54

$\begin{array}{lll}0.69 & 38 \quad 37\end{array}$

160

250

180

290

150

250

56

$\begin{array}{lll}0.64 & 31 & 34\end{array}$

280

48

$0.64 \quad 37 \quad 41$

220

48

58

0.61

$39 \quad 47$

170

58

$0.69 \quad 32 \quad 34$

190

44
47

$0.72 \quad 37 \quad 45$

240

49

$0.7 \quad 46 \quad 36$

250

36

$0.71 \quad 50 \quad 31$

69

$\begin{array}{lll}0.5 & 46 \quad 49\end{array}$

320 
Paciente PESO ALtURA S PP DDVE DSVE Feeco Ao AE MASSA

$\begin{array}{lrrrrrrrrrr}\text { PCCS } & 68 & 182 & 11 & 10 & 72 & 50 & 0.66 & 31 & 52 & 230 \\ \text { MJS } & 63 & 160 & 14 & 13 & 91 & 80 & 0.32 & 50 & 37 & 540 \\ \text { MRF } & 66 & 158 & 10 & 10 & 71 & 51 & 0.62 & 37 & 46 & 240 \\ \text { VRC } & 60 & 165 & 12 & 11 & 78 & 53 & 0.68 & 45 & 37 & 330 \\ \text { KMAA } & 66 & 168 & 10 & 10 & 65 & 41 & 0.73 & 35 & 43 & \\ \text { PMC } & 98 & 178 & 11 & 13 & 78 & 47 & 0.78 & 32 & 45 & 270 \\ \text { JBMM } & 56 & 166 & 14 & 12 & 61 & 45 & 0.59 & 41 & 36 & \\ \text { DM } & 57 & 168 & 11 & 11 & 72 & & 0.45 & 36 & 45 & 280 \\ \text { JMBF } & 65 & & 11 & 11 & 80 & 56 & 0.65 & 38 & 42 & \\ \text { JAJ } & 58 & 190 & 13 & 13 & 76 & 50 & 0.71 & 43 & 40 & 340 \\ \text { ACO } & 75 & 170 & 12 & 12 & 90 & 78 & 0.34 & 55 & 43 & \\ \text { VBS } & 75 & 166 & 8 & 8 & 76 & 52 & 0.67 & 44 & 36 & 190 \\ \text { CM } & 90 & 180 & 12 & 12 & 78 & 60 & 0.54 & 49 & 39 & 280 \\ \text { DLB } & 65 & 173 & 12 & 12 & 79 & 59 & 0.58 & 39 & 44 & 340 \\ \text { JBN } & 63 & 165 & 12 & 12 & 70 & 49 & 0.65 & 32 & 42 & 290 \\ \text { RCGA } & 63 & 175 & 10 & 11 & 76 & 57 & 0.57 & 32 & 40 & \\ \text { MCS } & 45 & 149 & 8 & 8 & 60 & 45 & 0.57 & 33 & 35 & 160\end{array}$


Número

Eppendorf Paciente V/M 1 JBSS

2 APP

$3 \mathrm{ALR}$

${ }_{4} \mathrm{GMP}$

5 MVR

6 JWC

7 RAP

8 LHR

${ }_{9} \mathrm{GVP}$

10RTC

11 JFS

12RAS

${ }_{13} \mathrm{ACL}$

14 WLM

15 LMN

$16 \mathrm{ES}$

17 JAM

18 RPS

${ }_{19} \mathrm{CCM}$

20 ERM

21 JNS

$22 \mathrm{MR}$

${ }_{24}$ NPR

25 GPS

${ }_{26} \mathrm{RP}$

${ }_{27} \mathrm{~GB}$

28 PLC

$29 \mathrm{EC}$

30 PAM

${ }_{31}$ CFA

32 VJS

33 AVP

${ }_{34} \mathrm{MMA}$
IL-1-

$\begin{array}{ll}\text { IL-6 beta } & 0\end{array}$

$1.02<5,0<5,0$

$0.83<5,0 \quad<5,0$

$1.29<5,0<5,0$

$1.04<5,0<5,0$

0.91

$11.5<5,0$

0.7

$5.7<5,0$

0.82

$1.06<5,0 \quad<5,0$

$0.99<5,0<<5,0$

1.12

$0.9<5,0$

$8.2<5,0$

0.88

$1.08<5,0$

1.06

$0.77<5,0$

0.77

$1.03<5,0$

$0.66<5,0$

1.07

$5.7<5,0$

$12.9<5,0$

0.95

$12<5,0$

1.57

$12.5<5,0$

1.17

0.62

$8<5,0$

1.09

$7.3<5,0$

$<4,0$

252

$1<5,0<5,0$

$<5,0<5,0$

$0.6<5,0<5,0$

0.93

$8<5,0$

$0.8 \quad 14.3<5,0$

$1.04<5,0<5,0$

0.85

$6.7<5,0$ 28.8

224

122

12.2

11.7

92.1

240

144

6

18.2

69.4

7.9

68.6

11.6

133

209

23.2

172

211

752

25.3

230 171 219

256 24.4

217 21.3
TNF STNFRI STNFRII IL6R IL1RA Endotelina

$463.495 \quad 1416.387 \quad 18488.01$

0

7.792

$813.311 \quad 2379.82 \quad 47047.43 \quad 83.039$

6.985

$\begin{array}{llll}667.426 & 1357.113 & 31607.66 & 37.199\end{array}$

8.81

$714.042 \quad 1718.992 \quad 39539.27$

0

16.957

$634.448 \quad 1629.944 \quad 44514.67$

0

14.411

$601.746 \quad 1550.91 \quad 29421.56$

0

7.919

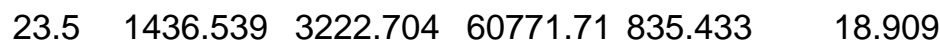

$893.719 \quad 1577.659 \quad 25674.54 \quad 450.375$

5.331

$854.51 \quad 2393.409 \quad 39429.45243 .486$

9.362 
Número Eppendorf Paciente V/M 35 VSN

$37 \mathrm{RSD}$

38 DSE

39 ANA

40 SAM

41 TJS

42 DAR

${ }_{43}$ FSR

${ }_{44}$ ACSA

45MVA

${ }_{46}$ AFS

${ }_{47} \mathrm{CAL}$

48 RM

49 NCS

$50 \mathrm{JAO}$

51 LTS

52 ALD

53 JMSR

54 JBSS

$55 \mathrm{SP}$

${ }_{56}$ ELP

57 VSA

58 VLFS

59 ABBS

60 LSS

61RGO

62 CAF

63RLS

${ }_{64}$ WRVS

${ }_{65}$ CGS

66 JCG

$67 \mathrm{JGB}$

68 GIS

69 EFL

70 LBD

${ }_{71}$ NSG
IL-1-

beta

$$
\text { IL-6 }
$$$$
<5,0<5,0
$$

TNF

STNFR 16.5

18.7

0.96

$5.5<5,0$

107

$0.9 \quad 24<5,0$

$0.69<5,0<5,0$

$0.96 \quad 8.5<5,0$

0.65

$18.5<5,0$

0.86

$21.3<5,0$

0.74

$6.4<5,0$

$1.02<5,0<5,0$

$0.83<5,0<5,0$

$0.85<5,0<5,0$

1.03

$12<5,0$

$0.97<5,0 \quad<5,0$

0.79

$11.3<5,0$

0.6

$8.6<5,0$

0.86

$7.7<5,0$

$2.46<5,0 \quad<5,0$

$0.93<5,0<5,0$

$1.32<5,0<5,0$

$0.77<5,0 \quad<5,0$

1.08

$9.3<5,0$

$0.71<5,0<5,0$

0.72

$13<5,0$

0.82

$9.6<5,0$

0.86

$24.9<5,0$

0.98

$12.3<5,0$

0.88

$9.3<5,0$

0.96

$8.8<5,0$

$1.08<5,0$

$<5,0$

1

$11.5<5,0$

1.33

$6.6<5,0$

0.85

$12.7<5,0$

$0.97<5,0 \quad<5,0$

$1.19 \quad 14.5<5,0$

0.81

$8.5<5,0$

0.77

$17.4<5,0$ 179

59

158

5.4

232

34.4

48.7

25.1

311

131

65.8

147

86.2

74.7

16.9

14.8

7.6

14.5

205

10.8

38.5

122

11

16.9

49.3

96

46.7 $\begin{array}{lllll}104 & 1374.253 & 2256.85 & 25451.19 & 240.296\end{array}$

$951.89 \quad 1067.207 \quad 29326.13$

0

31.215

$1089.053 \quad 2006.962 \quad 27772.76$

0

17.509

$696.224 \quad 1276.892 \quad 29421.56$

0

2.53

$\begin{array}{llll}705.124 & 1650.344 & 26577.19 & 39.332\end{array}$

5.118

$1089.053 \quad 1165.11150692 .51$

0

3.548

$530.826 \quad 1248.994 \quad 30432.49$

0

11.865

$\begin{array}{lllll}98.6 & 349.513 & 2552.636 & 39264.99 & 0\end{array}$

8.683

$\begin{array}{llllll}9 & 1158.727 & 2670.882 & 25051.49 & 0 & 10.974\end{array}$

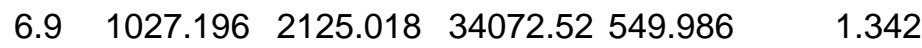

$\begin{array}{lllll}9.5 & 705.124 & 1486.391 & 18182.8 & 0\end{array}$

6.222

$85.1 \quad 765.671 \quad 1641.833 \quad 47166.86108 .884$

9.447

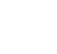




\begin{tabular}{|c|c|c|c|c|c|c|c|c|}
\hline $\begin{array}{l}\text { Número } \\
\text { Eppendorf Paciente V/M }\end{array}$ & IL-6 & $\begin{array}{l}\text { IL-1- } \\
\text { beta }\end{array}$ & TNF & sTNFRI & sTNFRII & IL6R & IL1RA & Endotelina \\
\hline $73 \mathrm{GGV}$ & $0.68<5,0$ & $<5,0$ & 4.3 & 845.326 & 1983.275 & 23311.46 & 0 & 7.41 \\
\hline $74 \mathrm{MACP}$ & & $7.6<5,0$ & 214 & 811.032 & 1924.181 & 18258.88 & 0 & 0.323 \\
\hline $75 \mathrm{CPS}$ & 1.16 & $21.6<5,0$ & 24.8 & 619.152 & 1859.28 & 36202.34 & 3.585 & 17.297 \\
\hline 76 PCCS & 0.86 & $10.6<5,0$ & 12.2 & 2050.039 & 4197.142 & 32452.86 & 0 & 15.345 \\
\hline $77 \mathrm{MJS}$ & $0.84<5,0$ & $<5,0$ & 142 & & & & & \\
\hline $78 \mathrm{MRF}$ & 0.9 & $10.1<5,0$ & 9.5 & & & & & \\
\hline 79 VRC & 0.85 & $31<5,0$ & 232 & 1214.476 & 1741.515 & 41878.99 & 0 & 2.106 \\
\hline $80 \mathrm{KMAA}$ & & $7.9<5,0$ & 159 & 734.175 & 1403.495 & 41203.98 & 0 & 7.58 \\
\hline 81 PMC & $0.81<5,0$ & $<5,0$ & 19.2 & 861.408 & 1602.883 & 35520.4 & 0 & 0.705 \\
\hline 82 JBMM & & $21.9<5,0$ & 5.3 & 1449.05 & 2424.573 & 29564.98 & 0 & 2.869 \\
\hline 83 DM & 0.81 & $6.4<5,0$ & 8.5 & 854.51 & 2410.921 & 26759.5 & 0 & 0 \\
\hline $84 \mathrm{JMBF}$ & & $29.2<5,0$ & 44.7 & 795.107 & 1905.638 & 37263.51 & 0 & 0.62 \\
\hline $85 \mathrm{JAJ}$ & 0.7 & $9.4<5,0$ & 37.5 & 641.022 & 1357.113 & 20894.3 & 321.356 & 8.683 \\
\hline${ }_{86} \mathrm{ACO}$ & & $17.4<5,0$ & 9.8 & 667.426 & 1262.916 & 31262.72 & 0 & 2.954 \\
\hline 87 VBS & 1.29 & $9.2<5,0$ & 24.3 & 575.79 & 1900.262 & 47645.98 & 0 & 3.761 \\
\hline${ }_{88} \mathrm{CM}$ & $0.81<5,0$ & $<5,0$ & 30.8 & 1327.219 & 1393.853 & 35834.38 & 26.202 & 1.13 \\
\hline 90 DLB & $0.82<5,0$ & $<5,0$ & 173 & 1337.099 & 1832.638 & 35051.89 & 0 & 0 \\
\hline $91 \mathrm{JBN}$ & $0.7<5,0$ & $<5,0$ & 15.8 & 1027.196 & 2025.251 & 54274.71 & 0 & 0 \\
\hline $92 \mathrm{RCGA}$ & & $24.3<5,0$ & 89.5 & 1426.523 & 1848.576 & 38501.83 & 0 & 1.172 \\
\hline $93 \mathrm{MCS}$ & 0.96 & 19.7 & & 440.702 & 1669.124 & 21138.52 & 0 & 0.451 \\
\hline
\end{tabular}

